\title{
A COMPREHENSIVE EXPERIMENTAL AND MODELING STUDY OF ISOBUTENE OXIDATION
}

Chong-Wen Zhou ${ }^{a}$, Yang Li ${ }^{a}$, Eoin O'Connor ${ }^{a}$, Kieran P. Somers ${ }^{a}$, Sébastien Thion ${ }^{b}$, Charles Keesee ${ }^{b}$, Olivier Mathieu $^{\mathrm{b}}$ Eric L. Petersen ${ }^{\mathrm{b}}$, Trent A. DeVerter ${ }^{\mathrm{c}}$, Matthew A. Oehlschlaeger ${ }^{\mathrm{c}}$, Goutham Kukkadapu $^{\mathrm{d}}$, Chih-Jen Sung ${ }^{\mathrm{d}}$, Majed Alrefae ${ }^{\mathrm{e}}$, Fathi Khaled ${ }^{\mathrm{e}}$, Aamir Farooq ${ }^{\mathrm{e}}$, Patricia Dirrenberger ${ }^{\mathrm{f}}$, Pierre-Alexandre Glaude ${ }^{\mathrm{f}}$, Frédérique Battin-Leclerc ${ }^{\mathrm{f}}$, Jeffrey Santner ${ }^{\mathrm{g}, \mathrm{h}}$, Yiguang $\mathrm{Ju}^{\mathrm{g}}$, Timothy Held ${ }^{\mathrm{g}, \mathrm{i}}$, Francis M. Haas ${ }^{\mathrm{g}}$, Frederick L. Dryer ${ }^{\mathrm{g}}$, Henry J. Curran ${ }^{\mathrm{a}}$

${ }^{a}$ Combustion Chemistry Centre, National University of Ireland Galway, Ireland. ${ }^{b}$ Department of Mechanical Engineering, Texas A\&M University, College Station, TX, United States. ${ }^{c}$ Department of Mechanical, Aerospace, and Nuclear Engineering, Rensselaer Polytechnic Institute, Troy, NY, United States. ${ }^{\mathrm{d}}$ Department of Mechanical Engineering, University of Connecticut, CT, United States. ${ }^{\mathrm{e}}$ Clean Combustion Research Center, King Abdullah University of Science and Technology, Thuwal, Saudi Arabia. f Laboratoire Réactions et Génie des Procédés, CNRS-Université de Lorraine, Nancy, France.

${ }^{\mathrm{g}}$ Department of Mechanical and Aerospace Engineering, Princeton University, Princeton, NJ, United States. ${ }^{\mathrm{h}}$ Current address: Argonne National Laboratory, Lemont, IL, United States. ${ }^{i}$ Current Address: Echogen Power Systems 405 South High Street, Akron, Ohio , United States.

\begin{abstract}
Isobutene is an important intermediate in the pyrolysis and oxidation of higher-order branched alkanes, and it is also a component of commercial gasolines. To better understand its combustion characteristics, a series of ignition delay time (IDT) and laminar flame speed (LFS) measurements have been performed. In addition, flow reactor speciation data recorded for the pyrolysis and oxidation of isobutene is also reported. Predictions of an updated kinetic model described herein are compared with each of these data sets, as well as with existing jet-stirred reactor (JSR) species measurements.

IDTs of isobutene oxidation were measured in four different shock tubes and in two rapid compression machines (RCMs) under conditions of relevance to practical combustors. The combination of shock tube and RCM data greatly expands the range of available validation data for isobutene oxidation models to pressures of $50 \mathrm{~atm}$ and temperatures in the range 666-1715 $\mathrm{K}$. Isobutene flame speeds were measured experimentally at $1 \mathrm{~atm}$ and at unburned gas temperatures of 298-398 K over a wide range of equivalence ratios. For the flame speed results, there was good agreement between different facilities and the current model in the fuel-rich region.

$A b$ initio chemical kinetics calculations were carried out to calculate rate constants for important reactions such as $\mathrm{H}$-atom abstraction by hydroxyl and hydroperoxyl radicals and the decomposition of 2-methylallyl radicals.

A comprehensive chemical kinetic mechanism has been developed to describe the combustion of isobutene and is validated by comparison to the presently considered experimental measurements. Important reactions, highlighted via flux and sensitivity analyses, include: (a) hydrogen atom abstraction from isobutene by hydroxyl and hydroperoxyl radicals, and molecular oxygen; (b) radical-radical recombination reactions, including 2-methylallyl radical self-recombination, the recombination of 2-methylallyl radicals with hydroperoxyl radicals; and the recombination of 2methylallyl radicals with methyl radicals; (c) addition reactions, including hydrogen atom and
\end{abstract}


hydroxyl radical addition to isobutene; and (d) 2-methylallyl radical decomposition reactions. The current mechanism accurately predicts the IDT and LFS measurements presented in this study, as well as the JSR and flow reactor speciation data already available in the literature.

The differences in low-temperature chemistry between alkanes and alkenes are also highlighted in this work. In normal alkanes, the fuel radical $\dot{\mathrm{R}}$ adds to molecular oxygen forming alkylperoxyl $\left(\mathrm{RO} \dot{\mathrm{O}}_{2}\right)$ radicals followed by isomerization and chain branching reactions which promote low-temperature fuel reactivity. However, in alkenes, because of the relatively shallow well $\left(\sim 20 \mathrm{kcal} \mathrm{mol}^{-1}\right)$ for $\mathrm{RO}_{2}$ formation compared to $\sim 35 \mathrm{kcal} \mathrm{mol}^{-1}$ in alkanes, the $\dot{\mathrm{R}}+\mathrm{O}_{2} \rightleftharpoons \mathrm{RO}_{2}$ equilibrium lies more to the left favoring $\dot{\mathrm{R}}+\mathrm{O}_{2}$ rather than $\mathrm{RO}_{2}$ radical stabilization. Based on this work, and related studies of allylic systems, it is apparent that reactivity for alkene components at very low temperatures $(<800 \mathrm{~K})$ emanates from hydroxyl radical addition followed by addition of molecular oxygen to radical. At intermediate temperatures $(800-1300 \mathrm{~K})$, alkene reactivity is controlled by hydrogen abstraction by molecular oxygen and the reactions between resonantly stabilized radicals and hydroperoxyl radicals which results in chain branching. At higher temperatures $(>1300 \mathrm{~K})$, the reactivity is mainly governed by the competition between hydrogen abstractions by molecular oxygen and ÖH radicals.

Keywords: Isobutene oxidation, shock tube, rapid compression machine, chemical kinetics, ignition, flame speed, $a b$ initio 


\section{Introduction}

Isobutene, one of the butene isomers, is a known component of transportation fuels, as well as being an important intermediate in the pyrolysis and oxidation of higher-order branched hydrocarbons such as isooctane. The pyrolysis and oxidation of methyl and ethyl tertiary-butyl ethers, used worldwide as octane enhancers, also produces a significant amount of isobutene. Therefore, kinetic modeling of the combustion of commercial fuels requires a reliable computational tool that can predict the pyrolysis and oxidation behaviors of isobutene and similar compounds (1- and 2-butene). Serving as an archetypal alkene fuel, isobutene is also a precursor for soot formation. Following $\mathrm{H}$-atom abstraction from isobutene, a resonantly stabilized 2-methylallyl radical is formed. Allylic species are implicated in the formation of aromatic and subsequent poly-aromatic hydrocarbon species [1]; therefore, understanding the oxidation chemistry of isobutene is important in helping mitigate pollutant formation.

Moreover, understanding the combustion chemistry of the butene isomers is a prerequisite for a comprehensive description of the chemistry of $\mathrm{C} 1-\mathrm{C} 4$ hydrocarbon and oxygenated fuels. For the development and validation of combustion models, it is thus crucial to improve our knowledge of detailed C4 combustion chemistry. Building a comprehensive kinetic model for isobutene is also an extension of our work on propene [2,3].

Several research groups have investigated isobutene pyrolysis and oxidation in shock tubes [4-10], a turbulent flow reactor [11], a jet-stirred reactor [12] and in premixed laminar flames [13-15]. Yasunaga et al. [9] investigated the pyrolysis and oxidation of isobutene behind reflected shock waves over a temperature range of 1000-1800 K, measuring the product distribution using infrared laser absorption spectroscopy and gas-chromatography. The authors reported species profiles for $\mathrm{CH}_{4}$ (methane), $\mathrm{C}_{2} \mathrm{H}_{6}$ (ethane), $\mathrm{C}_{2} \mathrm{H}_{2}$ (acetylene), $\mathrm{C}_{3} \mathrm{H}_{4}$-p (propyne), $\mathrm{C}_{3} \mathrm{H}_{4}$-a (allene), $\mathrm{C}_{3} \mathrm{H}_{6}$ (propene), 1,3$\mathrm{C}_{4} \mathrm{H}_{6}$ (1,3-butadiene) and $\mathrm{C}_{6} \mathrm{H}_{6}$ (benzene).

Bauge et al.[4] measured ignition delay times of isobutene/oxygen mixture containing 74.45-98.5\% argon diluent between $3 \mathrm{~ms}$ and $760 \mathrm{~ms}$ in the temperature range of 1230-1930 K, over the pressure range of 9.5-10.5 atm and covering the equivalence ratio of 1.0 to 3.0. They also measured speciation data in a continuous-flow stirred-tank reactor at 1 atm in the temperature range 833-913 K. Curran [10] measured ignition delay times for isobutene/oxygen mixtures containing 80.8-98.8\% argon diluent in the temperature range $1200-1980 \mathrm{~K}$, at pressures in the range $2.2-4.5 \mathrm{~atm}$, and over the equivalence ratio range of $0.1-4.0$.

Dias and Vandooren [13] studied a lean, premixed isobutene/hydrogen/oxygen/argon flame $(\varphi=$ 0.225) using molecular beam mass spectrometry at low pressure (40 mbar). They reported the following detected species: $\mathrm{H}_{2}, \dot{\mathrm{C}} \mathrm{H}_{3}, \ddot{\mathrm{O}}, \dot{\mathrm{O}} \mathrm{H}, \mathrm{HO}_{2}, \mathrm{H}_{2} \mathrm{O}, \mathrm{C}_{2} \mathrm{H}_{2}$ (acetylene), $\mathrm{CO}, \mathrm{C}_{2} \mathrm{H}_{4}$ (ethylene), $\mathrm{CH}_{2} \mathrm{O}$ (formaldehyde), $\mathrm{O}_{2}, \mathrm{Ar}, \mathrm{C}_{3} \mathrm{H}_{6}$ (propene), $\mathrm{CO}_{2}, \mathrm{CH}_{3} \mathrm{CHO}$ (acetaldehyde), 1,3- $\mathrm{C}_{4} \mathrm{H}_{6}$ (1,3-butadiene), $\mathrm{iC}_{4} \mathrm{H}_{8}$ (isobutene), $\mathrm{C}_{3} \mathrm{H}_{6} \mathrm{O}$ (acetone), $\mathrm{C}_{4} \mathrm{H}_{6} \mathrm{O}$ (1-propen-1-one, 2-methyl) and tautomers of isobutanal $\left(\mathrm{C}_{4} \mathrm{H}_{8} \mathrm{O}\right.$, prop-1-en-1-ol).

There have been several kinetic mechanisms published in the literature that can be used to simulate isobutene combustion [12, 14-16]. Dagaut and co-workers [12] studied the oxidation of isobutene in a jet-stirred reactor at high temperature $(\sim 800-1230 \mathrm{~K})$ and at 1, 5 and $10 \mathrm{~atm}$. Measured species profiles were reported as a function of temperature. Molecular species concentration profiles of $\mathrm{O}_{2}, \mathrm{H}_{2}, \mathrm{CO}$, $\mathrm{CO}_{2}, \mathrm{CH}_{2} \mathrm{O}, \mathrm{CH}_{4}, \mathrm{C}_{2} \mathrm{H}_{2}, \mathrm{C}_{2} \mathrm{H}_{4}, \mathrm{C}_{2} \mathrm{H}_{6}, \mathrm{C}_{3} \mathrm{H}_{4}$ (allene and propyne), $\mathrm{C}_{3} \mathrm{H}_{6}$, acetone, acrolein, methacrolein, 1- $\mathrm{C}_{4} \mathrm{H}_{8}, \mathrm{i}-\mathrm{C}_{4} \mathrm{H}_{8}, 1,3-\mathrm{C}_{4} \mathrm{H}_{6}, 1$-butyne, 2-methyl-1-butene, 2-methyl-2-butene, and benzene were obtained by probe sampling and gas chromatographs (GC) analysis. They also presented a chemical kinetic reaction mechanism capable of reproducing their speciation results. Zhang et al. [16] developed a model to describe the pyrolysis of the butene isomers in the temperature range 900-1900 $\mathrm{K}$ at low 
pressures ( 7.5-12.5 Torr), in which kinetic data for the thermal decomposition of butene isomers was measured and recently adopted in the kinetic model of isomeric butanols by Cai et al. [17]. Schenk et al. [14] developed a high-temperature kinetic model for the butene isomers based on a validation against low-pressure laminar premixed flames. However this study did not include some reactions essential to the ignition process in the low- to intermediate-temperature range. Most recently, Law and co-workers [15] reported laminar flame speeds and ignition temperatures for non-premixed counterflow flames at normal and elevated pressures. Their mechanism was built on previous studies by Zhang et al. [16] and Cai et al. [17] and included additional rate constants for the reactions of isobutene with $\dot{\mathrm{H}}$ and $\mathrm{O}$ atoms and $\dot{\mathrm{O}} \mathrm{H}, \mathrm{HO}_{2}$ and $\dot{\mathrm{C}} \mathrm{H}_{3}$ radicals.

In view of the above considerations, we can see that there is a lack of experimental data available in the literature for isobutene at low temperatures $(600-1000 \mathrm{~K})$ and at high pressures $(>10 \mathrm{~atm})$, which are conditions of direct relevance with respect to gasoline, diesel, and low-temperature combustion (LTC) engine technologies.

\section{Experimental methods}

Table 1. Ignition delay time, flame speed, and speciation measurements for isobutene oxidation used in this study for model validation.

\begin{tabular}{|c|c|c|c|c|c|c|}
\hline Reactor & $T(\mathrm{~K})$ & $p(\operatorname{atm})$ & $\varphi$ & $\% \mathrm{O}_{2}$ & $\%$ Diluent & Ref. \\
\hline \multicolumn{7}{|c|}{ Parameter range for isobutene oxidation available in the literature } \\
\hline \multicolumn{7}{|l|}{ Ignition delay time } \\
\hline Shock tube & $1200-1980$ & $2.2-4.6$ & $0.1-4.0$ & $0.9-18$ & 80.8-98.8 in Ar & {$[10]$} \\
\hline \multicolumn{7}{|l|}{ Speciation } \\
\hline JSR & $790-1250$ & $1.0-10.0$ & $0.2-2.0$ & $0.9-4.5$ & $95.35-99.4$ in $\mathrm{N}_{2}$ & [12] \\
\hline Flow reactor & $\begin{array}{c}1139-1150 \\
1081\end{array}$ & 1.0 & $0.42-1.29, \infty$ & $1.619-4.757$ & $94.91-99.5$ in $\mathrm{N}_{2}$ & {$[11]$} \\
\hline \multicolumn{7}{|l|}{ Flame speed } \\
\hline Flat flame burner & 298 & $1.0-10.0$ & $0.7-1.8$ & $19.76-20.5$ & $74.31-77.10$ in $\mathrm{N}_{2}$ & {$[15]$} \\
\hline \multicolumn{7}{|c|}{ Parameter range for isobutene oxidation available in this study } \\
\hline \multicolumn{7}{|l|}{ Ignition delay time } \\
\hline Shock tube & $940-1500$ & $10-50$ & $0.3-2.0$ & $19.63-20.78$ & $73.83-78.18$ in $\mathrm{N}_{2}$ & \\
\hline Shock tube & $1050-1650$ & $1.7-40$ & $0.5-2.0$ & $0.857-20.65$ & 76.32-99 in Ar & \\
\hline $\mathrm{RCM}$ & $666-996$ & $10-50$ & $0.3-2.0$ & $19.63-20.78$ & $73.83-78.18$ in $\mathrm{N}_{2}$ & \\
\hline \multicolumn{7}{|l|}{ Flame speed } \\
\hline Flat flame burner & $298-398$ & 1.0 & $0.6-1.9$ & $19.70-20.60$ & 74.06-77.37 in $\mathrm{N}_{2}$ & \\
\hline Spherical Flame & 298 & 1.0 & $0.75-1.5$ & $19.96-20.47$ & $75.05-76.97$ in $\mathrm{N}_{2}$ & \\
\hline
\end{tabular}


Table 1 compares the experimental conditions investigated as part of this study to those of studies found in the literature. Ignition delay times for isobutene oxidation were measured in four different shock tube facilities and two rapid compression machines (RCMs) shown below. Laminar flame speeds for isobutene were measured at the Université de Lorraine (LRPG). Spherical flame speed measurements were also recorded at Princeton University (PU) and Texas A\&M University (TAMU). All experimental data are provided in the appended Supplementary material.

\subsection{Ignition delay time measurements}

\subsubsection{NUI Galway (NUIG) high-pressure shock tube}

Ignition delay times were measured in the high-pressure shock tube at NUIG described in the recent study by Burke et al. [2]. Ignition delay times were recorded for isobutene/'air' mixtures at $\varphi=0.3$, $0.5,1.0$ and 2.0 at pressures of approximately 10, 30 and $50 \mathrm{~atm}$ and in the temperature range of approximately $940-1500 \mathrm{~K}$. The air was considered as a 21/79 vol. oxygen/nitrogen blend. All fuels were acquired from Sigma Aldrich at $99.5 \%$ purity. Oxygen, nitrogen, argon and carbon dioxide were acquired from BOC Ireland at high purity ( $\geq 99.5 \%)$. The overall uncertainty for each individual ignition delay time is estimated to be $20 \%$. Uncertainties in pressure, temperature, mixture composition, and those associated with the determination of the ignition delay time from the measured traces all contribute to the overall uncertainty.

The ignition delay time was defined as the interval between the rise in pressure due to the arrival of the reflected shock wave at the endwall and the maximum rate of rise of the pressure signal, as shown in Figure 1.

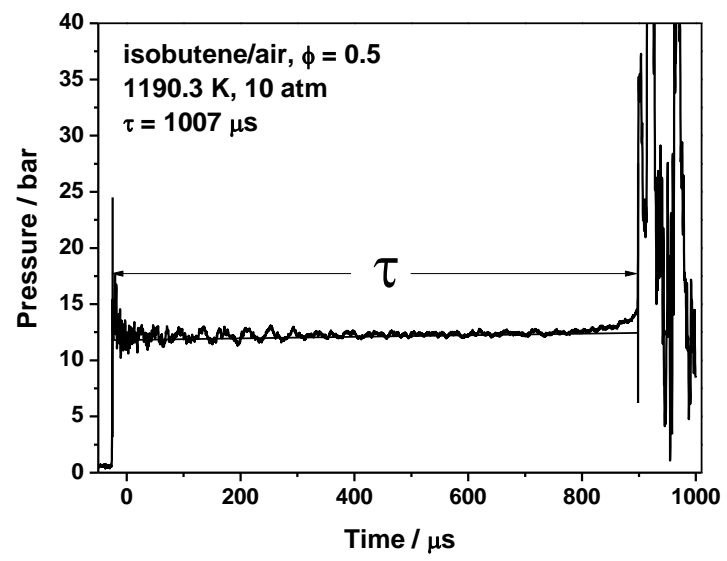

Figure 1. Sample pressure trace from NUI Galway shock tube.

\subsubsection{Texas A\&M University (TAMU) shock tube}

The single diaphragm, stainless steel, shock tube used at Texas A\&M University was $7.18 \mathrm{~m}$ long. The driven section had a $15.24 \mathrm{~cm}$ i.d., and was $4.72 \mathrm{~m}$ long, the driver section had an inner diameter of $7.62 \mathrm{~cm}$. Helium was used as the driver gas during this study. A schematic of the shock-tube setup has been given by Aul et al. [18]. All experimental methods were identical to those used in our recent collaborative study of propene ignition [2]. Ignition delay times for isobutene $/ \mathrm{O}_{2} / \mathrm{Ar}$ mixtures were measured at $\varphi=0.5$, and 1.0 with isobutene concentration ranges from $0.143 \%$ to $2 \%$ at pressures of 1.7 and $10 \mathrm{~atm}$ and in the temperature range of $1050-1765 \mathrm{~K}$. 
In addition to the endwall and sidewall transducers to monitor the test pressure, the chemiluminescence emission from the excited hydroxyl radical $\left(\mathrm{OH}^{\star}\right)$ located on the sidewall was also used to monitor the kinetics of the reaction. To detect possible pre-ignition events that could occur during the tests, chemiluminescence was also recorded using another photomultiplier but without a filter at the endwall location. Ignition delay time from the three measurements shown in Figure 2(a) and (b) predict very similar results. In Fig. 2(b), the ignition delay time for the $\mathrm{OH}^{\star}$ signal was defined as the time between the arrival of the shock wave at the endwall and the intersection of lines drawn along the steepest rate-of-change of $\mathrm{OH}^{\star}$ de-excitation (i.e., chemiluminescence) and a horizontal line which defines the zero-concentration level. Time zero is defined as the time at which the shock wave arrived at the endwall.

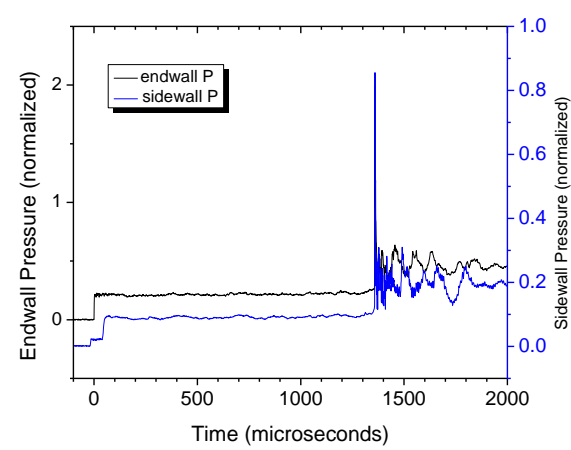

(a)

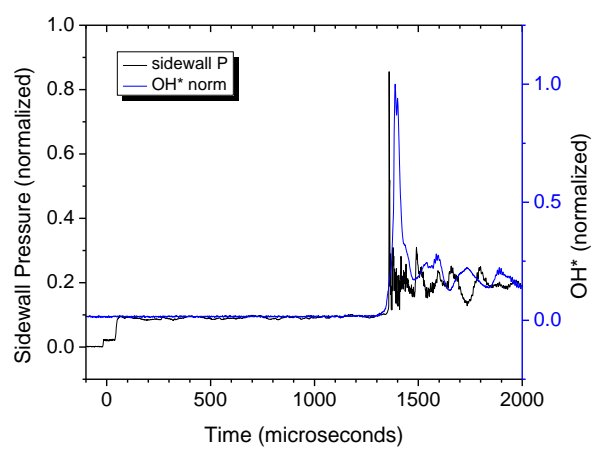

(b)

Figure 2. Ignition delay time measurements in the TAMU shock tube at $1222 \mathrm{~K}, \varphi=1.0,2 \%$ isobutene in Ar, 9.34 atm. (a) Pressure sensors located at both the endwall and sidewall locations. (b) Pressure and $\mathrm{OH}^{\star}$ emission measurements.

\subsubsection{Rensselaer Polytechnic Institute (RPI) shock tube}

Measurements of isobutene ignition delay times were made at RPI in the high-pressure shock tube described by Shen and Oehlschlaeger [19]. All experimental methods were identical to those used in our recent collaborative study of propene ignition [2]. For the present experiments with isobutene, which is gaseous at standard conditions, shock tube heating was not necessary. Ignition delay times were measured for isobutene/air mixtures at $\varphi=0.5,1.0$, and 2.0 at pressures around 10 atm and for isobutene $/ 12 \% \mathrm{O}_{2} / \mathrm{Ar}$ mixtures at $\varphi=1.0$ and 2.0 at pressures around 10 and $40 \mathrm{~atm}$. Reactant mixtures were made outside the shock tube in a mechanically-stirred mixing vessel. Isobutene was from SigmaAldrich at $99+\%$ purity and $\mathrm{O}_{2}, \mathrm{~N}_{2}$, and $\mathrm{Ar}$ were $99.995 \%$ pure from Noble Gas. Following reactant mixture preparation and mechanical mixing $(4 \mathrm{~h})$, reactant test gases were loaded into the shock tube driven section and ignition delay experiments performed. Ignition delay time determinations were made behind reflected shock waves by measuring the pressure at a side wall location $2 \mathrm{~cm}$ from the driven section end wall and hydroxyl radical emission $\left(\mathrm{OH}^{\star}\right)$ viewed through the driven section end wall. The onset of ignition was defined by extrapolating the maximum slope in $\mathrm{OH}^{\star}$ signal to the baseline and time-zero was defined as the time of shock reflection at the end wall, determined from the measured pressure and incident shock velocity. Figure 3 illustrates an example measurement. The reflected shock conditions were determined using the normal shock relations with input of the measured incident shock velocity, determined via the incident shock passage over a series of five pressure transducers spaced over the last meter of the driven section. The uncertainty in reflected shock temperature and pressure is estimated at approximately $\pm 1 \%$ and $\pm 1.5 \%$, respectively, for the conditions considered in this study. The uncertainty in ignition delay time is estimated at $\pm 20 \%$, based 
on contributions from uncertainty in reflected shock conditions and in determination of ignition delay from measured signals. The measured reflected shock pressure profiles show non-ideal pressure rise of $(d p / d t)\left(1 / p_{0}\right)=2-3 \% / \mathrm{ms}$ at the conditions studied.

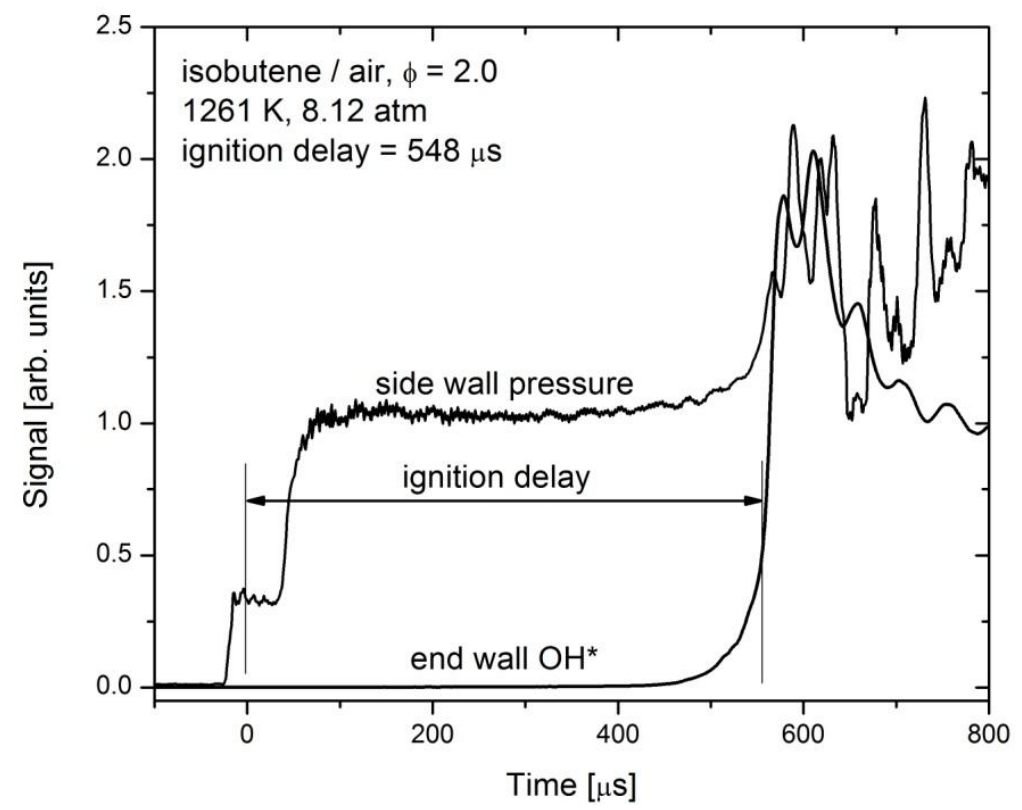

Figure 3. Example isobutene ignition delay time measurement from the RPI facility.

\subsubsection{King Abdullah University of Science and Technology (KAUST) shock tube}

The KAUST high-pressure shock tube (HPST) is used to measure the ignition delay times for isobutene/'air' mixtures at $\varphi=0.5,1.0$ and 2.0 at 40 atm. The HPST is described elsewhere [2] and explained briefly here. The HPST is constructed from stainless steel with an inner diameter of $10 \mathrm{~cm}$ and a total length of $13.2 \mathrm{~m}$. The driven section is $6.6 \mathrm{~m}$ long and the driver section length can be varied to a maximum of $6.6 \mathrm{~m}$; the two sections are separated by pre-scored aluminum diaphragms. The driven section was vacuumed before the experiment to less than $10^{-5}$ mbar using a turbo-molecular pump. A mixing vessel equipped with a magnetic stirrer was used to prepare gaseous mixtures. Helium was used as the driver gas in the experiments reported here. In order to measure the incident shock velocity, six PCB 113B26 piezoelectric pressure transducers (PZTs) were placed axially along the last $3.6 \mathrm{~m}$ of the driven section. Shock-jump equations were used to calculate the post-reflected shock conditions $\left(p_{5}\right.$ and $\left.T_{5}\right)$. Kistler 603B1 PZT located at $1.0 \mathrm{~cm}$ from the end-wall was used to record the pressure behind the reflected shock wave. The measured reflected shock pressure profiles showed nonideal pressure rise of $(d p / d t)\left(1 / p_{0}\right)=2-3 \% / \mathrm{ms}$ at the conditions of current experiments. The $\mathrm{OH}^{\star}$ emissions were monitored through Sapphire windows at the endwall and sidewall $(1.0 \mathrm{~cm}$ from the endwall) locations using PDA36A photo-detectors. The experimental setup is shown in Fig. 7 by Burke et al. [2]. Ignition delay time is defined as the time from the arrival of the reflected shock wave to the onset of ignition at the sidewall. Three diagnostics, pressure trace and the $\mathrm{OH}^{\star}$ emission detected at the endwall and the sidewall, were used to determine the onset of ignition. The three methods predict very similar ignition delay times, as illustrated in Figure 4. 


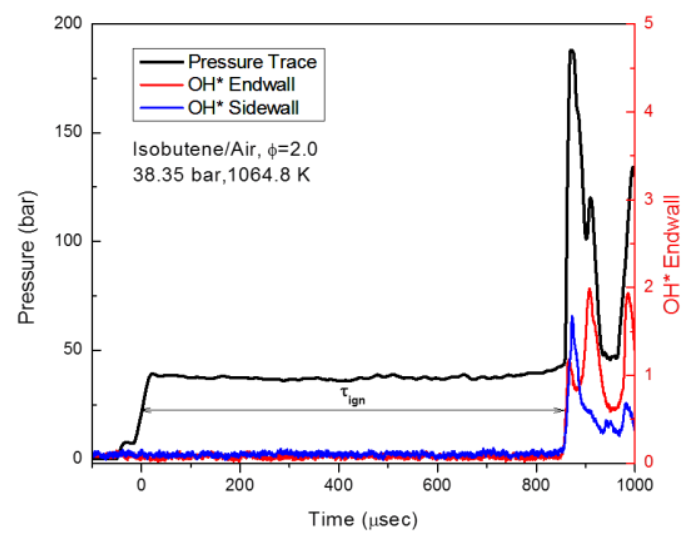

Figure 4. Example of isobutene ignition delay time measurement from the KAUST shock tube.

\subsubsection{NUI Galway rapid compression machine}

Ignition delay times for isobutene/'air' mixtures at $\varphi=0.3,0.5,1.0$ and 2.0 at pressures of approximately 10, 30 and $50 \mathrm{~atm}$ were measured at NUIG in the rapid compression machine and are similar to those described in the recent propene study by Burke et al. [2]. The ignition delay time definition in this work is shown in Figure 5 and is taken from the time of peak pressure at the end of compression to the time of maximum rate of pressure rise due to ignition.

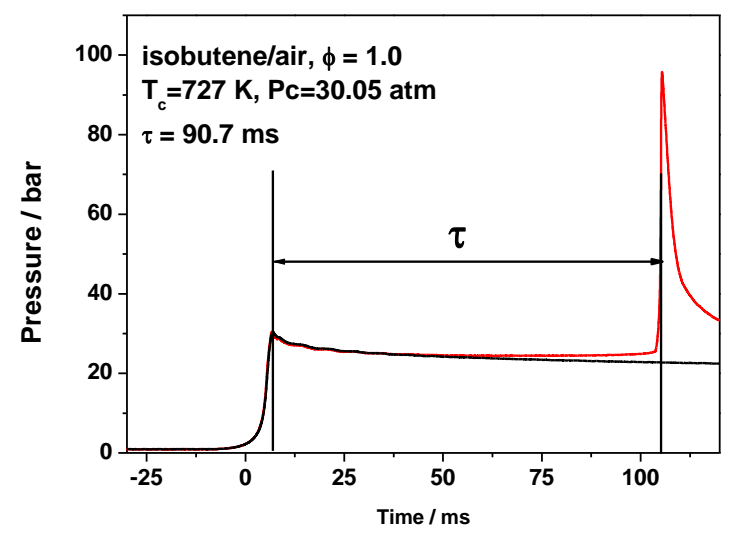

Figure 5. Sample pressure traces from NUI Galway RCM. — Non-reactive profile, — reactive profile.

We recognize that uncertainty quantification for experimental data is an essential step in assessing agreement between the experimental data and kinetic mechanism simulation results. It is natural to think in terms of two types of uncertainties for RCM experiments; uncertainties in the measured ignition delay time and also uncertainties in the measured and inferred thermodynamic state of the reacting gas.

We are confident that ignition delay times can be measured quite accurately within the RCM. This confidence stems from the high natural frequency of the transducer $(80 \mathrm{kHz})$ used to monitor incylinder pressure along with the sufficient time-resolution of the data acquisition unit $(20 \mathrm{kHz})$ to adequately capture both the end of compression time and the occurrence of the ignition event to within about $0.05 \mathrm{~ms}$. The a-synchronicity of the pistons' arrival at maximum compression in our dual piston machine contributes to shot-to-shot scatter in ignition delay measurements due to the stochastic change 
in the piston seating process. This a-synchronicity can cause inconsistencies for the defined end of compression time between reactive and non-reactive traces of up to $0.5 \mathrm{~ms}$, which only induces large uncertainties when comparing experimental and simulated ignition delay times for short ignition events (for example, $\pm 5 \%$ for an ignition delay of $5 \mathrm{~ms}$ and \pm 0.5 at $50 \mathrm{~ms}$ ).

While the RCM exhibits great accuracy for ignition delay measurements the characterization of the thermodynamic state of the reacting gas is more difficult, especially with regard to compressed temperatures that are evaluated from the adiabatic core hypothesis. Initial mixture mole fractions are expected to be accurate to within about $\pm 2 \%$ of their reported nominal value, where the main contribution of uncertainty comes from partial pressure measurements. Time resolved measurements of in-cylinder pressures are readily achievable with modern static and dynamic pressure transducers, which result in the measurement of the initial reactor pressure and transient pressure history to within approximately $\pm 0.05 \%$ and \pm 1 bar, respectively. Assuming perfect applicability of the adiabatic core hypothesis to the experiments conducted in this study and accounting for both uncertainties in the initial temperature and pressure measurements, the uncertainty of the inferred adiabatic core compressed temperature is less than approximately $\pm 15 \mathrm{~K}$.

\subsubsection{University of Connecticut (UConn) rapid compression machine}

The rapid compression machine (RCM) at UConn employs a creviced piston to compress test mixtures to elevated pressures and temperatures. The creviced piston is driven pneumatically and brought to rest by hydraulic pin-groove mechanism towards the end of the compression stroke. While the typical compression times are around 30-45 ms, the majority of pressure/temperature rise occurs in the last $6 \mathrm{~ms}$ of compression, as shown in Figure 6. A trigger from LabVIEW ${ }^{\circledR}$ initiates the compression event and starts data acquisition. Dynamic pressure in the reaction cylinder is measured using a thermal-shock resistant Kistler $6125 \mathrm{C}$ transducer in conjunction with $501 \mathrm{~B}$ charge amplifier. Test gas mixtures can be compressed to desired test conditions, compressed pressure $\left(p_{c}\right)$ and compressed temperature $\left(T_{C}\right)$, by independently varying compression ratio, intake pressure $\left(p_{0}\right)$, and intake temperature $\left(T_{0}\right)$. Compression ratios varying between 7 and 17 can be attained by varying stroke length or/and clearance length. Moreover, compressed temperature is deduced using the adiabatic core hypothesis.

The reaction cylinder is filled to the desired intake pressure with a homogenous fuel/oxidizer mixture prepared in a separate stainless steel mixing chamber of $17.47 \mathrm{~L}$, which is equipped with heaters to preheat the mixture to the desired intake temperature. In the current study, isobutene $(>99 \%)$ supplied by Sigma-Aldrich and ultra-high purity $(>99.99 \%) \mathrm{O}_{2}$ and $\mathrm{N}_{2}$ from Airgas are used to prepare homogenous isobutene/'air' mixtures in mixing chamber. The 'air' used in these experiments is a mixture of $\mathrm{O}_{2}$ and $\mathrm{N}_{2}$ in the molar ratio of 1:3.76. Fuel/oxidizer mixtures are prepared manometrically. The mixing chamber, intake manifold, and reaction cylinder are heated to the desired preheat temperature for about 4 hours before starting the experiments. Additionally, the mixing chamber is equipped with a magnetic stirrer which aids in preparation of homogeneous mixtures. Further details about the current RCM design and test procedure can be found in Das et al. [20].

Figure 6 shows the typical experimental repeatability and the definition of ignition delay used for reporting the present data. Ignition delay is defined as the time difference between the end of compression (EOC) and the maximum time derivative of the pressure after EOC. A minimum of four consecutive runs are conducted at each condition and the value close to the mean of the measured ignition delays is reported as the representative value. The scatter in ignition delays is less than $10 \%$ of the representative value for all the cases investigated. Furthermore, to ensure repeatability, ignition delay data obtained from each fresh mixture is checked with that from an earlier mixture. 


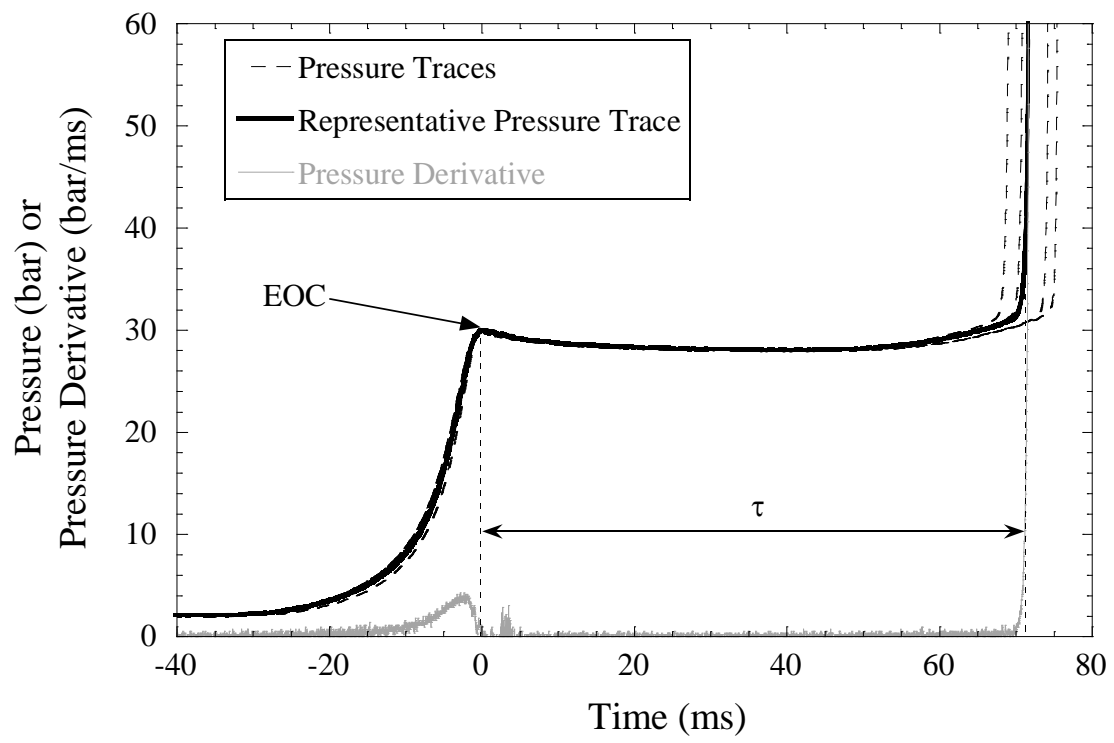

Figure 6. Plot showing experimental repeatability and definition of ignition delay at $\varphi=2.0$ in air, $p_{\mathrm{C}}=$ $30 \mathrm{bar}, T_{\mathrm{C}}=686 \mathrm{~K}, \tau=72 \mathrm{~ms}$.

In order to account for the effect of heat loss to the reactor walls on ignition delay, nonreactive experiments corresponding to each reactive run are taken to infer heat loss characteristics during compression and post compression periods. In these nonreactive experiments, isobutene/ $\mathrm{N}_{2}$ mixtures are prepared by replacing $\mathrm{O}_{2}$ with $\mathrm{N}_{2}$ in the corresponding reactive mixtures while maintaining the same fuel concentrations such that a similar specific heat ratio is maintained and similar heat loss conditions exist between the reactive case and the nonreactive case. Pressure traces from nonreactive runs are further used to generate volume vs. time histories in conjunction with the adiabatic core hypothesis. These volume histories are then imposed on auto-ignition simulations for characterizing the heat loss effect during the compression stroke and the post compression event.

\subsection{Flame Speed measurements}

Laminar flame speeds for isobutene were measured in three different facilities, which are located at Texas A\&M University (TAMU), Princeton University (PU) and Université de Lorraine (LRPG).

\subsubsection{Texas A\&M flames}

Laminar flame speed experiments were conducted in the high-temperature, high-pressure, constantvolume bomb at TAMU. This vessel has an internal diameter of $31.8 \mathrm{~cm}$ and an internal length of 28 $\mathrm{cm}$. Optical access is gained through fused-quartz windows located on either end of the vessel, each with a diameter of $12.7 \mathrm{~cm}$. The flame is centrally ignited by two electrodes. The relatively large volume of the vessel allows the flame to propagate at near-constant pressure for the course of the experiment, which ends when the flame reaches the diameter of the 12.7-cm window aperture. For the present experiments, the increase in pressure before the optical aperture limit was reached was, worstcase, less than 5\%. Full details on this experimental setup are given in Krejci et al. [21].

Mixtures were prepared using the partial pressure method with a 0-1000 Torr pressure transducer. Instrument-grade isobutene and Primary Standard Air were used to conduct all experiments. The initial conditions were 1 atm and $298 \mathrm{~K} \pm 2 \mathrm{~K}$. Images were taken using a Z-type schlieren setup and a highspeed camera (Photron Fastcam SA1.1) at a rate of 6,000 fps. These images were then processed using an internally developed MATLAB-based edge detection program. The burned, un-stretched laminar flame speed was extracted using the appropriate nonlinear method depending on the Markstein length 
as outlined by Chen [22]. Images that clearly showed either an ignition effect or a wall effect, based on the $d r / d t$ versus stretch plot, were neglected. The unburned, un-stretched flame speed was then determined using the density ratio calculated from the equilibrium chemistry.

Experimental uncertainty for the TAMU flame speed experiments was calculated using the Kline and McClintock method. The total uncertainty in the experiments is the square root of the square of the bias error plus the square of the random error. The bias error was based on inaccuracies in the temperature and pressure gauges used for the experiments, and the random error was based off of the average difference between the repeated points in the data set. The overall uncertainty was calculated to be just below $\pm 1.0 \mathrm{~cm} / \mathrm{s}$. Additional consideration was given in this study for differences in the measured values amongst the various apparatuses, as described in the results section.

\subsubsection{Princeton University flames}

Mass burning rates (the product of flame speed and unburned mixture density) were measured using the spherical flame method in a $10 \mathrm{~cm}$ diameter cylindrical chamber with a concentric pressure release chamber and two optical windows with details are shown in [23]. Mixtures were created from bottled air and isobutene (>99\%, Airgas) using the partial pressure method. To reduce compositional uncertainty caused by low fuel partial pressure, lean mixtures were prepared by first creating a rich mixture, allowing the mixture to homogenize for 10 minutes, partially evacuating the chamber, and then diluting with further air to reach the target equivalence ratio and pressure. After allowing the final mixture ten minutes to become quiescent, it is centrally ignited by a spark. High speed (15000 fps) schlieren imaging is utilized to image the flame propagation up to a radius of $3 \mathrm{~cm}$. The combustion pressure rise is released to the outer chamber after the flame front has passed the edge of the viewing window.

A flame edge detection program and circle fitting algorithm are used to determine the flame radius from each image. The stretched propagation speed $S_{b}$ and stretch rate $\kappa$ are extracted from the flame radius time history and corrected for asymmetric compression-induced flow effects as discussed in [24]. The un-stretched flame propagation speed $S_{b, 0}$ is then calculated through extrapolation to zero stretch using the linear stretch relation (for mixtures with near unity Lewis number), although the curvature method [22] gives results within 5\%. Low extrapolation uncertainty is expected, as $-0.1<\mathrm{Ma}$ $\mathrm{x} \mathrm{Ka}<0.2$ for all measurements [25]. Extrapolation endpoints are determined iteratively by locating the range where the residuals from the fit are below a threshold value and using this range to compute a new fit. This process is repeated while decreasing the threshold until stable endpoints (upper limit of flame radius) are found. The value reported here is the un-stretched laminar flame speed relative to the unburned gas, $S_{\mathrm{u}, 0}$, calculated by multiplying $S_{\mathrm{b}, 0}$ by the density ratio of burned to unburned gas. No data were used for flames that were observed to be wrinkled due to cellular or spiraling instabilities, affected by buoyancy, or influenced by transient response of the flame speed to stretch rate. The effect of thermal radiation on apparent burning rate is expected to be minor for these relatively fast flames [26].

\subsubsection{CNRS-Université de Lorraine flames}

The laminar burning velocities of isobutene oxidation were measured at Laboratoire Réactions et Génie des Procédés (LRGP) using the same atmospheric pressure heat flux burner as that used to study propene flames [2], as well as of components of natural gas [27] and gasoline [28, 29]. The heat flux method proposed first by de Goey and co-workers [4] allowed stabilizing adiabatic flat flames using heat loss compensation in order to derive adiabatic burning velocities directly from inlet gas flow rate measurements. The burner head was a perforated $30 \mathrm{~mm}$ diameter brass plate. The head was mounted on a mixing chamber enclosed in a thermostatic oil jacket, the temperature of which was set to 
the desired initial temperature of the fresh gas mixture. The circumference of the burner plate was heated with thermostatic oil set to about $50 \mathrm{~K}$ above the temperature of the unburned gas mixture so that the heat gain of the unburned gas mixture from the burner can compensate for the heat loss from the flame to the burner necessary to stabilize the flame.

The adiabaticity of the flame was checked by eight type $\mathrm{K}$ thermocouples inserted into holes of the burner plate and positioned at different distances and angles from the center to the periphery of the burner. When the temperature profile was flat, it meant that no heat was globally lost or gained by the flame and that the flame became adiabatic with respect to the burner. The adjustment of the flow rate of the gas mixture made it possible to find the appropriate gas velocity, which canceled out the net heat flux so that the radial temperature distribution in the burner plate was uniform. The flow rate at which the net heat flux was zero corresponded to the adiabatic flame burning velocity.

The burning velocity of isobutene/air mixtures has been investigated under atmospheric pressure for fresh gas temperature $298 \mathrm{~K}, 358 \mathrm{~K}$, and $398 \mathrm{~K}$ and equivalence ration ranging from 0.6 to 1.9. The air was considered as a $21 / 79$ vol. oxygen/nitrogen blend. Gas flow rates were measured using Bronkhorst High-Tech Mass Flow Controllers (MFC). Oxygen and nitrogen were delivered by Messer (purity $>99.995 \%$ vol.). Isobutene was provided by Air Liquide (purity $>99.5 \%$, without any noticeable content of other hydrocarbons).

The uncertainty in the laminar burning velocity can be first attributed to the uncertainty in the mass flow measurements (around $0.5 \%$ for each MFC) which can lead to a global uncertainty of $1.5 \%$ and around $1 \%$ in equivalence ratio. The uncertainty in reading the temperature with thermocouples which could lead to an error of around $0.2 \mathrm{~cm} / \mathrm{s}$ in the laminar burning velocity, and to errors due directly to flame distortions, such as edge effects (estimated around $0.2 \mathrm{~cm} / \mathrm{s}$ ). In the case of very rich mixtures, the change in the curvature of the temperature profile with the gas flow is more difficult to determine.

\subsection{Ignition delay time simulations and sensitivity analyses}

\subsubsection{Shock tube simulations}

Shock tube simulations were performed as zero-dimensional calculations and begin at the onset of the reflected shock period. The reflected shock pressure $\left(p_{5}\right)$ and temperature $\left(T_{5}\right)$ were used as the initial pressure and temperature, respectively. Constant volume, homogeneous and adiabatic conditions are assumed behind the reflected shock wave and no facility effects were necessarily included. For ignition delay calculations, the simulated ignition delay time is defined to be consistent with the particular diagnostic used in the experiment being simulated. The mechanism presented in this study contains a sub-mechanism for both excited $\mathrm{CH}^{\star}$ and $\mathrm{OH}^{\star}$ which have been adopted from Hall and Petersen [30], and Kathrotia et al. [31], respectively. CHEMKIN-PRO [32] is used to carry out the simulations.

\subsubsection{Rapid compression machine simulations}

The ignition delay time simulations of the RCM use a volume profile generated from the corresponding nonreactive pressure trace, for which an experiment is performed by replacing oxygen with nitrogen in the fuel/air mixtures. The volume history used for the simulation included the heat loss during the compression stroke by adding an empirically determined additional volume, and the heat loss after the end of compression was accounted for by the "adiabatic core expansion" approach [3335]. Non-reactive pressure-time traces are taken to correspond to each unique $p_{c}$ and $T_{C}$ condition studied. The volume history is then used as an input in the CHEMKIN-PRO [32] input file. 


\subsubsection{Brute-force sensitivity}

"Brute force" sensitivity analyses were carried out in order to identify the key reactions which control fuel reactivity. The analyses were performed by increasing and decreasing each reaction rate expression by a factor of two and calculating the effect on the predicted ignition delay time.

The sensitivity coefficient is defined as: $S=\frac{\ln \left(\tau_{+} / \tau_{-}\right)}{\ln \left(k_{+} / k_{-}\right)}=\frac{\ln \left(\tau_{+} / \tau_{-}\right)}{\ln (2.0 / 0.5)}$, where, $\tau_{+}$is the ignition delay time calculated with the increased rate constant and $\tau_{-}$is the ignition delay time calculated using the decreased rate constant. A positive sensitivity coefficient indicates an inhibiting reactivity while a negative sensitivity coefficient indicates a reaction promoting reactivity.

\subsection{Flame speed simulations and sensitivity analyses}

Flame speeds were simulated by the Premix module of CHEMKIN PRO [32]. A high-temperature version of the model which does not include low temperature chemistry was created to simulate the flame speed to avoid the high computational cost of using the full mechanism. The species removed include the 2-methylallyl radical self-recombination product, alkyl-peroxyl radicals, hydroperoxyl-allyl radicals, ketohydroperoxide species, to reduce the size of the mechanism. Metcalfe et al. [36] carried out extensive tests of flame speed calculations for $\mathrm{C}_{0}-\mathrm{C}_{2}$ molecular species using AramcoMech 1.3 and found that the high-temperature mechanism results in the same predictions as the full mechanism with a considerably reduced computational time. Simulations were converged to a grid-independent solution by assigning GRAD and CURV values of 0.02. The mixture-averaged diffusion method for calculating the transport coefficients was used. The Transport Data Estimator package of the Reaction Mechanism Generator software of Green and co-workers [37] has been used to provide relevant transport properties. Thermal diffusive effects were also accounted for and generally resulted in a noticeable reduction in flame speed. CHEMKIN-PRO was also used to perform the flame speed sensitivity analyses. 


\section{Computational method}

Rate constants calculations have been carried out for the following important reactions associated with isobutene oxidation and pyrolysis:

- $\mathrm{iC}_{4} \mathrm{H}_{8}+\dot{\mathrm{O} H} \leftrightarrow \mathrm{i}_{4} \mathrm{H}_{7}+\mathrm{H}_{2} \mathrm{O}$

- $\mathrm{iC}_{4} \mathrm{H}_{8}+\dot{\mathrm{O}} \mathrm{H} \leftrightarrow \mathrm{iC}_{4} \mathrm{H}_{7}-\mathrm{i} 1+\mathrm{H}_{2} \mathrm{O}$

- $\mathrm{iC}_{4} \mathrm{H}_{8}+\mathrm{HO}_{2} \leftrightarrow \mathrm{i}_{4} \mathrm{H}_{7}-\mathrm{i} 1+\mathrm{H}_{2} \mathrm{O}$

- $\mathrm{i}_{4} \mathrm{H}_{7} \leftrightarrow \mathrm{C}_{3} \mathrm{H}_{4}-\mathrm{a}+\dot{\mathrm{C}} \mathrm{H}_{3}$

The M062X method [38] with the 6-311++G(d,p) basis set were used in the geometry optimizations and frequency calculations of all of the species involved in this reaction using Gaussian 09 [39]. The same method was used to determine the potential energy surface scans for the individual hindered rotors associated with reactant and transition state. The electronic single point energies have been calculated at QCISD(T)/cc-pCXZ level of theory (where $X=\mathrm{T}$ and Q) which were extrapolated to the complete basis set (CBS) limit [40, 41].

Conventional transition-state theory [42] with an asymmetric Eckart tunneling correction [43] has been used to calculate the high-pressure limit rate constants in this work. The low-frequency torsional conserved modes were treated as hindered rotors using a Pitzer-Gwinn-like approximation [44] to calculate the partition function.

\section{Chemical kinetic mechanism development}

The current mechanism development is based on the $\mathrm{H}_{2} / \mathrm{O}_{2}$ sub-mechanism adopted from the study of Kéromnès et al. [45], the C1-C2 sub-mechanism, AramcoMech 1.3, adopted from the study of Metcalfe and co-workers [36] and the propene/allene/propyne sub-mechanism adopted from the recent publications of Burke et al. [2,3]. The important thermodynamic parameters are estimated using the group additivity method employed by Benson [46] with updated group values by Burke et al. [47] and utilized in the program developed by Ritter and Bozzelli [48]. During these developments, the mechanism has been validated against numerous experimental conditions and targets. Key reactions for isobutene oxidation at different temperature and pressure conditions were highlighted by sensitivity analyses for reflected shock ignition delay times, flux analyses and flame speed sensitivity analyses. The isobutene combustion chemistry model developed in this work has improved the predictions against a variety of experimental results. The comprehensive kinetic mechanism, thermochemistry and transport files will be provided as Supplementary material and will also be available to download at http://c3.nuigalway.ie/mechanisms.html.

\subsection{Important reaction classes highlighted}

Figure 7 highlights the important reactions controlling isobutene fuel oxidation at 10 and 30 atm and at fuel-lean $(\varphi=0.3)$ and fuel-rich $(\varphi=2.0)$ conditions at intermediate temperatures. The reactions of $\mathrm{iC}_{4} \mathrm{H}_{8}+\dot{\mathrm{OH}} \leftrightarrow \mathrm{i}_{4} \mathrm{H}_{7}+\mathrm{H}_{2} \mathrm{O}, \mathrm{iC}_{4} \mathrm{H}_{7}+\mathrm{iC}_{4} \mathrm{H}_{7} \leftrightarrow \mathrm{H} 15 \mathrm{DE} 25 \mathrm{DM}$ and $\mathrm{iC}_{4} \mathrm{H}_{7}+\dot{\mathrm{CH}}_{3}(+\mathrm{M}) \leftrightarrow \mathrm{aC}_{5} \mathrm{H}_{10}$ $(+\mathrm{M})$ inhibit reactivity for both fuel-lean and fuel-rich conditions at intermediate temperatures. When the pressure increases, the 2-methylallyl $\left(\mathrm{iC}_{4} \mathrm{H}_{7}\right)$ radical self-recombination reaction becomes more favored and inhibits the reactivity more pronouncedly than at lower pressures.

The reactions of $\dot{\mathrm{C}}_{4} \mathrm{H}_{7}$ with $\mathrm{HO}_{2}$ radicals are the most promoting ones at intermediate temperatures in both fuel-lean and fuel-rich mixtures. This is due to the formation of the highly reactive OH radicals and methyl-allyloxyl $\left(\mathrm{iC}_{4} \mathrm{H}_{7} \mathrm{O}\right)$ radicals; the latter ultimately decompose to produce 2-propenyl $\left(\dot{\mathrm{C}}_{3} \mathrm{H}_{5}-\mathrm{t}\right)$ radicals through different reaction pathways. These $\dot{\mathrm{C}}_{3} \mathrm{H}_{5}$-t radicals react with $\mathrm{O}_{2}$ to form $\mathrm{CH}_{3} \mathrm{COC}_{2}$ radicals and $\ddot{\mathrm{O}}$ atoms, which ultimately promotes reactivity. It is interesting to note that $\mathrm{H}$-atom abstraction from $\mathrm{iC}_{4} \mathrm{H}_{8}$ by $\mathrm{O}_{2}$ to form $\mathrm{iC}_{4} \mathrm{H}_{7}$ and $\mathrm{HO}_{2}$ radicals is the most promoting reaction for fuel- 
rich mixtures $(\varphi=2.0)$. This is because, at fuel-rich conditions, the concentration of the fuel is high and the two products, $\mathrm{iC}_{4} \mathrm{H}_{7}$ and $\mathrm{HO}_{2}$ radicals, will react further to produce methyl-allyloxy radical $\left(\mathrm{iC}_{4} \mathrm{H}_{7} \mathrm{O}\right)$ and the highly reactive $\dot{\mathrm{O}} \mathrm{H}$ radical. The reaction of $\mathrm{iC}_{4} \mathrm{H}_{8}+\dot{\mathrm{O}} \mathrm{H} \leftrightarrow \mathrm{i}_{4} \mathrm{H}_{7}-\mathrm{il}+\mathrm{H}_{2} \mathrm{O}$ promotes reactivity at all conditions studied, as the vinylic isobuten $1-y 1$ radical $\left(\mathrm{iC}_{4} \mathrm{H}_{7}-\mathrm{i} 1\right)$ reacts with molecular oxygen to form $\mathrm{CH}_{3} \mathrm{COCH}_{3}+\mathrm{HC} \mathrm{CO}$ and $\mathrm{iC}_{3} \mathrm{H}_{5} \mathrm{CHO}+\dot{\mathrm{O} H}$, promoting reactivity. The formation of $\mathrm{iC}_{3} \mathrm{H}_{5} \mathrm{CHO}$ mainly through the decomposition of $\mathrm{iC}_{4} \mathrm{H}_{7} \mathrm{O}$ radicals via the reaction $\mathrm{iC}_{4} \mathrm{H}_{7} \mathrm{O} \leftrightarrow$ $\mathrm{iC}_{3} \mathrm{H}_{5} \mathrm{CHO}+\dot{\mathrm{H}}$ is also an important species at intermediate temperatures. With a very weak bond strength $\left(\mathrm{iC}_{3} \mathrm{H}_{5} \mathrm{CO} \cdots \mathrm{H}\right)$ of $87.1 \mathrm{kcal} \mathrm{mol}^{-1}$, the aldehydic hydrogen atom is quite easy abstractable to form an $\mathrm{iC}_{3} \mathrm{H}_{5} \dot{\mathrm{C} O}$ radical, which decomposes to form $\mathrm{CO}$ and a $\dot{\mathrm{C}}_{3} \mathrm{H}_{5}$-t radical which promotes reactivity.

When the temperature increases to $1250 \mathrm{~K}$, the reaction $\mathrm{iC}_{4} \mathrm{H}_{8}+\mathrm{O}_{2} \leftrightarrow \mathrm{iC}_{4} \mathrm{H}_{7}+\mathrm{HO}_{2}$ is the most dominant one promoting reactivity at both fuel-lean and fuel-rich conditions over the entire pressure range investigated here, Figure 8 . The 2-methylallyl radical self-recombination reaction is not observed to be important at higher temperatures as the adduct readily decomposes.

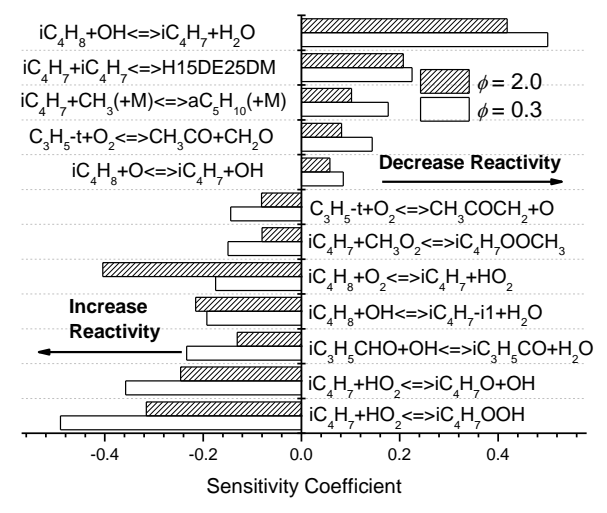

(a)

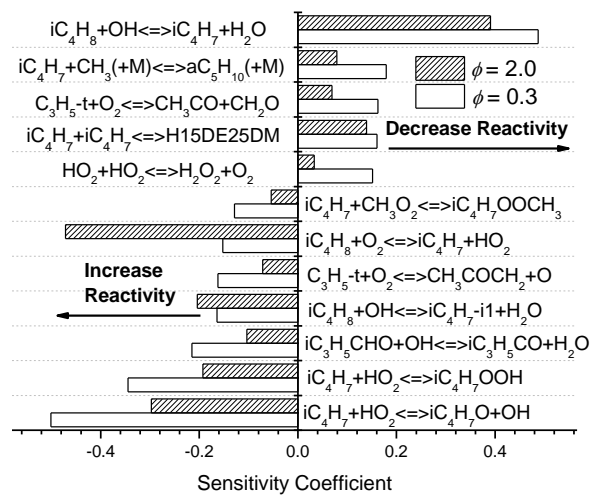

(b)

Figure 7. "Brute force" sensitivity analyses to ignition delay times performed at (a) $T=950 \mathrm{~K}, p=30$ atm, $\varphi=0.3$, and 2.0, (b) $T=900 \mathrm{~K}, p=10$ atm, $\varphi=0.3$, and 2.0. 


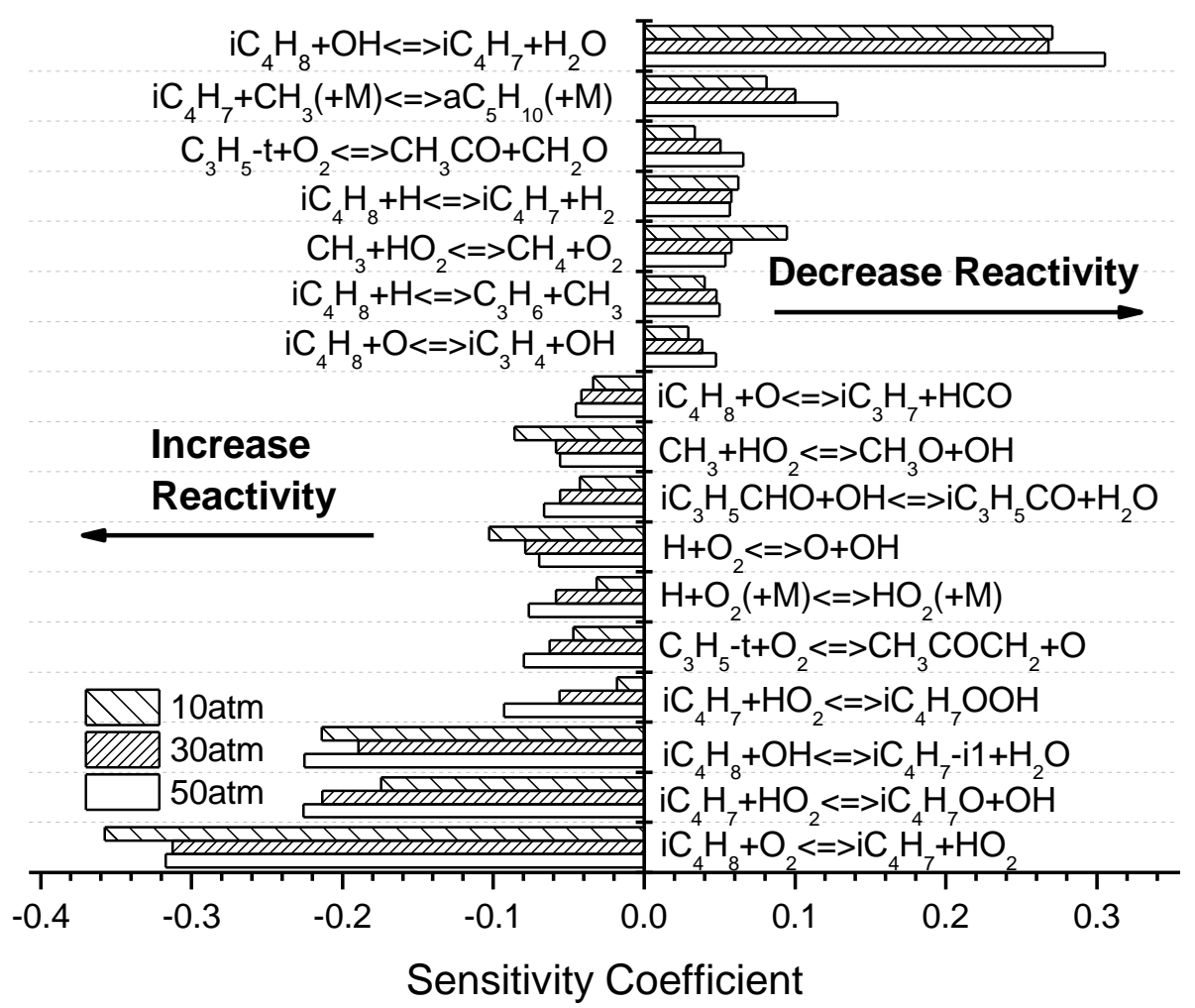

Figure 8. "Brute force" Sensitivity analyses to ignition delay times performed at $\varphi=1.0$, fuel/air, $T=$ $1250 \mathrm{~K}$ and different pressures.

All of the reactions highlighted here will be discussed in detail in the following sections and the detailed reaction pathways are shown in Figure 10. From the bond dissociation energy (BDE) comparison of propene and isobutene shown in Figure 9, we can see that the BDE of the $\mathrm{C}-\mathrm{C}$ bond in isobutene is $2.0 \mathrm{kcal} \mathrm{mol}^{-1}$ lower than that in propene and the allylic $\mathrm{C}-\mathrm{H}$ bond in isobutene is $0.8 \mathrm{kcal}$ $\mathrm{mol}^{-1}$ higher than in propene. Thus, for some of the important reaction rate constants, we use analogous rate constants from propene for isobutene with some reasonable adjustment; for some of the important reaction rate constants we also carried out $a b$ initio calculations. Moreover, details of the choice of rate constants are discussed and explained in the following sections.

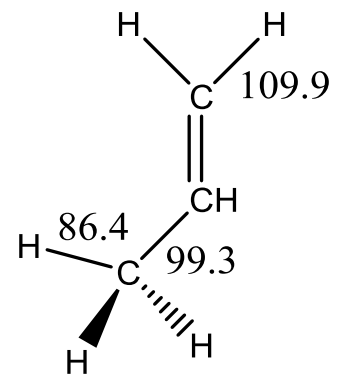

propene<smiles>C=C(C)CC</smiles>

isobutene

Figure 9. Bond dissociation energy (in $\mathrm{kcal} / \mathrm{mol}$ ) comparison between propene and isobutene obtained at QCISD(T)/CBS//M062x/6-311++G(d,p) at $0 \mathrm{~K}$. 
Figure 10. Generalized reaction pathways included in this work for isobutene oxidation. F: fuel; $\mathrm{R}_{\mathrm{A}}$ : allylic radical, $\mathrm{R}_{\mathrm{VS}}$ : vinylic secondary radical; $\mathrm{R}_{\mathrm{VT}}$ : vinylic tertiary radical; $\mathrm{R}_{\mathrm{A}} \mathrm{O}$ : methyl-allyloxyl radical; F': 2-methyl-1-butene; alcoholic KHP: alcoholic keto-hydroperoxide; Dienes: 2,5-dimethyl1,5-hexadiene.

\subsection{Unimolecular decomposition}

Two important reaction channels highlighted here are the allylic $\mathrm{C}-\mathrm{H}$ bond fission reaction channel which has the lowest bond dissociation energy (forming 2-methylallyl $\left(\mathrm{i}_{4} \dot{\mathrm{H}}_{7}\right)$ radical and a $\dot{\mathrm{H}}$ atom) and the $\mathrm{C}-\mathrm{C}$ bond fission reaction channel (forming $\dot{\mathrm{C}}_{3} \mathrm{H}_{5}-\mathrm{t}$ and $\mathrm{CH}_{3}$ radicals):

- $\mathrm{iC}_{4} \mathrm{H}_{8} \leftrightarrow \mathrm{i}_{4} \dot{\mathrm{H}}_{7}+\dot{\mathrm{H}}$

- $\mathrm{iC}_{4} \mathrm{H}_{8} \leftrightarrow \dot{\mathrm{C}}_{3} \mathrm{H}_{5}-\mathrm{t}+\mathrm{CH}_{3}$

Speciation measurements of isobutene pyrolysis in the PU flow reactor [49] are sensitive to isobutene decomposition, Figure 11. The high-pressure limit rate constant has been adopted by analogy with propene [50] with further QRRK calculations to estimate the pressure fall off. However in order to improve agreement with flow reactor speciation measurements from [49], the rate constant for the formation of methylallyl radical and atomic hydrogen has been increased by a factor of two. This adjustment is well within the uncertainty of the rate constant estimation. Figure 11 shows the influence of this adjustment. 
Figure 11. Influence of rate constants for $\mathrm{iC}_{4} \mathrm{H}_{8} \leftrightarrow \mathrm{iC}_{4} \mathrm{H}_{7}+\dot{\mathrm{H}}$ in flow reactor speciation analysis for isobutene pyrolysis $\left(0.503 \% \mathrm{iC}_{4} \mathrm{H}_{8}\right.$, in $\mathrm{N}_{2}, p=1 \mathrm{~atm}, T=1150 \mathrm{~K}$. Symbols: APFR experimental measurements [49], lines: mechanism predictions, time shift: -0.26 s.). — This study, - - - analogy to propene [50].

\subsection{Fuel-radical reactions}

$\mathrm{H}$-atom abstraction reactions by various radicals from isobutene have been included in this work. There are two different types of hydrogen atom in isobutene that can be abstracted: one from the methyl site forming the resonantly stabilized $\mathrm{iC}_{4} \mathrm{H}_{7}$ radical and the other from the terminal carbon to form a vinylic radical $\left(\mathrm{i}_{4} \mathrm{H}_{7}-\mathrm{i} 1\right)$. As shown in Figure 9, the bond dissociation energy comparison between those two types of $\mathrm{C}-\mathrm{H}$ bonds tells us the formation of the 2-methylallyl radical is dominant because it is about $22.9 \mathrm{kcal} \mathrm{mol}^{-1}$ weaker than the vinylic one.

\subsection{1 $i \mathrm{C}_{4} \mathrm{H}_{8}+\dot{\mathrm{O} H} \leftrightarrow$ Products}

For the reaction of ÖH radicals with isobutene, both abstraction and addition pathways are included in the current kinetic mechanism.

\subsubsection{H-Abstraction by $\dot{O} H$ radicals}

As shown in Figure 7 and Figure 25, predicted ignition delay times are highly sensitive to the $\mathrm{H}$ atom abstraction reaction by $\dot{\mathrm{O}} \mathrm{H}$ radicals from isobutene forming 2 -methylallyl $\left(\mathrm{i}_{4} \mathrm{H}_{7}\right)$ radicals in a very large range of temperatures and pressures. This reaction inhibits reactivity throughout the entire temperature range of the ignition delay time measurements, because it consumes a highly reactive $\dot{\mathrm{O}} \mathrm{H}$ radical and forms a resonantly stabilized and thus relatively unreactive $\mathrm{iC}_{4} \mathrm{H}_{7}$ radical. The $\mathrm{iC}_{4} \mathrm{H}_{7}$ radicals undergo radical-radical self-recombination or can react with methyl radicals via chain terminating reactions which inhibit reactivity, while the reaction of $\mathrm{i}_{4} \mathrm{H}_{7}$ with $\mathrm{HO}_{2}$ promotes reactivity at intermediate temperatures as discussed earlier. Rate constants for the reaction of isobutene with $\dot{\mathrm{O} H}$ radicals has been reported by Sun et al. [51] at the CCSD(T)/6-311++G(d,p)//BH\&HLYP/6-311G(d,p) level of theory. As this reaction dominates reactivity over the entire temperature range, we have also calculated the rate constants in this work at a higher level of theory (QCISD(T)/CBS//M062X/6$311++\mathrm{G}(\mathrm{d}, \mathrm{p}))$ to obtain more accurate electronic energies and rate constants. Figure 12 shows that the two calculation results are at worst $40 \%$ different from one another with different curvature. Comparison with the available experimental measurement taken by Baker et al. [52] at $753 \mathrm{~K}$ is also shown in Figure 12, and it is a factor of two faster than our calculations. 


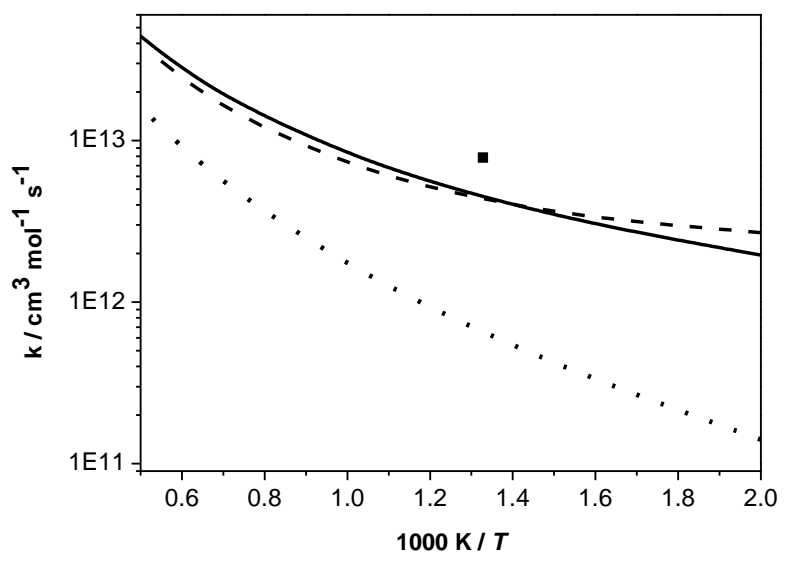

Figure 12. Rate constants comparison of $\mathrm{iC}_{4} \mathrm{H}_{8}+\mathrm{OH}$. 2-methylallyl radical formation: — This study (ab-initio), ${ }^{-----}$Sun et al. [51], - Baker [52] ; vinylic isobuten1-yl radical formation This study (ab-initio).

\subsubsection{2 $\dot{\mathrm{OH}}$ addition to $\mathrm{iC}_{4} \mathrm{H}_{8}$}

$\dot{\mathrm{OH}}$ radical addition to $\mathrm{iC}_{4} \mathrm{H}_{8}$ is important at temperatures lower than $850 \mathrm{~K}$ and the analogous rate constants from propene plus $\dot{\mathrm{OH}}$ radical as calculated by Zador $e t$ al. [53] were used in this work.

- $\mathrm{iC}_{4} \mathrm{H}_{8}+\dot{\mathrm{O} H} \leftrightarrow \mathrm{iC}_{4} \mathrm{H}_{8} \mathrm{OH}-\mathrm{it}$

- $\mathrm{iC}_{4} \mathrm{H}_{8}+\dot{\mathrm{OH}} \leftrightarrow \mathrm{iC}_{4} \mathrm{H}_{8} \mathrm{OH}-\mathrm{ti}$

- $\mathrm{iC}_{4} \mathrm{H}_{8}+\dot{\mathrm{O}} \mathrm{H} \leftrightarrow \mathrm{iC}_{4} \mathrm{H}_{7} \mathrm{OH}+\dot{\mathrm{H}}$

- $\mathrm{iC}_{4} \mathrm{H}_{8}+\dot{\mathrm{O}} \mathrm{H} \leftrightarrow \mathrm{sC}_{3} \mathrm{H}_{5} \mathrm{OH}+\dot{\mathrm{C}} \mathrm{H}_{3}$

- $\mathrm{iC}_{4} \mathrm{H}_{8}+\dot{\mathrm{O} H} \leftrightarrow \mathrm{iC}_{3} \mathrm{H}_{5} \mathrm{OH}+\dot{\mathrm{C}}_{3}$

- $\mathrm{iC}_{4} \mathrm{H}_{8}+\dot{\mathrm{O}} \mathrm{H} \leftrightarrow \mathrm{sC}_{4} \mathrm{H}_{7} \mathrm{OH}-\mathrm{i}+\dot{\mathrm{H}}$

- $\mathrm{iC}_{4} \mathrm{H}_{8}+\dot{\mathrm{O}} \mathrm{H} \leftrightarrow \mathrm{CH}_{3} \mathrm{COCH}_{3}+\dot{\mathrm{C}} \mathrm{H}_{3}$

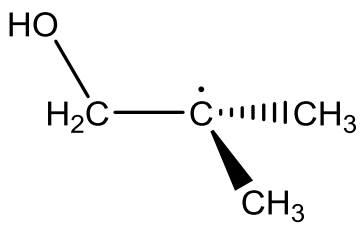

$\mathrm{iC}_{4} \mathrm{H}_{8} \mathrm{OH}-\mathrm{it}$

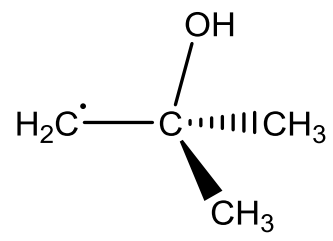

$\mathrm{iC}_{4} \mathrm{H}_{8} \mathrm{OH}-\mathrm{ti}$

Figure 13. Structures of the two species formed by $\mathrm{OH}$ radical addition to $\mathrm{iC}_{4} \mathrm{H}_{8}$.

The competition between the formation of $\mathrm{i}_{4} \mathrm{H}_{8} \mathrm{OH}$-it and $\mathrm{i}_{4} \mathrm{H}_{8} \mathrm{OH}$-ti radicals, Figure 13, plays a significant role in dictating the predicted reactivity in the low temperature range.

Taking the increased steric hindrance by the methyl group in isobutene into consideration, we take the branching ratio of these two channels as being 75:25 rather than 50:50 and keep the total rate constant the same as that for $\dot{\mathrm{OH}}$ addition to propene. The influence to the ignition delay times in the low temperature range can be seen in Figure 14; this reaction does not influence the high temperature ignition delay time. Baker et al. [52] have also investigated the rate constant of $\dot{\mathrm{OH}}$ addition to isobutene at $753 \mathrm{~K}$, and their rate constants are about an order of magnitude faster than what we use in this work. A detailed reason for this is unknown. From the flux analysis shown in Figure 26 we observe that at $730 \mathrm{~K}$ and $30 \mathrm{~atm}, \dot{\mathrm{O} H}$ radical addition reaction consumes $21.7 \%$ of the fuel, with $17.3 \%$ of the 
fuel forming $\mathrm{i}_{4} \mathrm{H}_{8} \mathrm{OH}$-it radicals through terminal addition and $4.4 \%$ forming $\mathrm{i}_{4} \mathrm{H}_{8} \mathrm{OH}$-ti radicals through addition to the central carbon atom. When the temperature increases to $850 \mathrm{~K}$, only $7.9 \%$ of $\mathrm{iC}_{4} \mathrm{H}_{8}$ is consumed through terminal addition and central addition no longer contributes at all. As the temperature increases further to $950 \mathrm{~K}$, $\dot{\mathrm{O}} \mathrm{H}$ radical addition reactions do not contribute to fuel consumption.

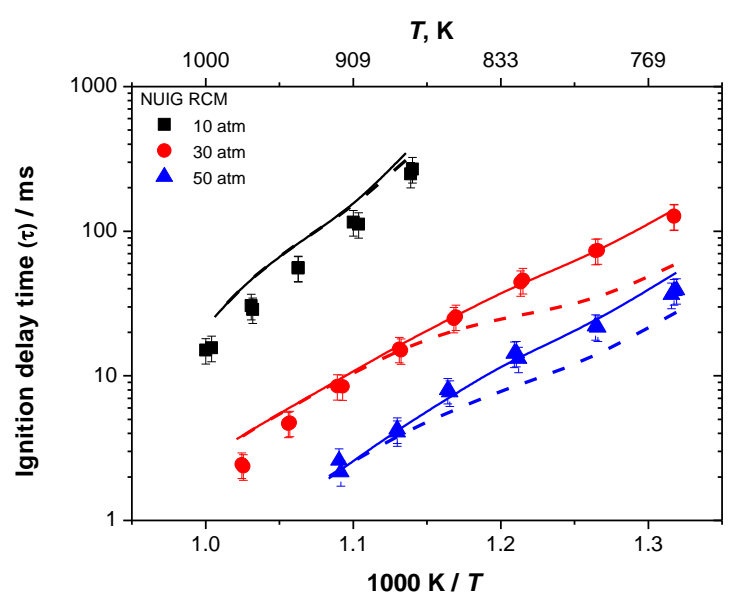

Figure 14. Branching ratio effects from the $\dot{\mathrm{OH}}$ terminal and central addition to $\mathrm{iC}_{4} \mathrm{H}_{8}$ to ignition delay times at $\varphi=0.5$, fuel in air, $p=10,30$ and 50 atm. Terminal vs. central: solid line (75:25); dashed line (50:50).

\subsubsection{Addition of $i \dot{\mathrm{C}}_{4} \mathrm{H}_{8} \mathrm{OH}$-it and $\mathrm{i}_{4} \mathrm{H}_{8} \mathrm{OH}$-ti radicals to $\mathrm{O}_{2}$}

Sun et al. [54] calculated the rate constants of $\mathrm{iC}_{4} \mathrm{H}_{8} \mathrm{OH}$-it and $\mathrm{iC}_{4} \mathrm{H}_{8} \mathrm{OH}$-ti radical addition to $\mathrm{O}_{2}$ and their subsequent decomposition reactions. They used canonical transition state theory to calculate the elementary rate constants and QRRK theory to calculate pressure- and temperature-dependent rate constants. As shown in Figure 26, the formation of $\mathrm{CH}_{3} \mathrm{COCH}_{3}, \mathrm{CH}_{2} \mathrm{O}$ and $\mathrm{OH}$ radical is the dominant product set resulting from $\mathrm{iC}_{4} \mathrm{H}_{8} \mathrm{OH}$-it radical addition to $\mathrm{O}_{2}$.

The competing two channels for the decomposition of $\mathrm{QCH}_{2} \mathrm{CO}\left(\mathrm{CH}_{3}\right)_{2}$ are shown in Figure 15. The channel forming $\mathrm{CH}_{3} \mathrm{COCH}_{3}, \mathrm{CH}_{2} \mathrm{O}$ and $\mathrm{OH}$ radical (via the typical Waddington mechanism) inhibits reactivity while the other channel forming $\dot{\mathrm{C}} \mathrm{H}_{3}$ radical and $\mathrm{CH}_{3} \mathrm{COCH}_{2} \mathrm{OOH}$ promotes reactivity. The analogous high-pressure limit rate constants for these two channels calculated by Villano et al. [55] are quite different from the rate constants obtained by Sun et al. [54]. In this work, we use the rate constants for $\dot{\mathrm{C}}_{3} \mathrm{CCOOH} \leftrightarrow \mathrm{C}_{2} \mathrm{C}=\mathrm{C}+\mathrm{CH}_{2} \mathrm{O}+\dot{\mathrm{O} H}$ and $\dot{\mathrm{C}}_{2} \mathrm{CCOOH} \leftrightarrow \mathrm{C}=\mathrm{CCOOH}+\dot{\mathrm{CH}}_{3}$ calculated by Villano et al. [55] as analogies to $\mathrm{R} 1682$ and $\mathrm{R} 1683$ respectively to give a better ignition delay time prediction, especially at lower temperatures, Figure 16.

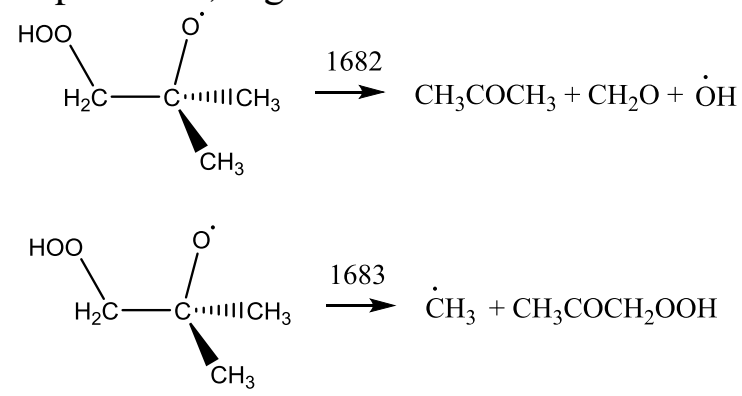

Figure 15. Competition decomposition channels of the adducts, $\mathrm{QCH}_{2} \mathrm{CO}\left(\mathrm{CH}_{3}\right)_{2}$.

The flux analysis presented in Figure 26 shows only $4.4 \%$ of isobutene forms $\mathrm{iC}_{4} \mathrm{H}_{8} \mathrm{OH}$-ti radicals through their reaction with $\dot{\mathrm{OH}}$ radicals at $730 \mathrm{~K}$, but its subsequent chain branching reaction with 
molecular oxygen pronouncedly promotes low temperature reactivity, Figure 17 . Our current treatment captures the low temperature reactivity of isobutene oxidation quite well; while further fundamental research studies to provide accurate pressure and temperature dependence rate constants for the first and second radical addition to molecular oxygen reactions are needed to give a better understanding of the low temperature chemistry of alkene fuel oxidation.

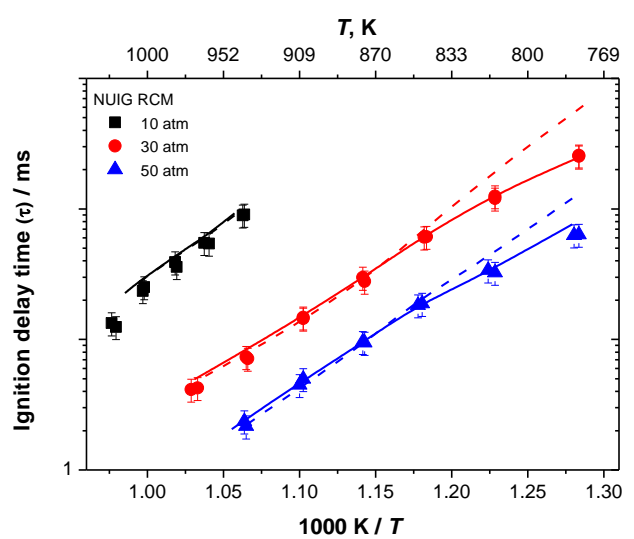

(a) $\varphi=0.3$, fuel in air

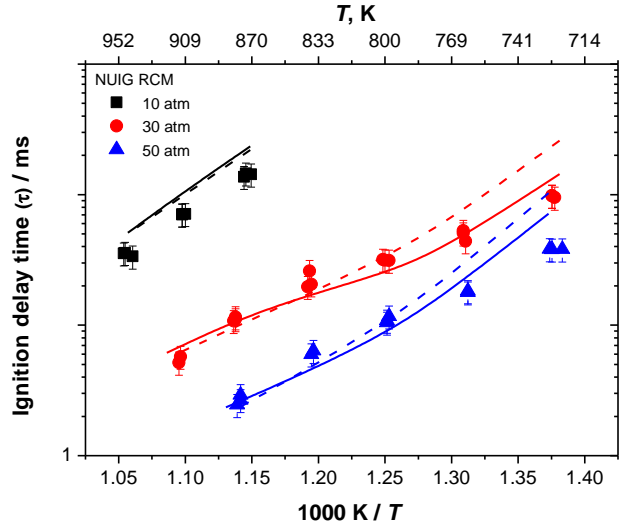

(c) $\varphi=1.0$, fuel in air

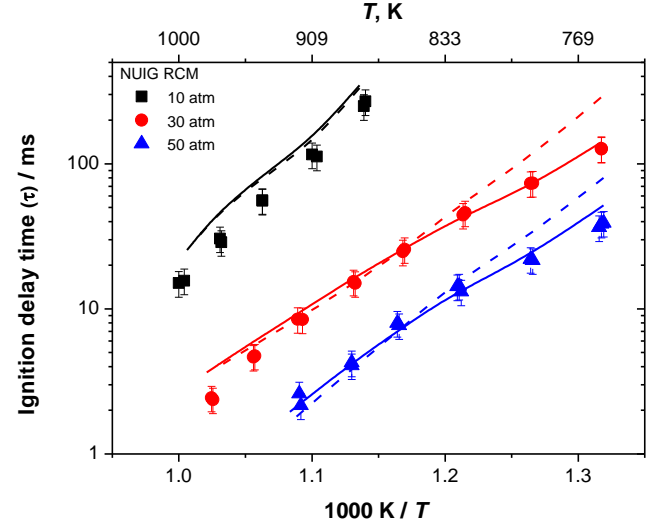

(b) $\varphi=0.5$, fuel in air

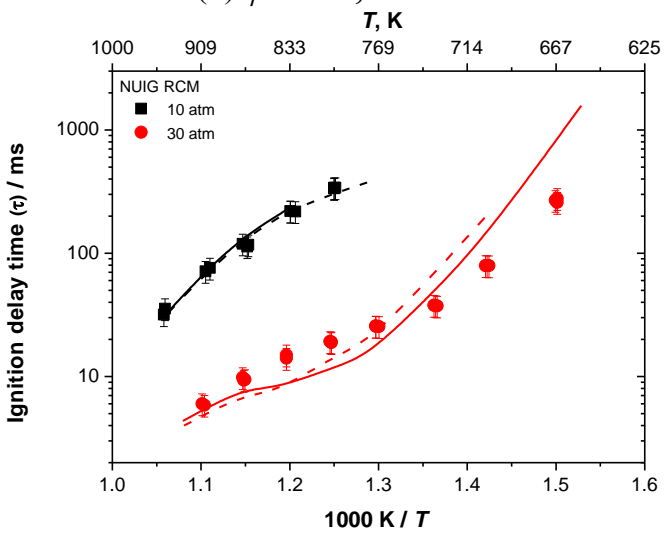

(d) $\varphi=2.0$, fuel in air

Figure 16. Influence of replacing rate constants for reactions 1682 and 1683 from Sun et al. [54] (dashed line) to Villano et al. [55] (solid line) to ignition delay time.

The second addition to molecular oxygen has also been included and its influence to the ignition delay times at lower temperatures is shown in Figure 17. The rate constants for the reaction channels are taken by analogy to rate constants from Miyoshi [56] for the entrance channel of the second (hydroperoxyl-alkyl) radical addition to molecular oxygen and Goldsmith et al. [57] for the following isomerization and decomposition reaction channels. 


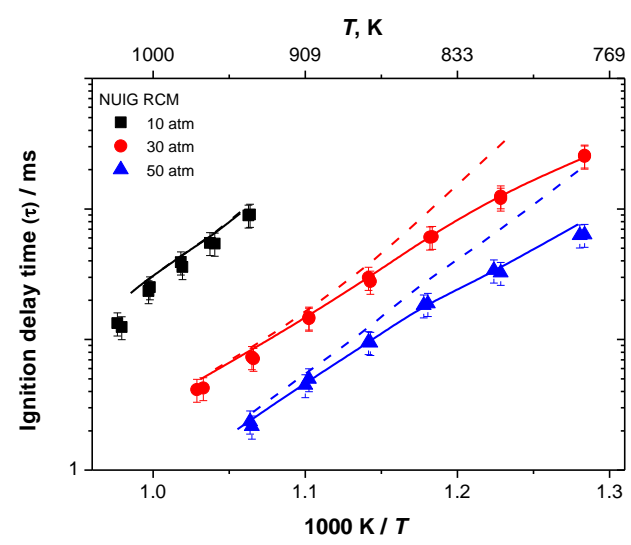

(a) $\varphi=0.3$, fuel in air

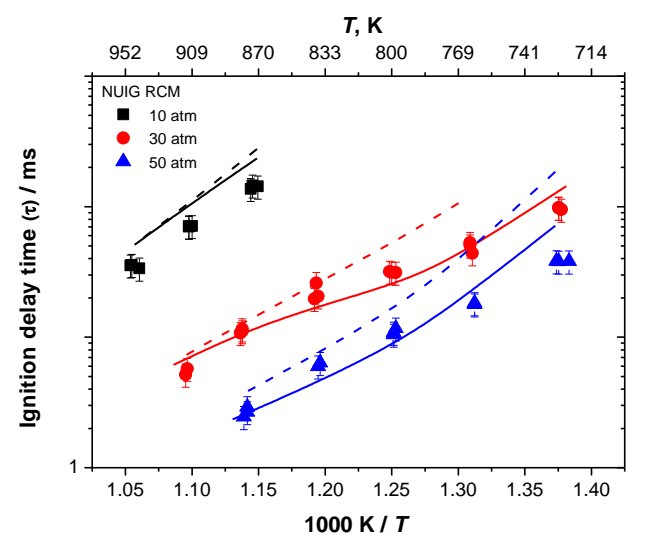

(c) $\varphi=1.0$, fuel in air

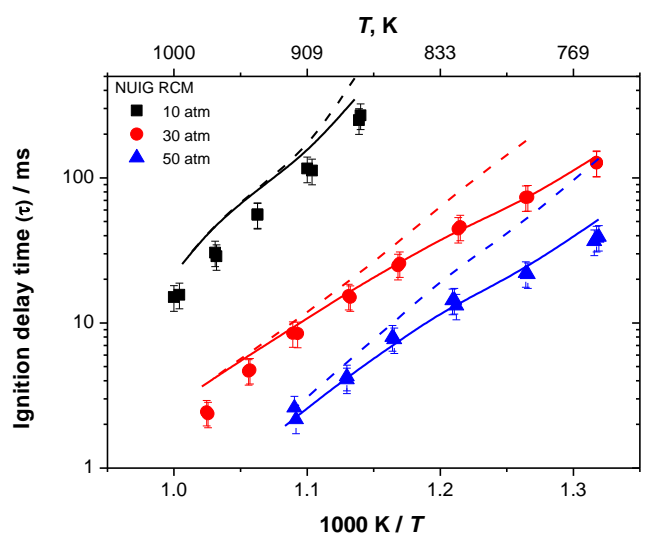

(b) $\varphi=0.5$, fuel in air

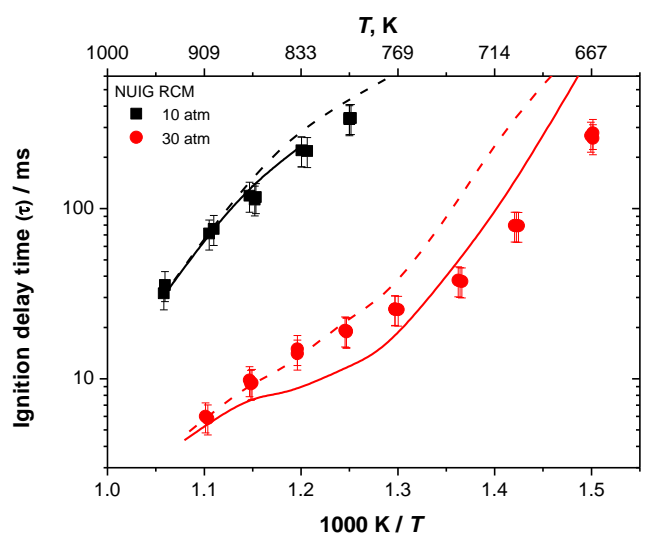

(d) $\varphi=2.0$, fuel in air

Figure 17. Model predictions by including (solid line) and excluding (dashed line) the second addition to molecular oxygen reaction class on ignition delay times prediction.

\subsection{2 $i \mathrm{C}_{4} \mathrm{H}_{8}+\dot{H} \leftrightarrow$ Products}

Flux analyses have identified the reaction between isobutene and hydrogen atom is important (cf., Figure 26). At low and intermediate temperatures $(<950 \mathrm{~K})$, hydrogen atom addition to isobutene inhibits reactivity as the $\mathrm{tC}_{4} \mathrm{H}_{9}$ radicals formed mostly decompose to $\mathrm{iC}_{4} \mathrm{H}_{8}$ and a $\dot{\mathrm{H}}$ atom. Sensitivity analyses (Figure 8) shows that the formation of propene and a $\dot{\mathrm{C}} \mathrm{H}_{3}$ radical inhibits reactivity at higher temperatures as it forms an unreactive $\dot{\mathrm{C}} \mathrm{H}_{3}$ radical from a very reactive hydrogen atom, and this reaction also competes with the main chain branching reaction promoting reactivity, $\dot{\mathrm{H}}+\mathrm{O}_{2} \leftrightarrow \ddot{\mathrm{O}}+$ $\dot{\mathrm{O}} \mathrm{H}$. Accurate characterization of this propene formation channel is also important for predicting $\mathrm{C}_{3} \mathrm{H}_{6}$ profiles in species-resolved experiments.

Previously [2, 3], the estimated high-pressure limit rate constants for these reaction channels from Curran [58] were used in the mechanism. In this study, we used analogous rate constants for $\dot{H}$ atom addition to, and abstraction from, propene calculated by Miller and Klippenstein [59] at a high level of theory to describe the potential energy surface. Conventional transition state theory was used to calculate the abstraction reactions rate constants; RRKM theory was used to calculate micro-canonical, J-resolved rate constants for the dissociation processes, and master-equation methods to determine phenomenological rate constants for all of the non-abstraction reactions. In our mechanism, the rate 
constant for the reaction channel forming $\mathrm{C}_{3} \mathrm{H}_{6}$ and $\dot{\mathrm{C}} \mathrm{H}_{3}$ radicals needs to be divided by a factor of three to predict well propene formation in the flow reactor data taken by Held et al [49].

\subsection{3 $i \mathrm{C}_{4} \mathrm{H}_{8}+\dot{\mathrm{C}} \mathrm{H}_{3} \leftrightarrow$ Products}

Similar to $\mathrm{H}$-atom abstraction by $\dot{\mathrm{OH}}$ radicals described above, methyl radicals can abstract two different types of $\mathrm{H}$-atom from isobutene to form 2-methylallyl radicals plus methane and/or isobuten1yl radicals plus methane, respectively. However, only the channel producing 2-methylallyl radicals and methane was found to occur. This reaction is predicted to be an important source of methane detected in the JSR. We have adopted the rate constants estimated by Yasunaga et al. [9] in our mechanism.

\subsection{4 $\mathrm{iC}_{4} \mathrm{H}_{8}+\mathrm{HO}_{2} \leftrightarrow$ Products}

Both the $\mathrm{H}$-abstraction reaction channels by $\mathrm{HO}_{2}$ radical and the $\mathrm{HO}_{2}$ radical addition reaction channels have been taken into consideration.

\section{H-abstraction reaction by $\mathrm{H}_{2}$}

- $\mathrm{iC}_{4} \mathrm{H}_{8}+\mathrm{HO}_{2} \leftrightarrow \mathrm{iC}_{4} \mathrm{H}_{7}+\mathrm{H}_{2} \mathrm{O}_{2}$

- $\mathrm{iC}_{4} \mathrm{H}_{8}+\mathrm{HO}_{2} \leftrightarrow \mathrm{iC}_{4} \mathrm{H}_{7}-\mathrm{i} 1+\mathrm{H}_{2} \mathrm{O}_{2}$

The rate constant for the $\mathrm{H}$-abstraction reactions of isobutene by hydroperoxyl radical forming 2methylallyl radical $\left(\mathrm{i}_{4} \mathrm{H}_{7}\right)$ is adopted from the theoretical study of Zádor et al. [60]. The rate constant for the other $\mathrm{H}$-abstraction channel forming the vinylic isobuten1-yl $\left(\mathrm{iC}_{4} \mathrm{H}_{7}-\mathrm{i} 1\right)$ radical was calculated in this work.

$\mathrm{HO}_{2}$ addition to $\mathrm{iC}_{4} \mathrm{H}_{8}$

- $\mathrm{iC}_{4} \mathrm{H}_{8}+\mathrm{HO}_{2} \leftrightarrow \mathrm{iC}_{4} \mathrm{H}_{9} \dot{\mathrm{O}}_{2}{ }^{a}$

- $\mathrm{iC}_{4} \mathrm{H}_{8}+\mathrm{HO}_{2} \leftrightarrow \dot{\mathrm{C}}_{4} \mathrm{H}_{8} \mathrm{O}_{2} \mathrm{H}-\mathrm{t}^{b}$

- $\mathrm{iC}_{4} \mathrm{H}_{8}+\mathrm{HO}_{2} \leftrightarrow \mathrm{tC}_{4} \mathrm{H}_{9} \dot{\mathrm{O}}_{2}^{c}$

- $\mathrm{iC}_{4} \mathrm{H}_{8}+\mathrm{HO}_{2} \leftrightarrow \mathrm{tC}_{4} \mathrm{H}_{8} \mathrm{O}_{2} \mathrm{H}-i^{c}$

- $\mathrm{iC}_{4} \mathrm{H}_{8}+\mathrm{HO}_{2} \leftrightarrow \mathrm{iC}_{4} \mathrm{H}_{8} \mathrm{O}+\dot{\mathrm{O}} \mathrm{H}^{c}$

- $\mathrm{tC}_{4} \mathrm{H}_{8} \mathrm{O}_{2} \mathrm{H}-\mathrm{I} \leftrightarrow \mathrm{iC}_{4} \mathrm{H}_{8} \mathrm{O}+\dot{\mathrm{O}}^{c}$

${ }^{a}$ rate constants from Villano et al. [61] ${ }^{b}$ rate constants from Villano et al. [62] ${ }^{c}$ rate constants from Zador [60]

The rate constants for the addition reactions of hydroperoxyl radicals to isobutene have been investigated by different groups [60-62]. Zador et al. calculated the rate constants for $\mathrm{HO}_{2}$ radical addition to the central unsaturated carbon atom in isobutene to form a hydroperoxy-alkyl radical and its following reaction to form a cyclic ether and an hydroxyl radical. The QCISD(T)/cc-pVœZ//B3LYP/6$311++\mathrm{G}(\mathrm{d}, \mathrm{p})$ level of theory was used to obtain the electronic energy barrier heights, based on which the multi-well master equations were solved to calculate the pressure and temperature dependence of the rate constants. Dean and co-workers did a systematic investigation of alkylperoxyl radical decompositions to alkenes and hydroperoxyl radicals [61], and $\mathrm{HO}_{2}+$ olefin addition channels [62] using electronic structure calculations performed at the CBS-QB3 level of theory. The rate constants for the dissociation reactions were obtained from calculated equilibrium constants and a literature review of experimental rate constants for the reverse association reactions. In this work, we use rate constants from Villano et al. [61, 62] for the first two reaction channels and for the last four reaction channels rate constants from Zador et al. [60] have been adopted. 


\subsection{5 $\quad \mathrm{iC}_{4} \mathrm{H}_{8}+\mathrm{O}_{2} \leftrightarrow$ Products}

$\mathrm{H}$-atom abstraction by molecular oxygen from isobutene forming $\mathrm{i}_{4} \mathrm{H}_{7}+\mathrm{HO}_{2}$ radicals was found to be sensitive over the entire temperature range, inhibiting reactivity at temperatures below $900 \mathrm{~K}$ and promoting reactivity at temperatures above $900 \mathrm{~K}$.

Several research groups have investigated the reaction between $\mathrm{iC}_{4} \mathrm{H}_{8}$ and molecular oxygen. Ingham et al. [63] have studied the rate constants in the temperature range 673-793 K. Chen and Bozzelli [64] used canonical transition state theory to calculate the rate constants in the temperature range $300-2000 \mathrm{~K}$. Interestingly, there is a large uncertainty between these two results with a factor of two to five difference in the overlapping temperature range $(650-800 \mathrm{~K})$ studied. Goldsmith et al. theoretically investigated the reaction of propene with molecular oxygen as part of their study of the reactions between allyl and hydroperoxyl radicals [65]. In order to directly compare these rate constants, they were written in the opposite direction using the CHEMRev software [66]. Yasunaga et al. [9] estimated this rate constant to give a very good explanation of the product distributions obtained from IR absorption and emission profiles etc. In this work, the rate constant provided by Yasunaga et al. was adopted and was increased by $40 \%$ over the temperature range. Comparisons of the rate constants are shown in Figure 18 and their influence on ignition delay times are shown in Figure 19.

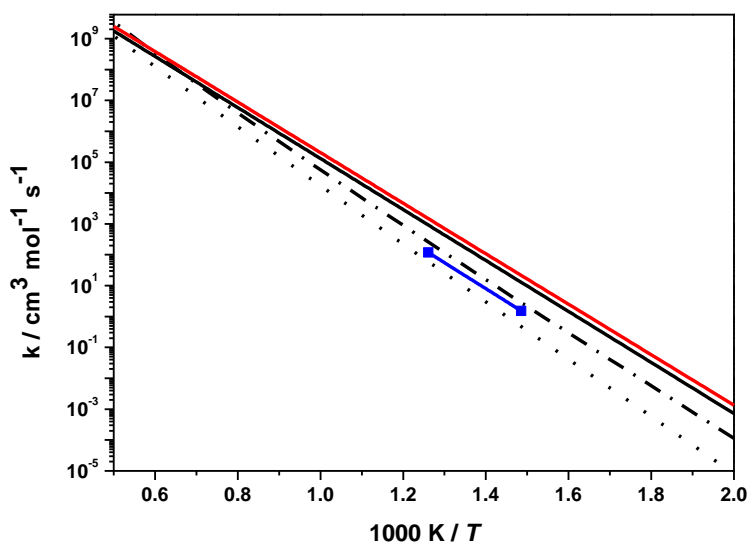

Figure 18. Rate constants comparison of $\mathrm{iC}_{4} \mathrm{H}_{8}+\mathrm{O}_{2}$. — This study, — Yasunaga et al. [9], Ingham et al. [63], ${ }^{\cdots \cdot}$ Chen and Bozzelli [64], ${ }^{-}{ }^{-}$Goldsmith et al. for propene [65].

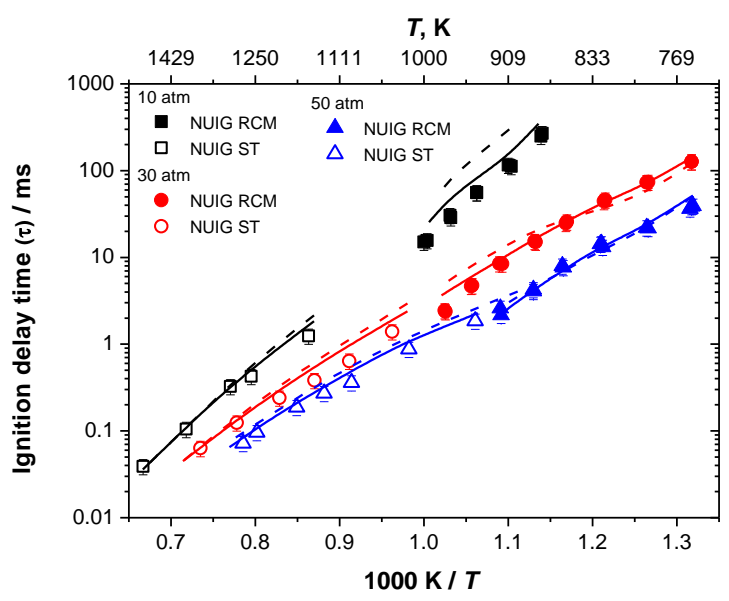

Figure 19. Influence of rate constants for $\mathrm{iC}_{4} \mathrm{H}_{8}+\mathrm{O}_{2} \leftrightarrow \mathrm{iC}_{4} \mathrm{H}_{7}+\mathrm{HO}_{2}$ to ignition delay times at $\varphi=0.3$, fuel in air, $p=10,30$ and $50 \mathrm{~atm}$. Solid line: this study, dashed line: analogy to propene [3]. 


\subsection{6 $i C_{4} H_{8}+\ddot{O} \leftrightarrow$ Products}

Hydrogen atom abstraction by atomic oxygen did not show significant sensitivity in this work. Rate constants for these reactions are adopted from the ones used by analogy for propene [67]. Oxygen atom can also add to isobutene to produce the following products:

- $\mathrm{iC}_{4} \mathrm{H}_{8}+\ddot{\mathrm{O}} \leftrightarrow \mathrm{i}_{3} \mathrm{H}_{7}+\mathrm{HC} \mathrm{O}$

- $\mathrm{iC}_{4} \mathrm{H}_{8}+\ddot{\mathrm{O}} \leftrightarrow \dot{\mathrm{C}} \mathrm{H}_{2} \mathrm{CO}+\dot{\mathrm{C}} \mathrm{H}_{3}+\dot{\mathrm{C}} \mathrm{H}_{3}$

- $\mathrm{iC}_{4} \mathrm{H}_{8}+\ddot{\mathrm{O}} \leftrightarrow \mathrm{iC}_{3} \mathrm{H}_{6} \mathrm{CO}+\dot{\mathrm{H}}+\dot{\mathrm{H}}$

As shown above, oxygen atom addition reactions form two or more radicals through the three reaction pathways; thus these are chain branching reactions. This reaction class has not been studied previously either experimentally or theoretically. Further experimental or theoretical investigation of this reaction class under combustion conditions will be helpful in improving the accuracy of the model.

$$
\begin{aligned}
& 4.4 i \dot{\mathrm{C}}_{4} \mathrm{H}_{7} \leftrightarrow \text { Products } \\
& \quad \text { - } \quad \mathrm{iC}_{4} \mathrm{H}_{7} \leftrightarrow \mathrm{C}_{3} \mathrm{H}_{4}-\mathrm{a}+\dot{\mathrm{C}}_{3}
\end{aligned}
$$

The decomposition of $\mathrm{iC}_{4} \mathrm{H}_{7}$ radicals will be competitive with its recombination reactions with other radicals such as $\dot{\mathrm{C}} \mathrm{H}_{3}, \mathrm{HO}_{2}, \dot{\mathrm{iC}}_{4} \mathrm{H}_{7}$, etc. in the intermediate temperature range. The rate constant for this reaction has been calculated in this work as discussed in Section 3.

$$
\begin{aligned}
& 4.5 i \dot{\mathrm{C}}_{4} H_{7}+R \leftrightarrow \text { Products } \\
& \text { 4.5.1 } i \dot{\mathrm{C}}_{4} H_{7}+\dot{\mathrm{C}} H_{3} \leftrightarrow a C_{5} H_{10}
\end{aligned}
$$

The recombination reaction of 2-methylallyl and methyl radicals to form 2-methyl-1-butene is an important reaction pathway which inhibits reactivity at intermediate and higher temperatures, Figure 7 , Figure 8 and Figure 27. The current mechanism predicts that this reaction produces nearly all of the 2methyl-1-butene detected in the JSR experiments. Our recommended rate constant is taken from Tsang [67] by analogy with allyl and methyl radical recombination.

\subsection{2 $\quad i_{\dot{C}_{4}} H_{7}+H_{O_{2}} \leftrightarrow$ products}

The reactions of 2-methylallyl and hydroperoxyl radicals are observed to be very important across a range of conditions, especially at low- to intermediate-temperatures, Figure 7 and Figure 26. A rate of production analysis shows that at approximately $730 \mathrm{~K}, 30 \mathrm{~atm}$, and $\varphi=1.0$, the reaction of 2 methylallyl radical with hydroperoxyl radical consumes approximately $47.1 \%$ of all 2 -methylallyl radicals, Figure 26. Pressure dependent rate constants for the bi-molecular reactions of allyl radical with hydroperoxyl radical have been extensively studied by Goldsmith et al. [57]; analogous rate constants have been used to describe the reaction between 2-methylallyl radical and hydroperoxyl radical with the following important reaction channels:

- $\mathrm{iC}_{4} \mathrm{H}_{7}+\mathrm{HO}_{2} \leftrightarrow \mathrm{iC}_{4} \mathrm{H}_{7} \mathrm{OOH}$

- $\mathrm{i}_{4} \mathrm{H}_{7}+\mathrm{HO}_{2} \leftrightarrow \mathrm{iC}_{4} \mathrm{H}_{7} \dot{\mathrm{O}}+\dot{\mathrm{O}} \mathrm{H}$

- $\mathrm{iC}_{4} \mathrm{H}_{7} \mathrm{OOH} \leftrightarrow \mathrm{iC}_{4} \mathrm{H}_{7} \mathrm{O}+\dot{\mathrm{O}} \mathrm{H}$

$\mathrm{iC}_{4} \mathrm{H}_{7} \mathrm{O} \leftrightarrow$ Products

- $\mathrm{iC}_{4} \mathrm{H}_{7} \mathrm{O} \leftrightarrow \dot{\mathrm{C}}_{3} \mathrm{H}_{5}-\mathrm{t}+\mathrm{CH}_{2} \mathrm{O}$

- $\mathrm{iC}_{4} \mathrm{H}_{7} \mathrm{O} \leftrightarrow \mathrm{iC}_{3} \mathrm{H}_{5} \mathrm{CHO}+\dot{\mathrm{H}}$

- $\mathrm{iC}_{4} \mathrm{H}_{7} \dot{\mathrm{O}} \leftrightarrow \mathrm{iC}_{3} \mathrm{H}_{5} \mathrm{OC}_{2}$

- $\mathrm{iC}_{4} \mathrm{H}_{7} \mathrm{O} \leftrightarrow \mathrm{iC}_{3} \mathrm{H}_{6} \mathrm{CHO}$ 
- $\mathrm{iC}_{3} \mathrm{H}_{5} \mathrm{CHO} \leftrightarrow \mathrm{iC}_{3} \mathrm{H}_{5} \dot{\mathrm{CO}}+\dot{\mathrm{H}}$

- $\mathrm{iC}_{3} \mathrm{H}_{5} \dot{\mathrm{CO}} \leftrightarrow \dot{\mathrm{C}}_{3} \mathrm{H}_{5}-\mathrm{t}+\mathrm{CO}$

Methyl-allyloxyl radicals can undergo both decomposition and isomerization reactions to produce different type of products. 2-propenyl radical and formaldehyde, methacrolein and atomic hydrogen, and propene and formyl radicals can be formed through its decomposition reaction. Rate constants for these reactions were taken from the study of Goldsmith et al. [65] for propene by analogy. H-atom abstraction from methacrolein $\left(\mathrm{iC}_{3} \mathrm{H}_{5} \mathrm{CHO}\right)$ to form $\mathrm{iC}_{3} \mathrm{H}_{5} \dot{\mathrm{CO}}$ radical and $\mathrm{H}_{2} \mathrm{O}$ promotes reactivity at intermediate temperatures (Figure 7, Figure 8, and Figure 25). The rate constant for this reaction channel is taken from the ab initio calculations of Mendes et al. [68]. H-atom abstractions from metharolein by $\mathrm{HO}_{2}$ and $\dot{\mathrm{C}} \mathrm{H}_{3}$ radicals and $\dot{\mathrm{H}}$ atoms have also been included from calculations by Mendes et al. [68].

$$
\begin{aligned}
& \text { 4.5.3 } i \dot{C}_{4} H_{7} / i \dot{C}_{4} H_{7}-i 1+O_{2} \leftrightarrow \text { Products } \\
& \text { - } \mathrm{i}_{4} \mathrm{H}_{7}-\mathrm{i} 1+\mathrm{O}_{2} \leftrightarrow \mathrm{CH}_{3} \mathrm{COCH}_{3}+\mathrm{HCO} \\
& \text { - } \mathrm{iC}_{4} \mathrm{H}_{7}-\mathrm{i} 1+\mathrm{O}_{2} \leftrightarrow \mathrm{tC}_{3} \mathrm{H}_{6} \mathrm{CHO}+\ddot{\mathrm{O}} \\
& \text { - } \mathrm{iC}_{4} \mathrm{H}_{7}-\mathrm{i} 1+\mathrm{O}_{2} \leftrightarrow \mathrm{iC}_{3} \mathrm{H}_{5} \mathrm{CHO}+\dot{\mathrm{O}} \mathrm{H}
\end{aligned}
$$

Chen and Bozzelli [64] have theoretically studied the reaction mechanism of 2-methylallyl radical. Unlike saturated alkanes in which the fuel molecule radical $\dot{\mathrm{R}}$ reacts with $\mathrm{O}_{2}$ to form an $\mathrm{RO}_{2}$ radical with a heat release of $\sim 35 \mathrm{kcal} \mathrm{mol}^{-1}$, for the unsaturated alkenes the analogous reaction process only produces $\sim 20 \mathrm{kcal} \mathrm{mol}^{-1}$ of heat, or specifically $21.5 \mathrm{kcal} \mathrm{mol}^{-1}$ for $\mathrm{iC}_{4} \mathrm{H}_{7}+\mathrm{O}_{2} \leftrightarrow \mathrm{iC}_{4} \mathrm{H}_{7} \dot{\mathrm{O}}_{2}$ in this work. The well of the $\mathrm{iC}_{4} \mathrm{H}_{7} \dot{\mathrm{O}}_{2}$ radical formed is shallow and thus back dissociation to $\mathrm{i}_{4} \mathrm{H}_{7}+\mathrm{O}_{2}$ is favored over the higher barrier isomerization reaction processes. Thus, the reactions of $\mathrm{iC}_{4} \mathrm{H}_{7}$ radicals with molecular oxygen are not found to be particularly sensitive in this study. Rate constants for reactions and thermodynamics data for species involved in the $\mathrm{iC}_{4} \mathrm{H}_{7}+\mathrm{O}_{2}$ reactions have been adopted from the study by Chen and Bozzelli [64]. To the best of our knowledge, there are no previous studies of the reaction of isobuten1-yl radical with molecular oxygen; rate constants for this reaction have been adopted by analogy with propene [3].

\subsection{2,5-dimethyl, 1-5-hexadiene \\ - $\mathrm{iC}_{4} \mathrm{H}_{7}+\mathrm{iC}_{4} \mathrm{H}_{7} \leftrightarrow \mathrm{H} 15 \mathrm{De} 25 \mathrm{DM}$ \\ - $\mathrm{iC}_{4} \mathrm{H}_{7}+\mathrm{iC}_{4} \mathrm{H}_{7} \leftrightarrow \mathrm{C}_{3} \mathrm{H}_{4}-\mathrm{a}+\mathrm{aC}_{5} \mathrm{H}_{10}$}

2-methylallyl radicals react via chain terminating self-recombination reaction to form 2,5dimethyl,1-5-hexadiene, significantly inhibiting reactivity at low- and intermediate-temperatures. The reaction between two 2-methylallyl radicals can also form allene and 2-methyl-1-butene. However, this reaction channel can be neglected as the rate constant is about two orders of magnitude lower than the 2-methylallyl radical self-recombination rate constants and does not contribute to fuel reactivity. Rate constants for this reaction are taken from Tranter and co-workers [69] for the allyl radical selfrecombination and have been divided by a factor of 2.3 to match the low temperature ignition delay time measurements, Figure 20. If the $\mathrm{i}_{4} \mathrm{H}_{7}$ radical self-recombination reaction were removed from the system, the reactivity would increase significantly in the lower temperature range as shown in Figure 21. 


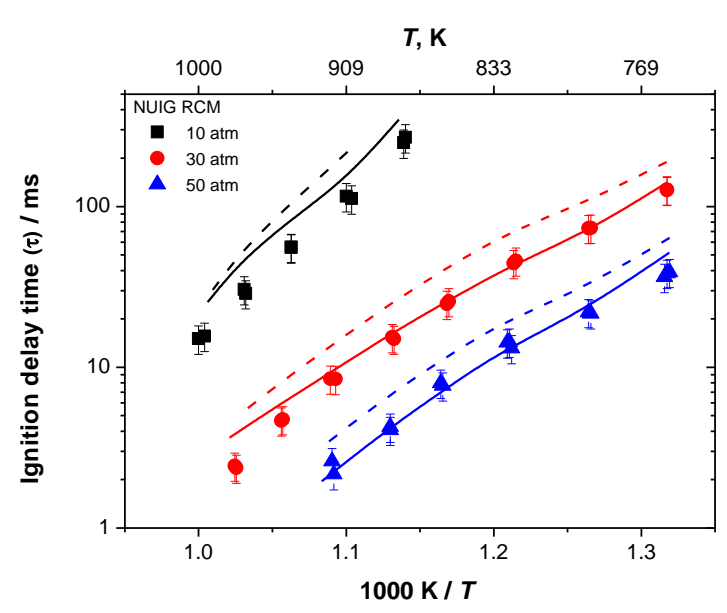

Figure 20. Influence of rate constants for $\mathrm{iC}_{4} \mathrm{H}_{7}+\mathrm{i}_{4} \mathrm{H}_{7}$ on ignition delay times at $\varphi=0.5$ in air, $p=10$, 30 and $50 \mathrm{~atm}$. Solid line: this study, dashed line: same as for allyl-allyl from Fridlyand et al. [69].

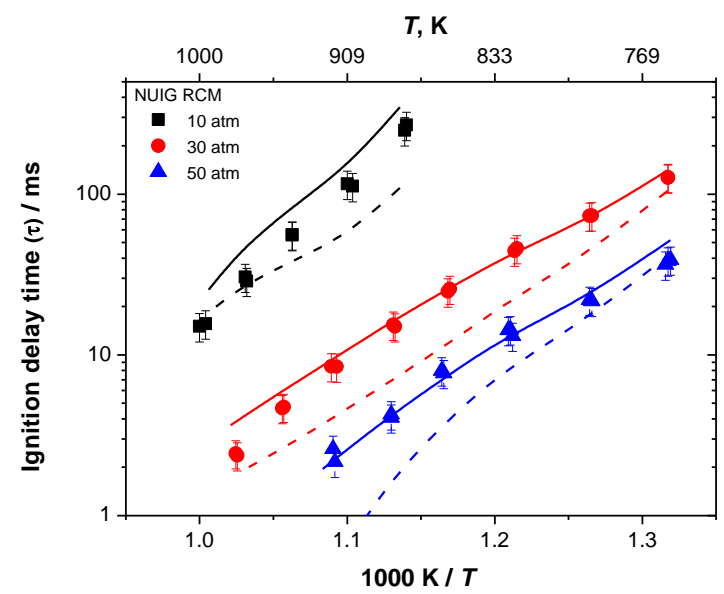

Figure 21. Influence of rate constants for $\mathrm{i}_{4} \mathrm{H}_{7}+\mathrm{i}_{4} \mathrm{H}_{7}$ to ignition delay times at $\varphi=0.5$ in 'air', $p=$ 10, 30 and $50 \mathrm{~atm}$. Solid line: this study; dashed line: excluding recombination channel.

\subsection{2,5-dimethyl,1-5-hexadiene sub-mechanism}<smiles>C=C(C)CCC(=C)C</smiles>

H15De25DM<smiles>[CH2]C(=C)CCC(=C)C</smiles>

H15De25DM-a<smiles>C=C(C)C=CC(=C)C</smiles>

H15De25DM-s

Figure 22. Molecular structures of 2,5-dimethyl,1-5-hexadiene and the important radicals formed.

As shown in Figure 22, there are two different types of hydrogen atom that can be abstracted in the symmetric structure of 2,5-dimethyl,1-5-hexidene to form the allyl-type radical (H15De25DM-a) and secondary allylic-type radical (H15De25DM-s). H-atom abstraction from 2,5-dimethyl,1-5-hexidene by $\dot{\mathrm{O}} \mathrm{H}, \mathrm{HO}_{2}$ and $\dot{\mathrm{C}} \mathrm{H}_{3}$ radicals, $\mathrm{O}$ and $\dot{\mathrm{H}}$ atoms, and $\mathrm{O}_{2}$ have been taken into consideration in the mechanism. The radicals formed can react with $\mathrm{HO}_{2}$ radicals at this low- and intermediate-temperature 
range; they can also decompose directly via $\beta$-scission. Estimated rate constants are used for their reaction with $\mathrm{HO}_{2}$ radical based on analogy with normal alkanes. For the latter two $\beta$-scission reactions in the following equation array rate constants were estimated by analogy with propene $+\mathrm{CH}_{2} \mathrm{O}$ and acetaldehyde + allyl as recommended by Curran [58].

- $\mathrm{H} 15 \mathrm{De} 25 \mathrm{DM}-\mathrm{a}+\mathrm{HO}_{2} \leftrightarrow \mathrm{H} 15 \mathrm{De} 25 \mathrm{DM}-\mathrm{aO}+\dot{\mathrm{OH}}$

- $\mathrm{H} 15 \mathrm{De} 25 \mathrm{DM}-\mathrm{s}+\mathrm{HO}_{2} \leftrightarrow \mathrm{H} 15 \mathrm{De} 25 \mathrm{DM}-\mathrm{sO}+\dot{\mathrm{O} H}$

- $\mathrm{H} 15 \mathrm{De} 2 \mathrm{M}-\mathrm{t}+\mathrm{CH}_{2} \mathrm{O} \leftrightarrow \mathrm{H} 15 \mathrm{De} 25 \mathrm{DM}-\mathrm{aO}$

- $\mathrm{iC}_{3} \mathrm{H}_{5} \mathrm{CHO}+\mathrm{iC}_{4} \mathrm{H}_{7} \leftrightarrow \mathrm{H} 15 \mathrm{De} 25 \mathrm{DM}-\mathrm{sO}$

\section{Model validation}

The current chemical kinetic mechanism is validated against the ignition delay time and flame speed measurements carried out in this work, as well as literature speciation results from a jet-stirred reactor and a flow reactor.

\subsection{Ignition delay time validation}

Ignition delay times measured in this work (four shock tubes and two rapid compression machines) are presented here, together with the predictions of the current mechanism. The current mechanism captures the experimental results quite well.

A comprehensive comparison between different experimental facilities for both shock tubes and RCMs has been carried out in our previous work in developing the propene mechanism [2] and found that the experimental results of ignition delay time is within $20 \%$ between different facilities.

RCMs used in this work are designed differently, and hence each will have different heat loss. In our previous work on propene ignition delay time measurement [2], we found that the NUIG RCM exhibits more heat loss than the UConn facility. This difference in heat loss characteristics could lead to different ignition delay times obtained from the two RCM facilities. When simulating the ignition delay times from RCM measurements, we adopted the volume history for every experiment as input to account for the specific heat loss for each facility which allows each RCM to be simulated appropriately.

Figure 23 (a)-(d) shows the effect of pressure on ignition delay times measured in shock tubes and RCMs for fuel/'air' mixtures at $\varphi=0.3,0.5,1.0$, and 2.0. The experimental results show that high pressure is correlated with shortened ignition delay time at all equivalence ratios. When the pressure increasing, the reactant concentrations increases, enhancing overall reactivity. The current mechanism predicts the influence of pressure on ignition delay times over a wide range of temperature and equivalence ratios accurately. Sensitivity analyses (Figure 7, Figure 8, and Figure 25) together with flux analyses (Figure 26 and Figure 27) were carried out at different temperatures and pressures to determine the reactivity controlling reactions at those conditions. 


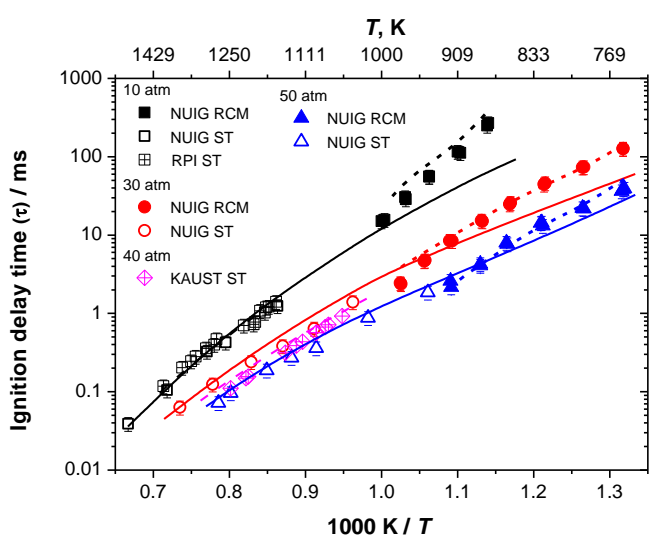

(a) $\varphi=0.3$, fuel/'aair', $p=10,30$ and $50 \mathrm{~atm}$.

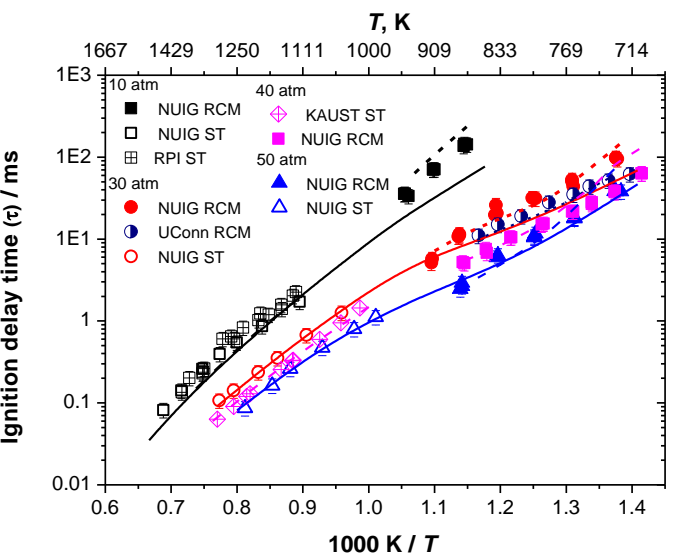

(c) $\varphi=1.0$, fuel/'air', $p=10,30$ and 50 atm. (b) $\varphi=0.5$, fuel/'air', $p=10,30$ and 50 atm.

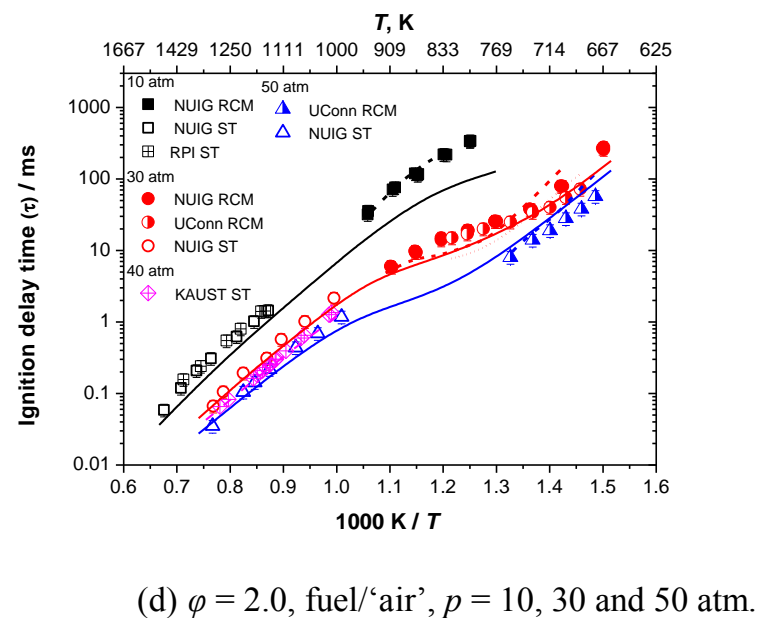

Figure 23. Influence of pressure on isobutene IDTs from shock tube and RCMs for fuel/'air' mixtures. Symbols: experimental data; solid lines: constant volume simulation, dashed lines: facilities effect

Figure 24 (a)-(f) shows a comparison between the ignition delay time measurements from TAMU and RPI against predictions from the current mechanism. The $\mathrm{OH}^{\star}$ concentration/time history from the model was used to compare with the $\mathrm{OH}^{\star}$ measurements from TAMU. The model captures most of these fuel-lean conditions except at $p=1.7$ atm in Figure 24 (e) and at conditions in Figure 24 (f), where the model predicts ignition times that are a little faster than the experimental results which is also true for isobutene/air mixtures at $\varphi=2.0$, Figure 23 (d). 


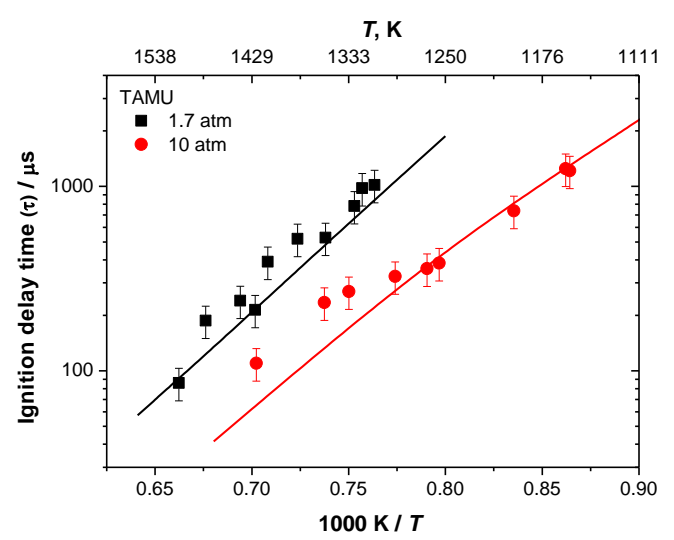

(a) $\varphi=0.5$, fuel $/ \mathrm{O}_{2} / \mathrm{Ar}, 1.72 \% \mathrm{iC}_{4} \mathrm{H}_{8}$.

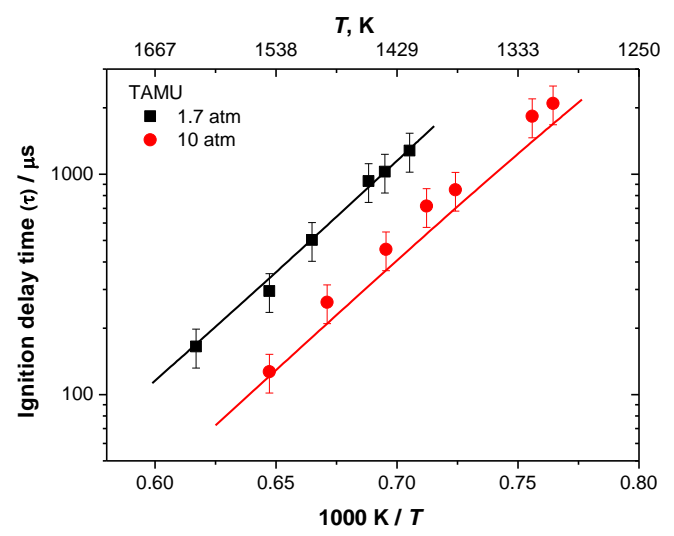

(c) $\varphi=1.0$, fuel $/ \mathrm{O}_{2} / \mathrm{Ar}, 0.667 \% \mathrm{iC}_{4} \mathrm{H}_{8}$.

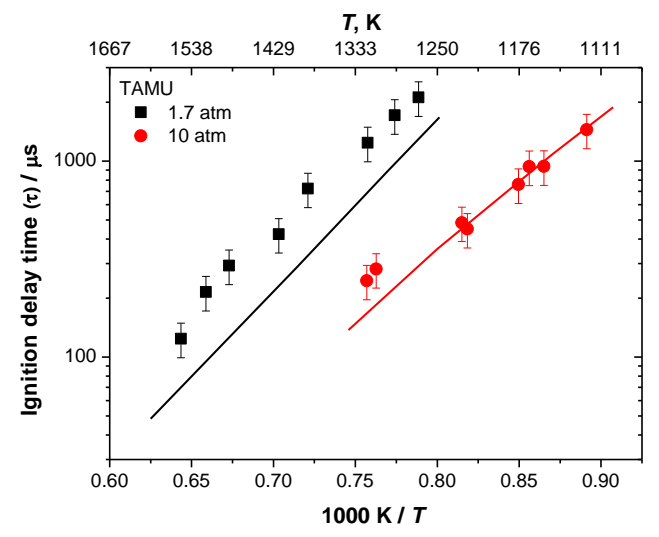

(e) $\varphi=1.0$, fuel $/ \mathrm{O}_{2} / \mathrm{Ar}, 3.38 \% \mathrm{iC}_{4} \mathrm{H}_{8}$.

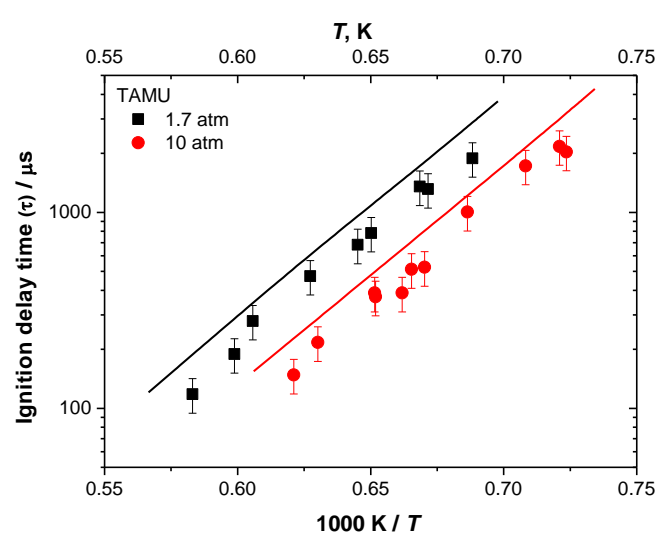

(b) $\varphi=1.0$, fuel/ $\mathrm{O}_{2} / \mathrm{Ar}, 0.143 \% \mathrm{iC}_{4} \mathrm{H}_{8}$.

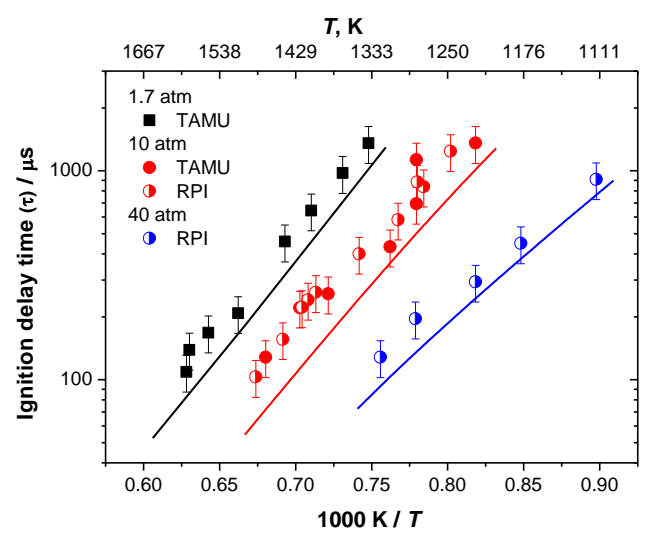

(d) $\varphi=1.0$, fuel $/ \mathrm{O}_{2} / \mathrm{Ar}, 2 \% \mathrm{iC}_{4} \mathrm{H}_{8}$.

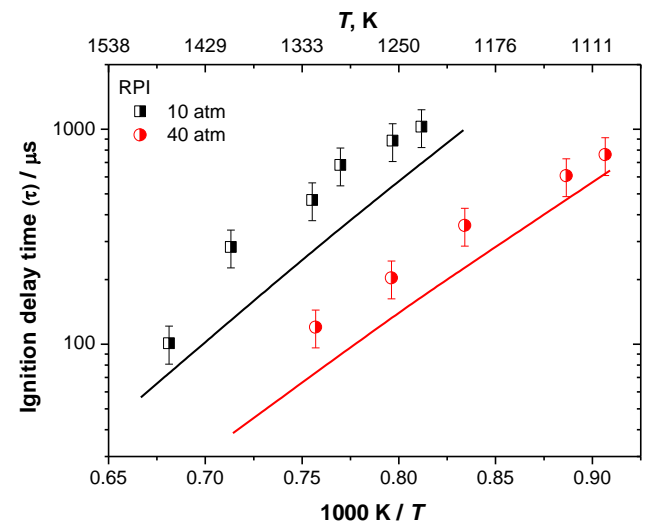

(f) $\varphi=2.0$, fuel $/ \mathrm{O}_{2} / \mathrm{Ar}, 4 \% \mathrm{iC}_{4} \mathrm{H}_{8}$.

Figure 24. Influence of pressure on isobutene IDTs from TAMU and RPI shock tube measurements for fuel $/ \mathrm{O}_{2} / \mathrm{Ar}$ mixtures. Symbols: experimental data; solid lines: constant volume simulation.

\subsection{Sensitivity and flux analyses}

In order to provide an overview of the isobutene combustion pathways that control reactivity, we performed a series of sensitivity analyses at $T=730 \mathrm{~K}, 850 \mathrm{~K}, 950 \mathrm{~K}$ and $1250 \mathrm{~K}$ at $\varphi=1.0$ and $p=30$ atm, Figure 25. Flux analyses at exactly the same conditions have also been carried out, Figure 26 and Figure 27. It is obvious that the $\mathrm{iC}_{4} \mathrm{H}_{8}+\dot{\mathrm{O}} \mathrm{H} \leftrightarrow \mathrm{iC}_{4} \mathrm{H}_{7}+\mathrm{H}_{2} \mathrm{O}$ reaction inhibits reactivity at all temperatures studied here and its flux increases as the temperature increases. 

though this channel accounts for only $4.4 \%$ of the total flux, the subsequent radical addition to molecular oxygen reactions generate the radical pool and ultimately promotes reactivity. Even though the $\mathrm{i}_{4} \mathrm{H}_{7}+\dot{\mathrm{i}}_{4} \mathrm{H}_{7} \leftrightarrow \mathrm{H} 15 \mathrm{DE} 25 \mathrm{DM}$ reaction inhibits reactivity, it only contributes $6.5 \%$ of the total flux. The addition of $\dot{\mathrm{H}}$-atoms to the terminal carbon atom in $\mathrm{iC}_{4} \mathrm{H}_{8}$ forming $\mathrm{tC}_{4} \mathrm{H}_{9}$ radicals consumes $18.6 \%$ of the fuel. Thereafter, $\mathrm{tC}_{4} \mathrm{H}_{9}$ radicals add to molecular oxygen and largely reforms $\mathrm{iC}_{4} \mathrm{H}_{8}$ and an $\mathrm{HO}_{2}$ radical. It is interesting to find that the reaction of $\mathrm{iC}_{4} \mathrm{H}_{8}+\mathrm{O}_{2} \leftrightarrow \mathrm{iC}_{4} \mathrm{H}_{7}+\mathrm{HO}_{2}$ inhibits reactivity at $730 \mathrm{~K}$, because the reaction proceeds in the reverse direction, consuming $\mathrm{iC}_{4} \mathrm{H}_{7}$ and $\mathrm{HO}_{2}$ radicals to form $\mathrm{iC}_{4} \mathrm{H}_{8}+\mathrm{O}_{2}$, hence preventing chain branching by recombination of methylallyl radicals with $\mathrm{HO}_{2}$ radicals (cf., Figure 26). At temperatures above $900 \mathrm{~K}$, this reaction proceeds in the forward direction, promoting reactivity.

At temperatures above $850 \mathrm{~K}$ fuel consumption by $\mathrm{OH}$ radical addition decreases with the overall flux of $\dot{\mathrm{O}} \mathrm{H}$ radical addition to the terminal carbon dropping to $7.9 \%$. The reaction of $\mathrm{iC}_{4} \mathrm{H}_{7}+\mathrm{iC}_{4} \mathrm{H}_{7} \leftrightarrow$ H15DE25DM becomes important in inhibiting reactivity as it consumes $20.7 \%$ of the $\mathrm{iC}_{4} \mathrm{H}_{7}$ radicals. This reaction becomes more important at $950 \mathrm{~K}$ at which temperature it consumes $39.4 \%$ of the $\mathrm{iC}_{4} \mathrm{H}_{7}$ radicals. In addition, the radical recombination reaction of $\mathrm{iC}_{4} \mathrm{H}_{7}+\dot{\mathrm{C}} \mathrm{H}_{3}(+\mathrm{M}) \leftrightarrow \mathrm{aC}_{5} \mathrm{H}_{10}(+\mathrm{M})$ becomes important in inhibiting reactivity, accounting for $7.9 \%$ of fuel consumption at $950 \mathrm{~K}$.

At $1250 \mathrm{~K}$, the reaction $\mathrm{iC}_{4} \mathrm{H}_{8}+\mathrm{O}_{2} \leftrightarrow \mathrm{iC}_{4} \mathrm{H}_{7}+\mathrm{HO}_{2}$ is the most one promoting reactivity in the system. The reaction $\mathrm{iC}_{4} \mathrm{H}_{7}+\dot{\mathrm{C}} \mathrm{H}_{3}(+\mathrm{M}) \leftrightarrow \mathrm{aC}_{5} \mathrm{H}_{10}(+\mathrm{M})$ which consume $24.6 \%$ of the $\mathrm{iC}_{4} \mathrm{H}_{7}$ radicals, inhibits reactivity. $26.7 \%$ of the $\mathrm{i}_{4} \mathrm{H}_{7}$ radicals formed decompose directly to generate allene and a methyl radical. Interestingly, the self-recombination reaction of $\mathrm{iC}_{4} \mathrm{H}_{7}$ to produce $\mathrm{H} 15 \mathrm{DE} 25 \mathrm{DM}$ becomes less important at $1250 \mathrm{~K}$, with only $5.6 \%$ of $\mathrm{iC}_{4} \mathrm{H}_{7}$ radicals consumed by this pathway compared to $39.4 \%$ at $950 \mathrm{~K}$. The decreasing dominance of this reaction at high temperatures implies that this reaction pathway will have a minimal effect on ignition delays at high temperatures (Figure 21) and also on laminar flame speed simulations. Thus, this justifies the decision not to include H15DE25DM chemistry for laminar flame speed simulations. 


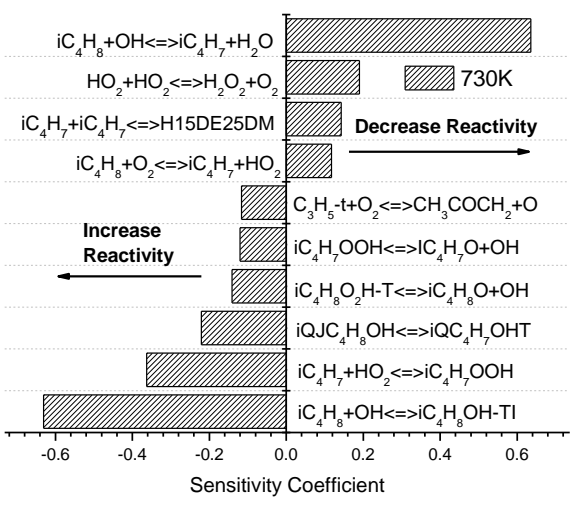

(a)

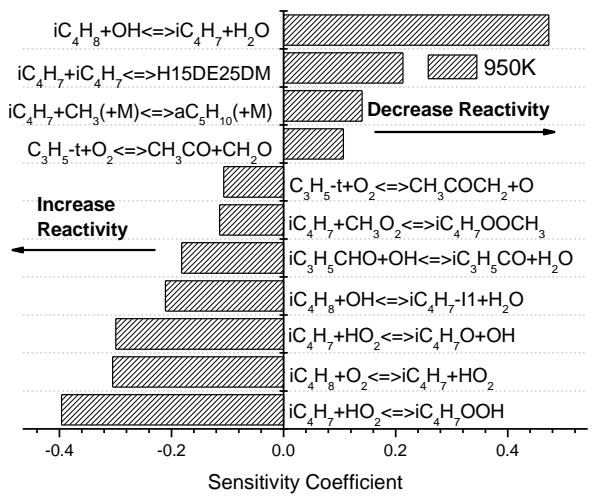

(c)

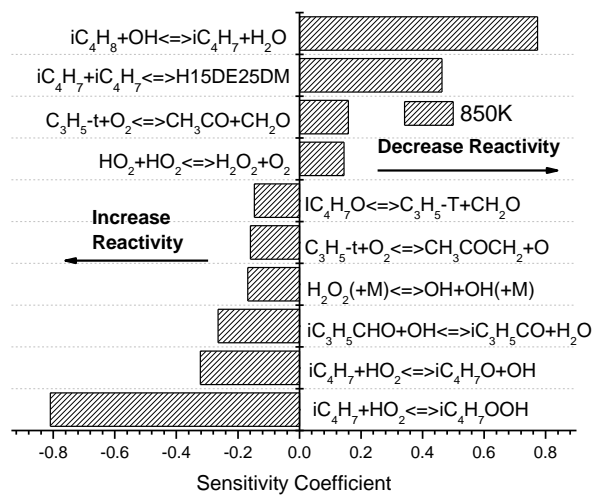

(b)

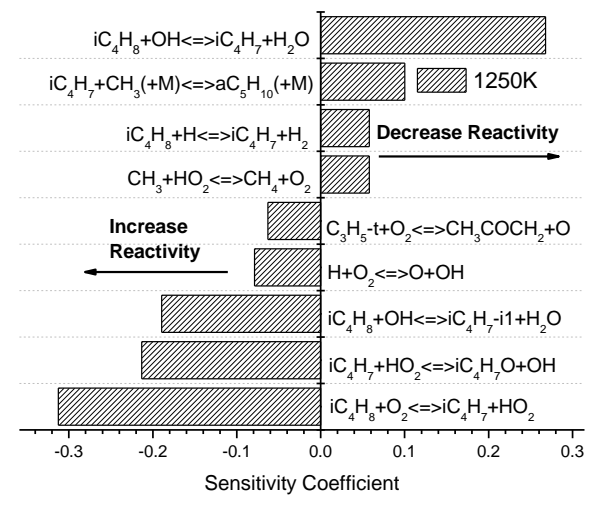

(d)

Figure 25. Sensitivity analyses to ignition delay times performed at $\varphi=1.0$, fuel/air, 30 atm, $T=730 \mathrm{~K}$, $850 \mathrm{~K}, 950 \mathrm{~K}$, and $1250 \mathrm{~K}$. 


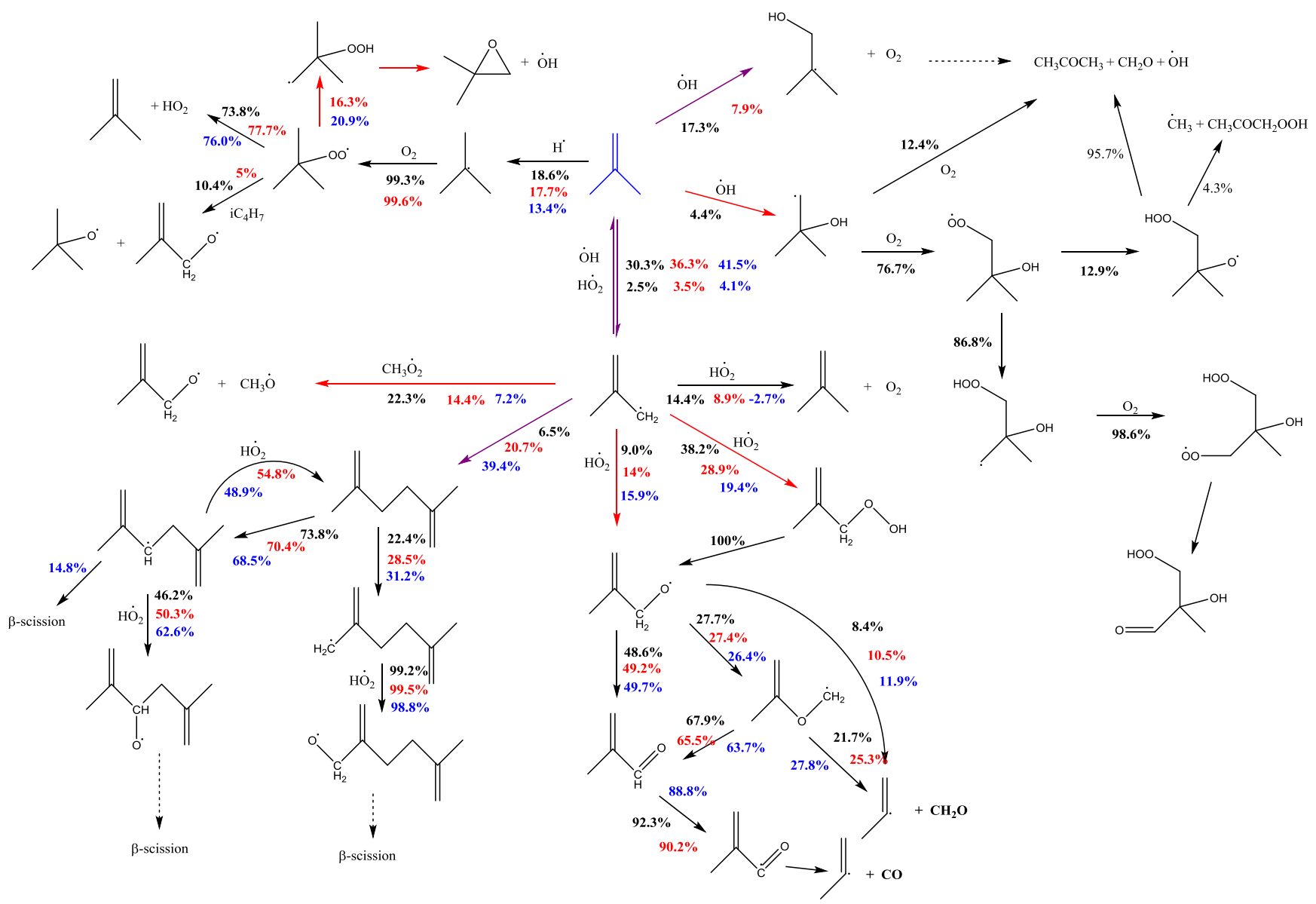

Figure 26. Flux analysis for the oxidation of $\varphi=1.0$, fuel/air mixture at $730 \mathrm{~K}$ (black), $850 \mathrm{~K}$ (red) and $950 \mathrm{~K}$ (blue) at $20 \%$ fuel consumption (red arrows: promote the reactivity; purple ones: inhibit reactivity). 


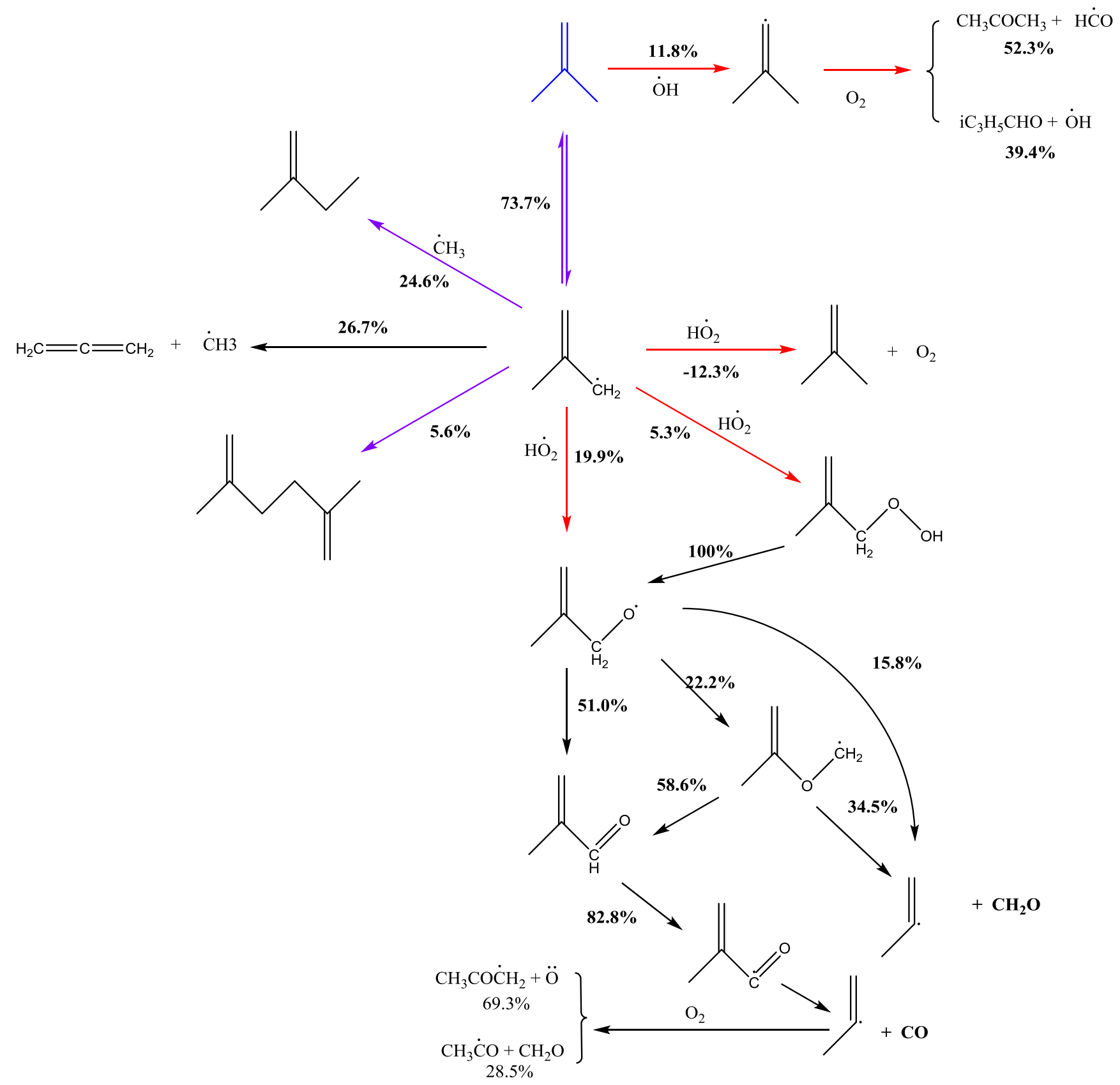

Figure 27. Flux analysis for the oxidation of $\varphi=1.0$, fuel/air mixture at $1250 \mathrm{~K}$ at $20 \%$ fuel consumption. (red arrows: promote the reactivity; purple ones: inhibit reactivity).

\subsection{Flame speed validations}

Figure 28 compares the predicted laminar burning velocities against those measured experimentally for isobutene in air at 1 atm pressure obtained from three different experimental facilities, LRPG, TAMU, and PU. Both the experiments and the simulation show that the temperature increase does not alter the location of the peak flame speed, which expectedly occurs at $\varphi \approx 1.1$. When compared to the experiments performed in the present study, the maximum values are under-predicted by around $5 \mathrm{~cm} / \mathrm{s}$, but the locations of these maxima are well predicted. Flame speed sensitivity analyses has been carried out at $\varphi=0.8$, Figure 28 (b). Many of the important reactions highlighted here are from the $\mathrm{H}_{2} / \mathrm{CO}$ sub-mechanism. Competition between the chain branching reaction of $\dot{\mathrm{H}}+\mathrm{O}_{2}$ 

speed predictions. Competition between production of $\mathrm{HO}_{2}$ and $\dot{\mathrm{H}}$ from formyl radical is also sensitive. The reaction of carbon monoxide with hydroxyl radical is also highlighted here. The highlighted isobutene reactions include $\mathrm{iC}_{4} \mathrm{H}_{8}+\dot{\mathrm{OH}} \leftrightarrow \mathrm{iC}_{4} \mathrm{H}_{7}+\mathrm{H}_{2} \mathrm{O}$, and $\mathrm{iC}_{4} \mathrm{H}_{8}+\dot{\mathrm{O}} \mathrm{H} \leftrightarrow \mathrm{iC}_{4} \mathrm{H}_{7}-\mathrm{i} 1+\mathrm{H}_{2} \mathrm{O}$, but their sensitivity coefficients are minor in comparison to the others discussed, and hence altering the kinetics of these reactions has limited influence on the predicted flame speed.

Notable in Figure 28 is the fact that there is about a $5-\mathrm{cm} / \mathrm{s}$ difference between the measured flame speeds for the two constant-pressure bomb experiments on the lean side. Some considerable effort was undertaken between the two groups (TAMU and PU) to resolve this discrepancy, focusing on experimental error, repeatability, and data reduction method. For example, with regard to the latter, the raw images of TAMU were post-processed by PU using their own methods. The results of this exercise led to the conclusion that there was no difference between the results obtained for the TAMU data when using either the TAMU or PU reduction methods. Hence, any potential differences in analysis method cannot make up the difference in the final flame speeds. With regard to repeatability, Figure 28 contains repeat data points taken at TAMU over a time lag of several months between two different measurement campaigns. As seen in Figure 28, the TAMU repeatability is within $0.5 \mathrm{~cm} / \mathrm{s}$.

One possible source of difference that was considered was the presence of leaks in the experimental setup, which could impact the final mixture composition, particularly for the minor component. A thorough leak rate study was also performed at TAMU, with the result that the worstcase leak rate was less than 0.3 Torr per hour. When filling with the partial pressure method, this worstcase leak rate will have the most impact on the first or minor component, in this case the fuel. Typically the addition of the isobutene to the vessel takes 15 to 20 minutes. This time lapse leads to the possibility that up to 0.1 Torr of air could enter the vessel with the fuel, therefore changing the actual partial pressure of the fuel. For a lean mixture nominally at $\varphi=0.8$, this increased amount of air will decrease the equivalence ratio from 0.8 to 0.796 , or about a $0.55 \%$ decrease. For a rich mixture nominally at $\varphi=1.4$, this level of air leakage will decrease the equivalence ratio to $\varphi=1.395$ or a decrease of about $0.34 \%$. Hence, for the TAMU rig the worst-case leakage has a minor impact on the final mixture and will not explain the difference between the TAMU and PU data on the lean side.

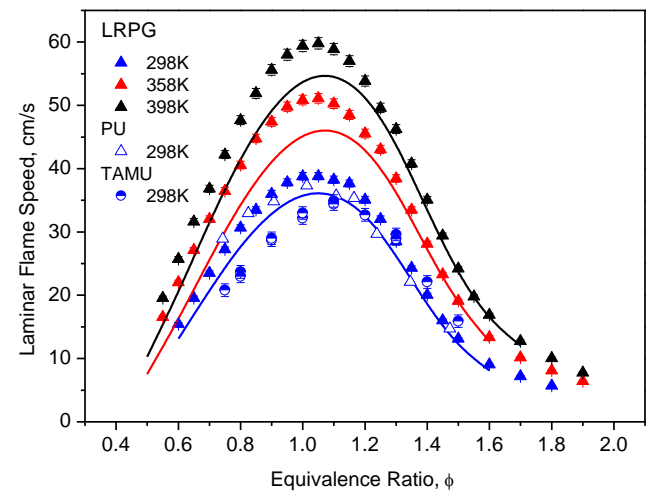

(a)

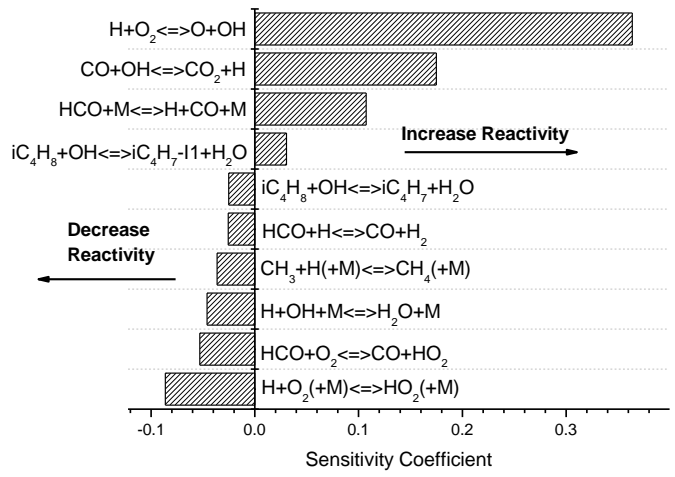

(b)

Figure 28. (a) Laminar flame speed for $\mathrm{iC}_{4} \mathrm{H}_{8}$ in air at $p=1$ atm. Symbols: experimental data, lines: current mechanism. (b) Flame speed sensitivity analysis at $\varphi=0.8, T=298 \mathrm{~K}$. 


\subsection{Speciation validations}

\subsubsection{Jet-stirred reactor results}

Dagaut et al. [12] have measured the concentration profiles of stable species during the oxidation of isobutene in a jet-stirred reactor at equivalence ratios in the range $0.2-2.0$, over a temperature range of $800-1240 \mathrm{~K}$, and in the pressure range 1-10 atm. Overall there is good agreement between the current mechanism and the experimental measurements, Figure 29-Figure 35. As we discussed above, the H15DE25DM formed through the 2-methylallyl radical self-recombination reaction is a very important intermediate species which was not reported in the JSR experimental results here. Methacrolein $\left(\mathrm{iC}_{3} \mathrm{H}_{5} \mathrm{CHO}\right)$ which formed through the decomposition of the important methyl-allyoxyl radical is also an important intermediate which is also not reported in the JSR experiments. Future speciation experiments, especially for these species, will be helpful in improving the model predictions. The species 2-methyl-1,3-butadiene is labelled as B13DE2M in Figures 29-Figure 35. The species 1,3butadiene $\left(\mathrm{C}_{4} \mathrm{H}_{6}\right)$ is always underestimated in the simulations; the same trends have also been found in our 1-butene [70] and 2-butene [71] combustion models. This may indicate that our current 1,3butadiene model needs to be updated.
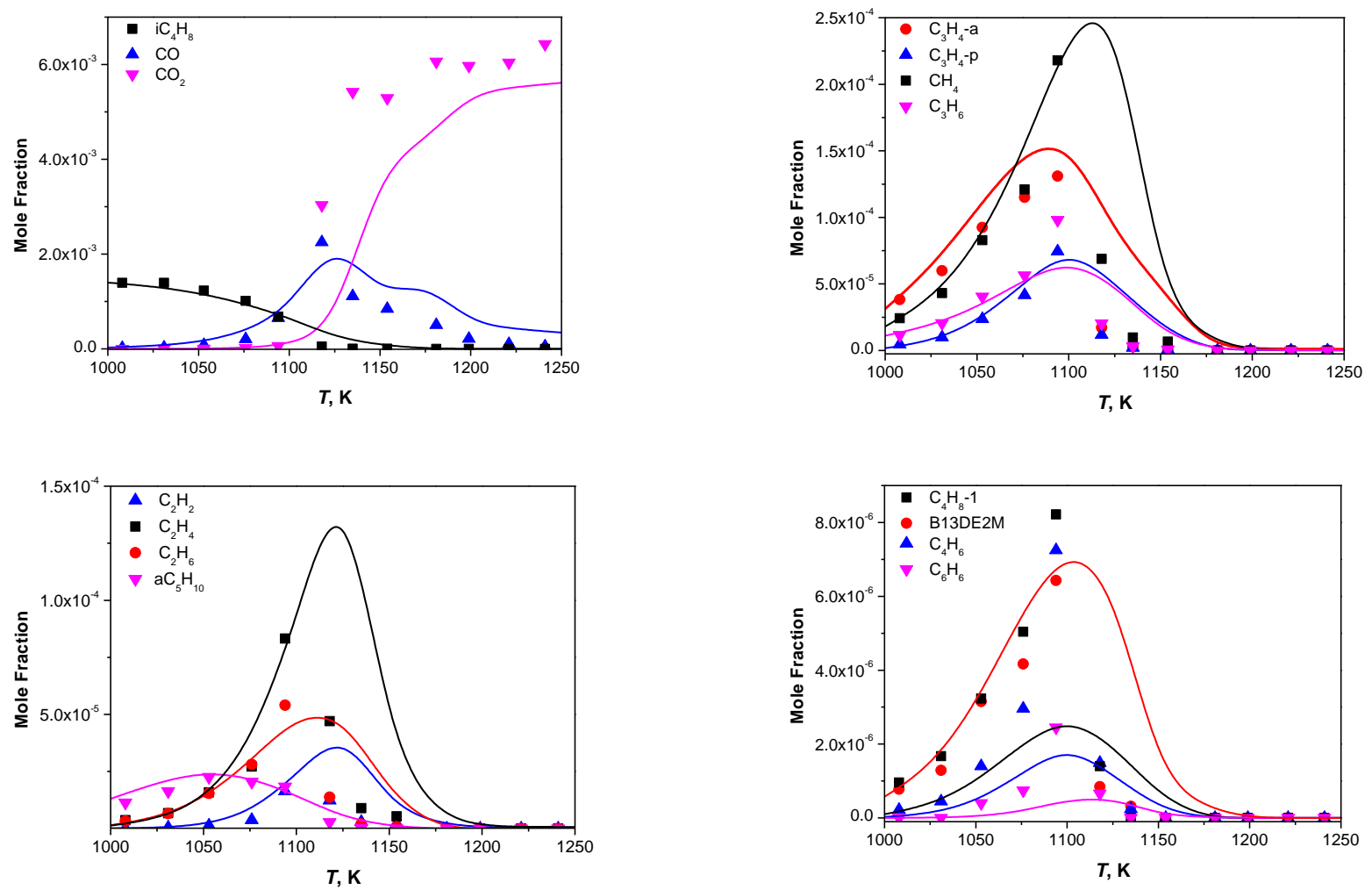

Figure 29. $0.15 \% \mathrm{iC}_{4} \mathrm{H}_{8}, 4.5 \% \mathrm{O}_{2}, 95.35 \% \mathrm{~N}_{2}, \varphi=0.2, p=1$ atm, $\tau=0.15$ s. Symbols: JSR experimental measurements [12], lines: current mechanism predictions. 

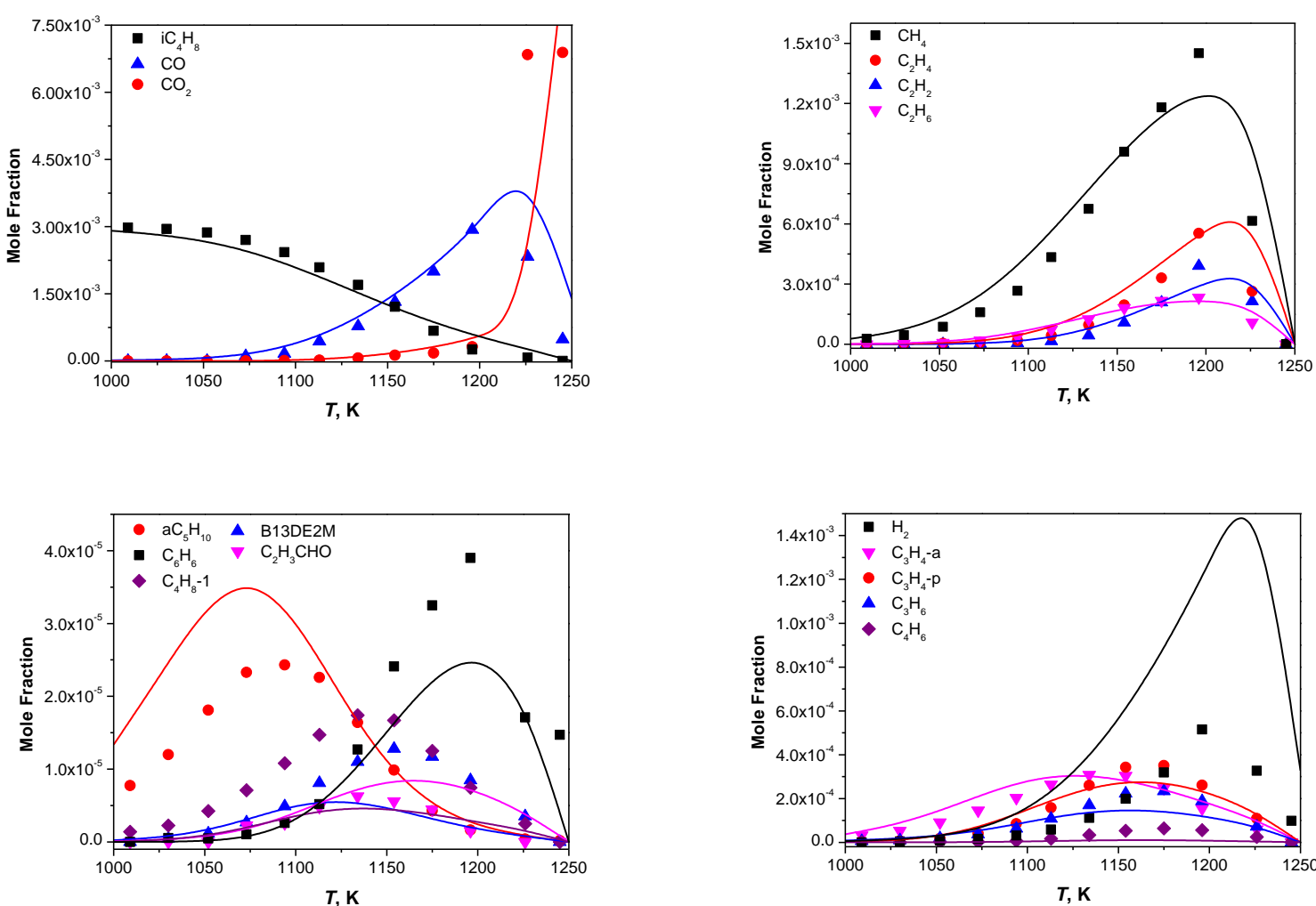

Figure 30. $0.3 \% \mathrm{iC}_{4} \mathrm{H}_{8}, 1.8 \% \mathrm{O}_{2}, 97.9 \% \mathrm{~N}_{2}, \varphi=1.0, p=1 \mathrm{~atm}, \tau=0.15$ s. Symbols: JSR experimental measurements [12], lines: current mechanism predictions.
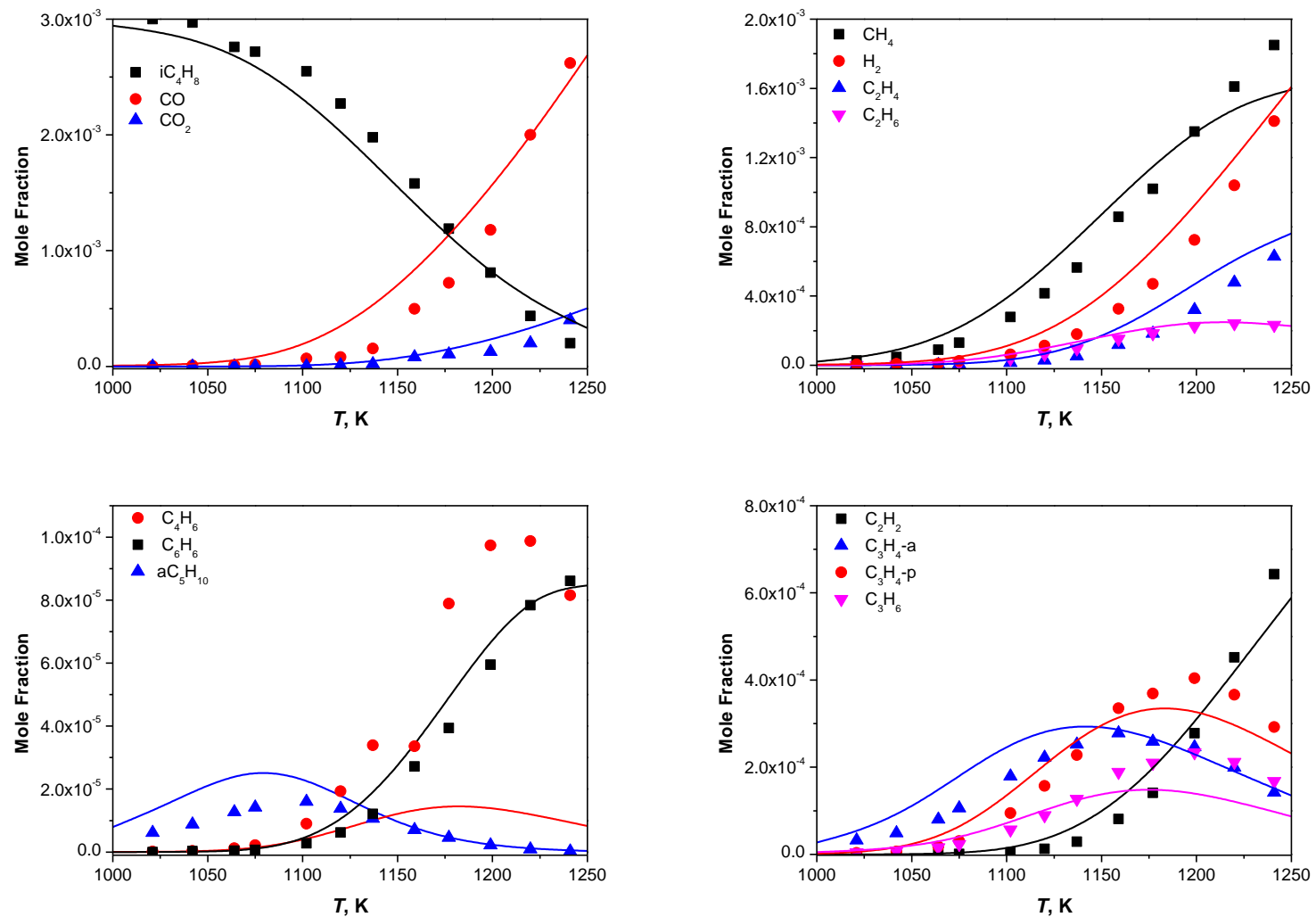

Figure 31. $0.3 \% \mathrm{iC}_{4} \mathrm{H}_{8}, 0.9 \% \mathrm{O}_{2}, 98.8 \% \mathrm{~N}_{2}, \varphi=2.0, p=1 \mathrm{~atm}, \tau=0.15$ s. Symbols: JSR experimental 
measurements [12], lines: current mechanism predictions.
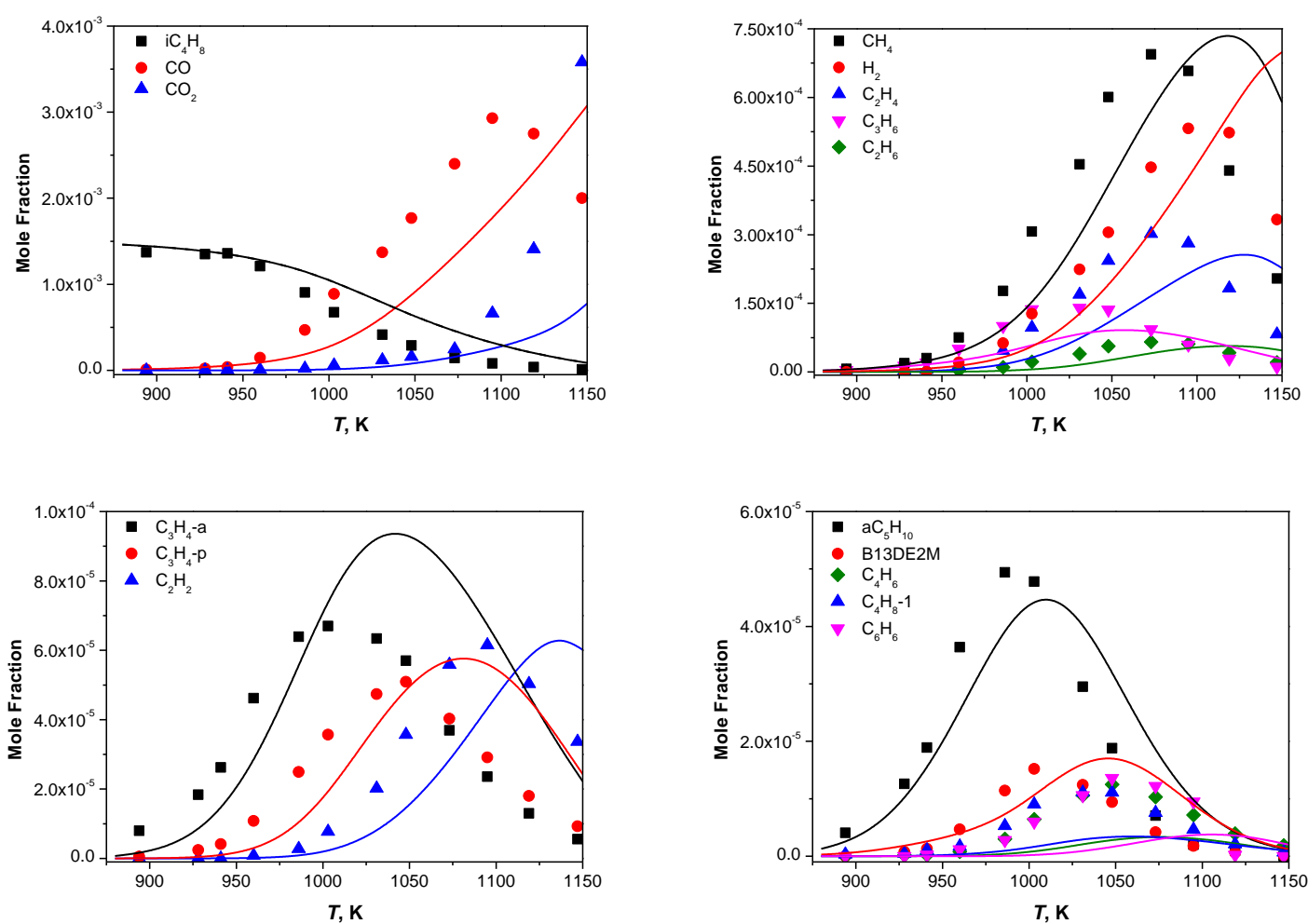

Figure 32. $0.15 \% \mathrm{iC}_{4} \mathrm{H}_{8}, 0.9 \% \mathrm{O}_{2}, 98.95 \% \mathrm{~N}_{2}, \varphi=1.0, p=5$ atm, $\tau=0.75$ s. Symbols: JSR experimental measurements [12], lines: current mechanism predictions.
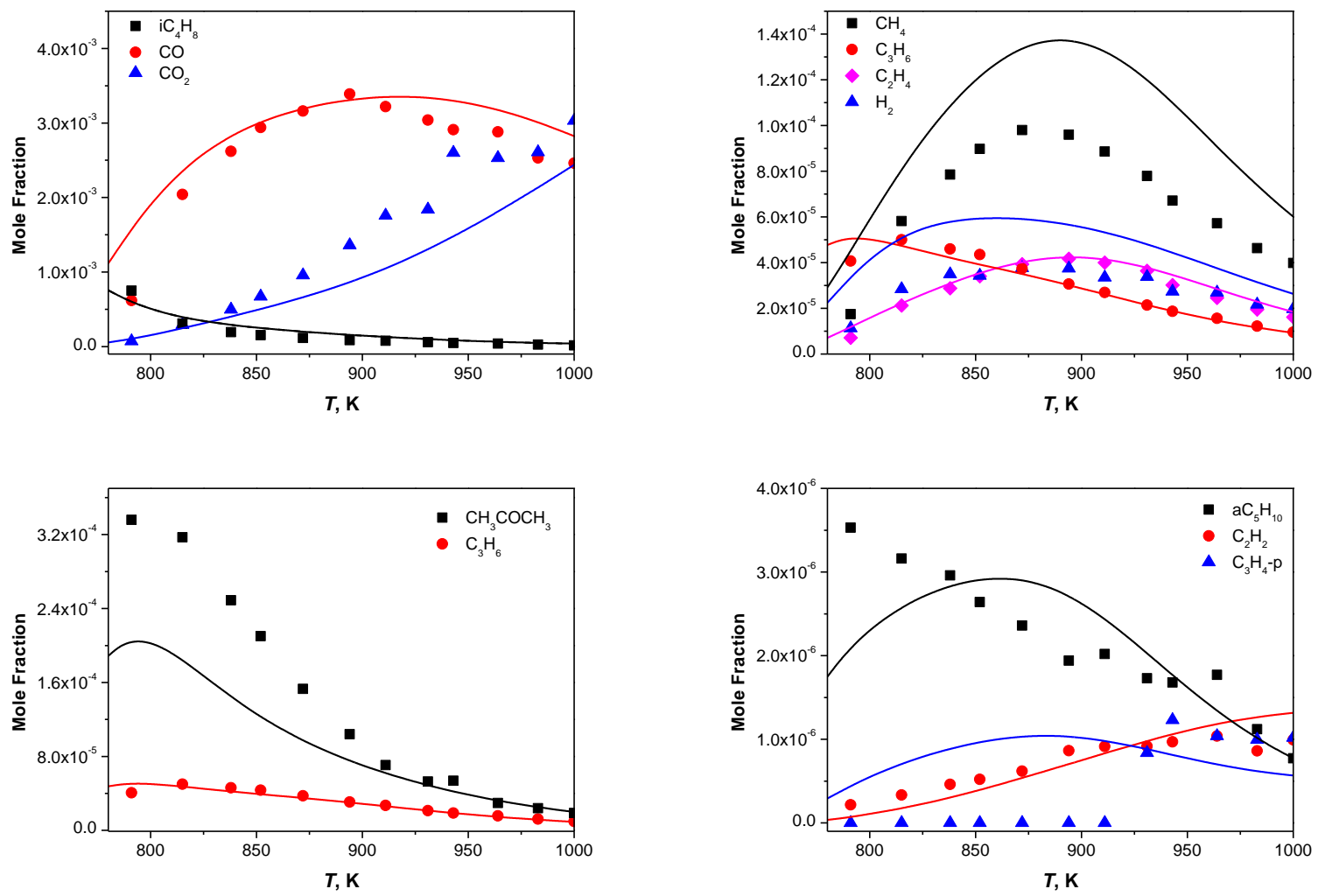
Figure 33. $0.15 \% \mathrm{iC}_{4} \mathrm{H}_{8}, 4.5 \% \mathrm{O}_{2}, 95.35 \% \mathrm{~N}_{2}, \varphi=0.2, p=10$ atm, $\tau=1.5$ s. Symbols: JSR experimental measurements [12], lines: current mechanism predictions.
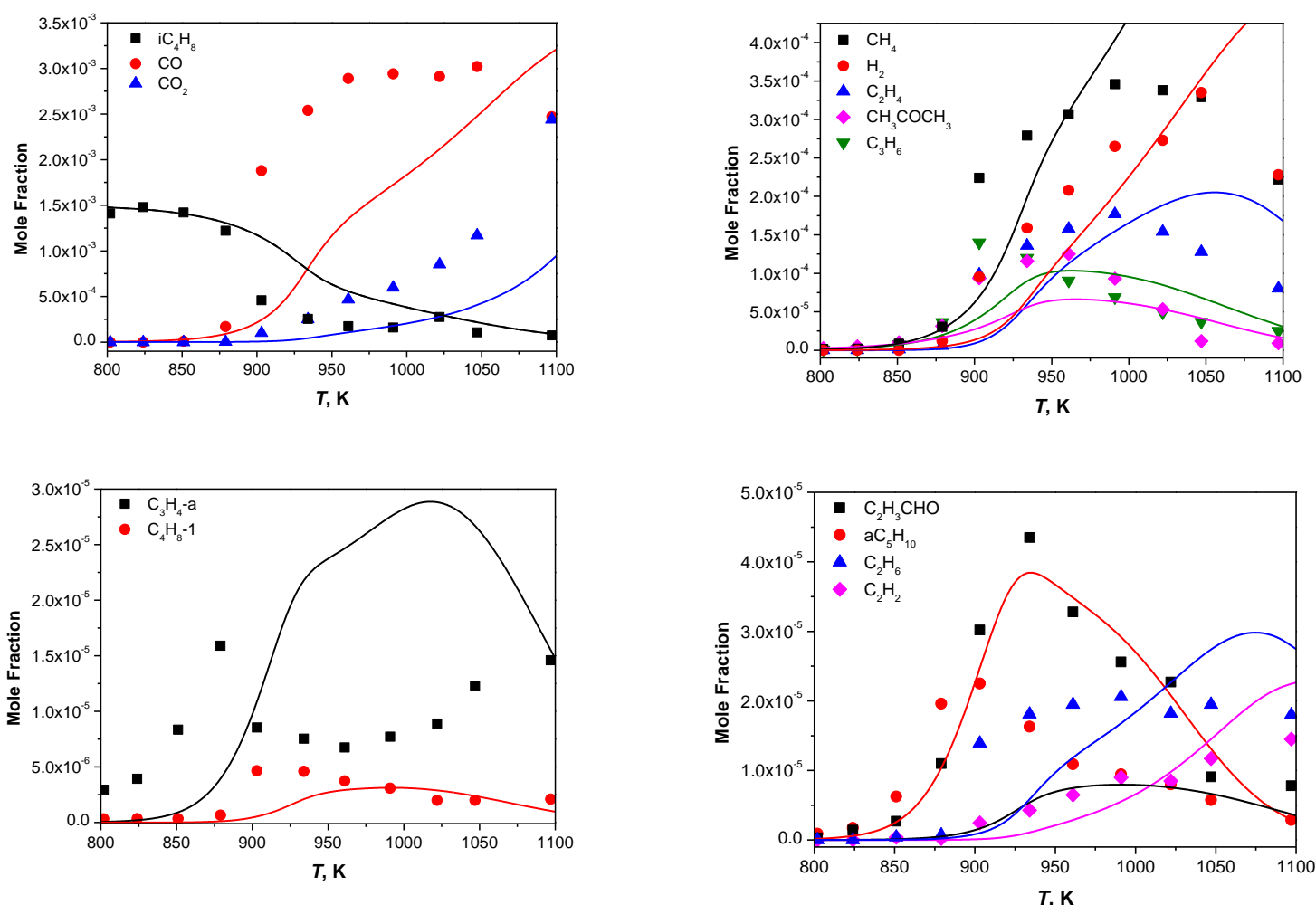

Figure 34. $0.15 \% \mathrm{iC}_{4} \mathrm{H}_{8}, 0.9 \% \mathrm{O}_{2}, 98.95 \% \mathrm{~N}_{2}, \varphi=1.0, p=10$ atm, $\tau=1.5$ s. Symbols: JSR experimental measurements [12], lines: current mechanism predictions.
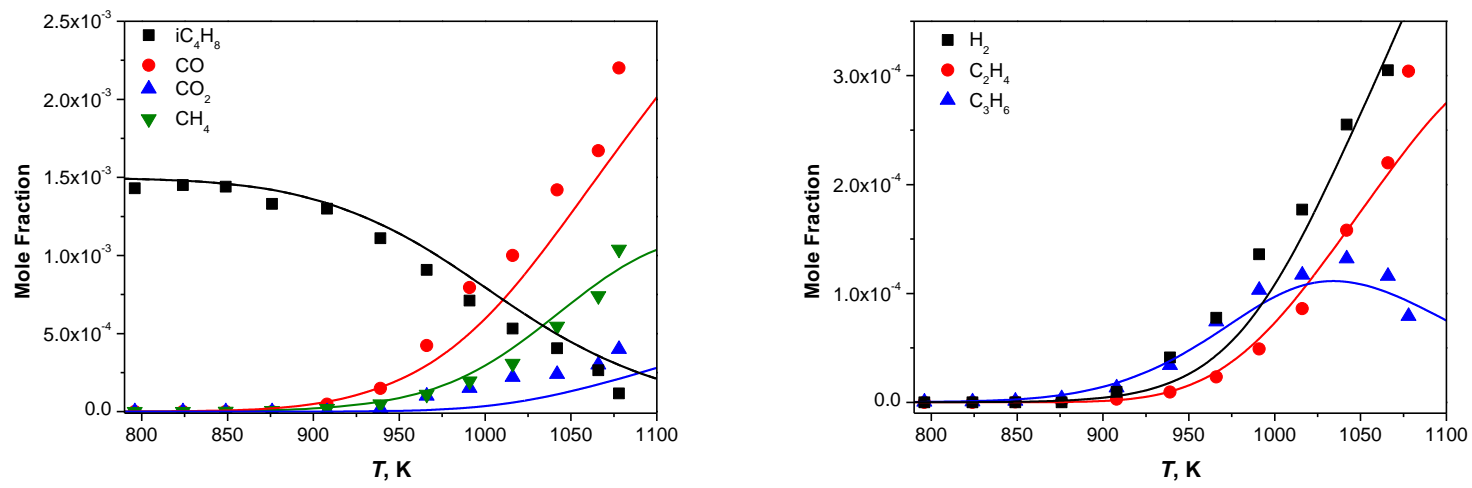

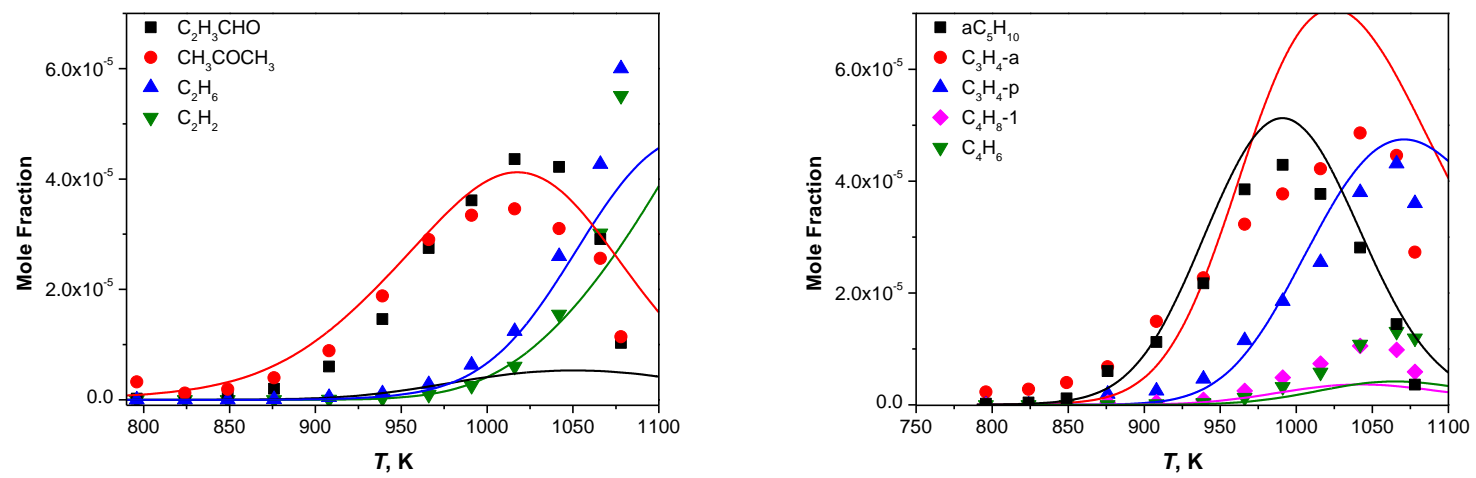

Figure 35. $0.15 \% \quad \mathrm{iC}_{4} \mathrm{H}_{8}, 0.45 \% \mathrm{O}_{2}, 99.4 \% \mathrm{~N}_{2}, \varphi=2.0, p=10$ atm, $\tau=1.5$ s. Symbols: JSR experimental measurements [12], lines: current mechanism predictions.

\subsubsection{Princeton Atmospheric Pressure Flow reactor (APFR)}

Dryer and coworkers [11,49] have experimentally studied the 1 atm pyrolysis and oxidation of isobutene in the Princeton APFR at initial reaction temperatures of $1081 \mathrm{~K}$ and $1139-1150 \mathrm{~K}$. Chemical dynamics in the APFR can be simulated using a zero-dimensional, constant pressure adiabatic assumption and a relative time shift between simulation and experimental time. The timeshifting technique has been thoroughly discussed by Dryer et al. [72, 73]. Results for $\mathrm{C}_{3} \mathrm{H}_{4}$ reported for these experiments and their corresponding simulations are for the sum of allene and propyne.

The single APFR isobutene pyrolysis speciation experiment from [49] provides an important test of isobutene destruction pathways that may otherwise be overwhelmed in the oxidizing experimental environments discussed previously. In hierarchical kinetic model construction, accurate description of pyrolytic pathways is prerequisite for developing accurate oxidation chemistry, and such an approach does much to rule out compensatory uncertainties in both the pyrolysis and oxidation sub-mechanisms. As shown in Figure 36, the present kinetic model generally predicts well the experimentally measured major and minor species profiles. At these conditions, the model indicates that fuel destruction flux is primarily due to the following four reactions:

$$
\begin{aligned}
& \mathrm{iC}_{4} \mathrm{H}_{8}+\dot{\mathrm{C}} \mathrm{H}_{3} \leftrightarrow \mathrm{iC}_{4} \mathrm{H}_{7}+\mathrm{CH}_{4} \\
& \mathrm{iC}_{4} \mathrm{H}_{8} \leftrightarrow \mathrm{i}_{4} \mathrm{H}_{7}+\dot{\mathrm{H}} \\
& \mathrm{iC}_{4} \mathrm{H}_{8}+\dot{\mathrm{H}} \leftrightarrow \mathrm{iC}_{4} \mathrm{H}_{7}+\mathrm{H}_{2} \\
& \mathrm{iC}_{4} \mathrm{H}_{8}+\dot{\mathrm{H}} \leftrightarrow \mathrm{C}_{3} \mathrm{H}_{6}+\dot{\mathrm{C}} \mathrm{H}_{3}
\end{aligned}
$$

Subsequent decomposition of $\mathrm{iC}_{4} \mathrm{H}_{7}$ generated in these reactions forms $\dot{\mathrm{C}} \mathrm{H}_{3}$ and $\mathrm{C}_{3} \mathrm{H}_{4}$-a. Consequently, each of the $\mathrm{iC}_{4} \mathrm{H}_{8}, \mathrm{CH}_{4}, \mathrm{C}_{3} \mathrm{H}_{4}-\mathrm{a}$, and $\mathrm{C}_{3} \mathrm{H}_{6}$ species evolution profiles provides important constraint for these fuel-related reactions. The relatively abundant pool of $\dot{\mathrm{C}} \mathrm{H}_{3}$ formed during fuel destruction may undergo self-recombination to form $\mathrm{C}_{2} \mathrm{H}_{6}$, which subsequently pyrolysis to $\mathrm{C}_{2} \mathrm{H}_{4}$ and then $\mathrm{C}_{2} \mathrm{H}_{2}$. Though the chemistry subsequent to $\dot{\mathrm{C}} \mathrm{H}_{3}$ self-recombination is secondary to the main fuel destruction pathways, its accurate description is critical for prediction of the $\dot{\mathrm{C}} \mathrm{H}_{3}$ pool, which is a central driver of the overall fuel decomposition process.

Figure 37-Figure 39 show the oxidation of isobutene at $1 \mathrm{~atm}$. In each of these cases, the isobutene pyrolysis sub-mechanism remains relatively important, despite the oxidizing environment. At temperature of $\sim 1140 \mathrm{~K}$ and for $\varphi=0.42,0.91$, and 1.29 , the model generally predicts well the both consumption of $\mathrm{iC}_{4} \mathrm{H}_{8}$ and the production of the key intermediates identified in the other flow reactor experiments. Direct comparison of these three experiments on an extent of reaction $\left(\mathrm{iC}_{4} \mathrm{H}_{8}\right.$ consumed) basis shows that the principal stable intermediates $\mathrm{CH}_{4}$ (from $\dot{\mathrm{C}} \mathrm{H}_{3}$ ) and $\mathrm{C}_{3} \mathrm{H}_{4}$-both generated from $\mathrm{iC}_{4} \mathrm{H}_{7}$ decomposition - have a modest dependence on equivalence ratio. For example, reactions of $\dot{\mathrm{C}} \mathrm{H}_{3}$ 
with $\mathrm{O}_{2}$ and $\mathrm{HO}_{2}$ compete with formation of $\mathrm{CH}_{4}$, and so the $\varphi=0.42$ case exhibits uniformly lower mole fraction of $\mathrm{CH}_{4}$ than the other cases. This effect is present (though diminished) with $\mathrm{C}_{3} \mathrm{H}_{4} \mathrm{~mole}$ fraction evolutions compared on an extent of reaction basis, and is virtually undetectable (within experimental uncertainty) for $\mathrm{C}_{3} \mathrm{H}_{6}$ profiles.

This behavior further suggests the importance of pyrolytic fuel destruction at these flow reactor conditions. The oxidative chemistry primarily couples with smaller species and does not directly compete with reactions specific to $\mathrm{iC}_{4} \mathrm{H}_{8}$ or its larger decomposition products. Oxidation of $\dot{\mathrm{C}} \mathrm{H}_{3}$ affects the pools of $\mathrm{CH}_{4}$ and $\mathrm{C}_{2}$ species formed subsequent to methyl-methyl recombination, but little affects destruction of the fuel itself.

At $1081 \mathrm{~K}$, very little $\mathrm{CO}$ or $\mathrm{CO}_{2}$ was observed experimentally [11], At this condition, the present model predicts well each of the $\mathrm{iC}_{4} \mathrm{H}_{8}, \mathrm{CH}_{4}, \mathrm{C}_{3} \mathrm{H}_{6}$, and $\mathrm{C}_{2} \mathrm{H}_{6}$ species evolution profiles. However, it over-predicts the formation of $\mathrm{C}_{3} \mathrm{H}_{4}$ species by a factor of $\sim 1.8$. Detailed discussion and figure is provided in the Supplementary information.
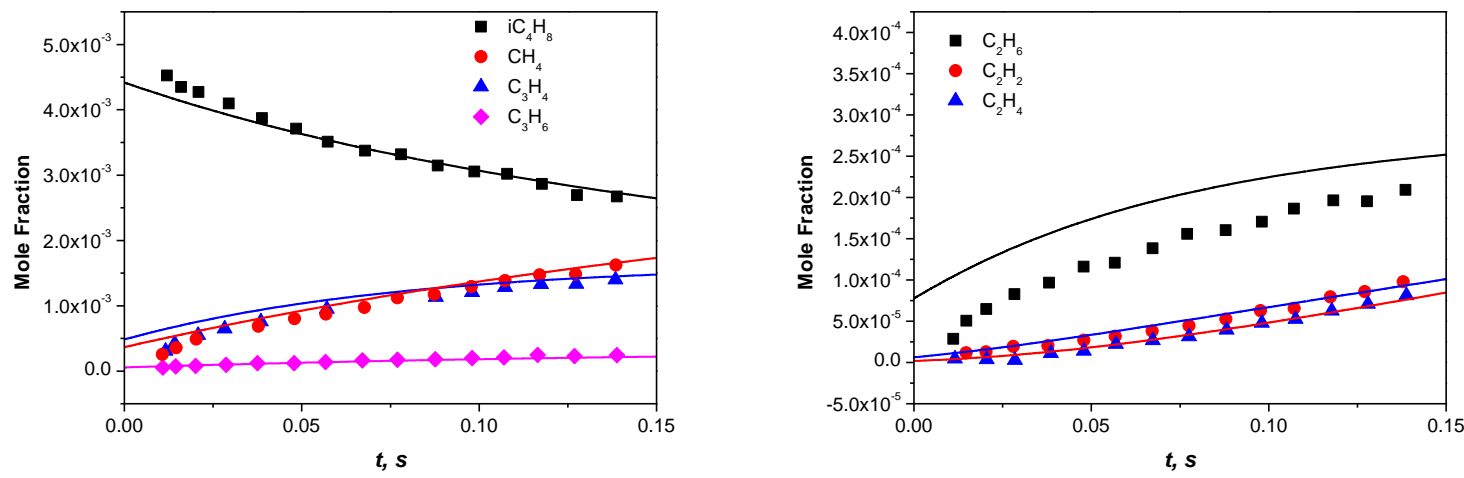

Figure 36. $0.503 \% \mathrm{iC}_{4} \mathrm{H}_{8}$, in $\mathrm{N}_{2}, \varphi=\infty, p=1$ atm, $T=1150 \mathrm{~K}$. Symbols: APFR experimental measurements [49], lines: current mechanism predictions, time shift: $-0.26 \mathrm{~s}$.
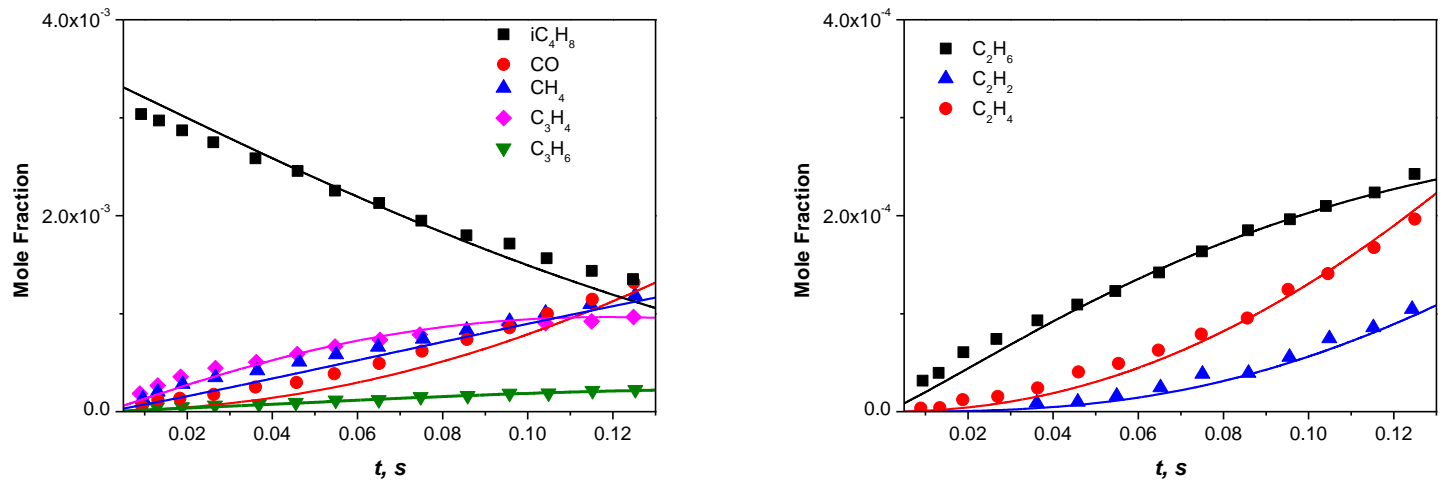

Figure 37. $0.34 \% \mathrm{iC}_{4} \mathrm{H}_{8}, 2.242 \% \mathrm{O}_{2}$ in $\mathrm{N}_{2}, \varphi=0.91, p=1$ atm, $T=1140 \mathrm{~K}$. Symbols: APFR experimental measurements [49], lines: current mechanism predictions, time shift: $-0.01 \mathrm{~s}$. 

Figure 38. $0.348 \% \mathrm{iC}_{4} \mathrm{H}_{8}, 1.619 \% \mathrm{O}_{2}$ in $\mathrm{N}_{2}, \varphi=1.29, p=1$ atm, $T=1142 \mathrm{~K}$. Symbols: APFR experimental measurements [49], lines: current mechanism predictions, time shift: $-0.02 \mathrm{~s}$.
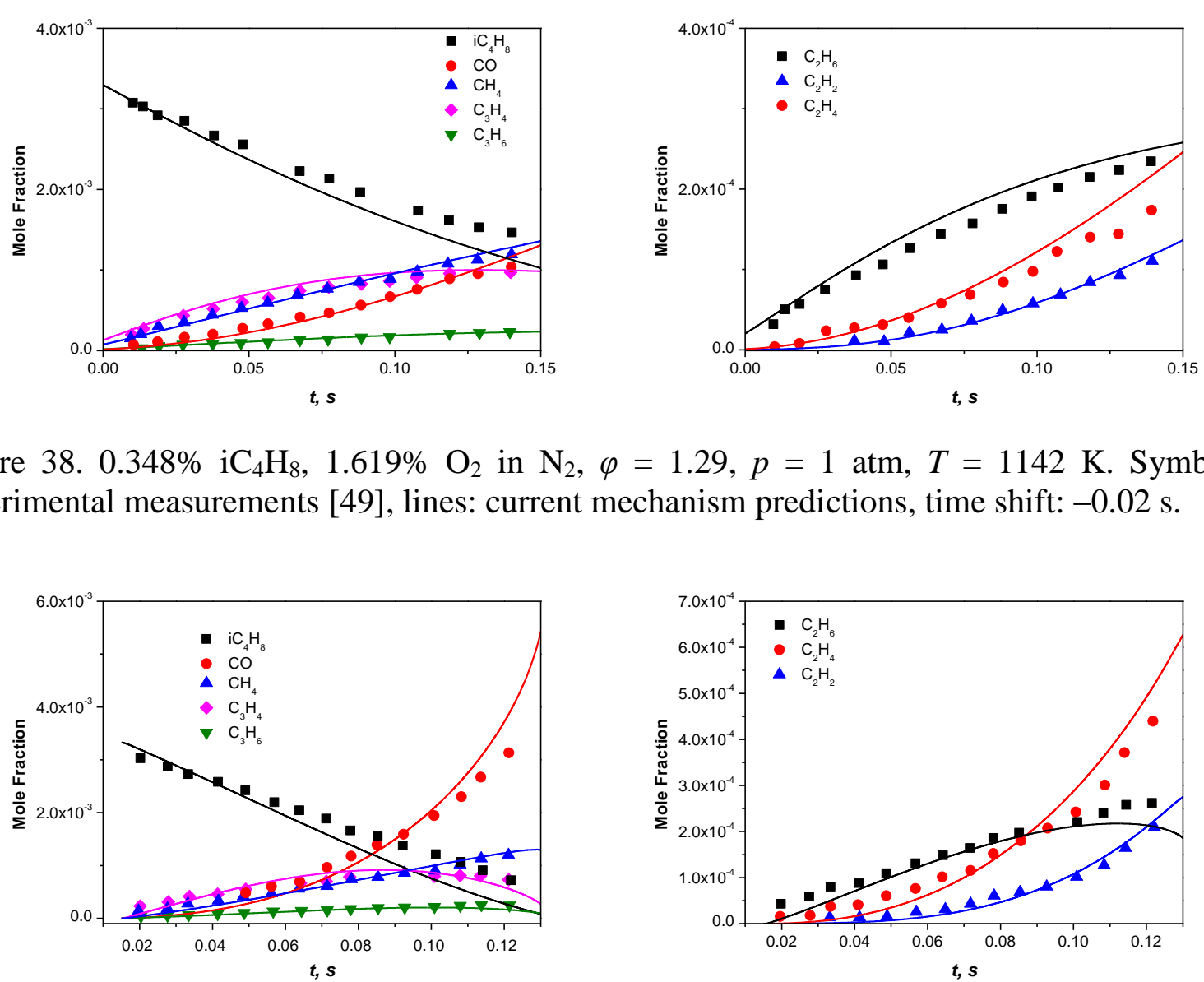

Figure 39. $0.333 \% \mathrm{iC}_{4} \mathrm{H}_{8}, 4.757 \% \mathrm{O}_{2}$ in $\mathrm{N}_{2}, \varphi=0.42, p=1$ atm, $T=1139 \mathrm{~K}$. Symbols: APFR experimental measurements [49], lines: current mechanism predictions, time shift: $0.01 \mathrm{~s}$.

\section{Conclusions}

This paper presents novel experiments on the ignition delay time and flame speed measurements of isobutene. We also describe the development of a detailed kinetic mechanism which is based on a combination of literature theoretical studies, newly presented ab initio calculations, and estimates by analogy with propene chemistry. The kinetic model includes comprehensive low- and high-temperature reaction pathways specific to unsaturated fuel chemistry. The mechanism is validated against our new experiments and relevant literature data with sensitivity and flux analyses used to identify important reaction pathways and kinetic parameters. The current mechanism captures well most of the experimental results of ignition delay times and flame speeds, as well as the speciation results from jetstirred reactor and flow reactor results from the literature.

$\mathrm{H}$-atom abstraction from isobutene by hydroxyl radicals significantly inhibits reactivity through the entire temperature and pressure range investigated because the reaction consumes very reactive hydroxyl radical to produce unreactive stabilized 2-methyallyl radical. H-atom abstraction from isobutene by molecular oxygen to form 2-methylallyl and hydroperoxyl radicals $\left(\mathrm{iC}_{4} \mathrm{H}_{8}+\mathrm{O}_{2} \leftrightarrow \mathrm{iC}_{4} \mathrm{H}_{7}\right.$ $\left.+\mathrm{HO}_{2}\right)$ inhibits reactivity at lower temperatures $(<900 \mathrm{~K})$ because, at these temperatures, the reaction proceeds in the reverse direction. This reaction promotes reactivity as the temperature increases and contributes significantly to the reactivity at higher temperatures for all mixtures. Its contribution to the reactivity is significant even at intermediate temperatures $(\sim 900 \mathrm{~K})$ under fuel-rich conditions. 
At low temperatures $(\sim 750 \mathrm{~K}), \dot{\mathrm{OH}}$ radical addition to $\mathrm{iC}_{4} \mathrm{H}_{8}$ is very important for fuel consumption and contributes significantly to the overall reactivity. At intermediate temperatures $(850-1000 \mathrm{~K})$, the reactions of 2-methylallyl $\left(\mathrm{i}_{4} \mathrm{H}_{7}\right)$ with hydroperoxyl radicals and $\mathrm{i}_{4} \mathrm{H}_{7}$ self-recombination reaction control the reactivity. At higher temperatures $(\sim 1250 \mathrm{~K})$, the reaction of $\mathrm{i}_{4} \mathrm{H}_{7}$ radicals with $\dot{\mathrm{C}} \mathrm{H}_{3}$ radicals becomes important.

JSR speciation predictions were shown to be in reasonable agreement with literature experimental data for equivalence ratios from 0.2 to 2 , temperatures of 800-1240 $\mathrm{K}$ and the pressures from 1 to 10 atm. The product of the 2-methylallyl radical self-recombination reaction, H15DE25DM, is a very important intermediate species which was not reported in the JSR results. Methacrolein, formed through the decomposition of the methyl-allyoxyl radical, is also an important intermediate which is absent from the JSR results. Future speciation experiments, especially for these species, will be helpful to improve the model. Model predictions for flow reactor speciation were shown to be in reasonable agreement with available literature data as well.

7. Research outlook

Isobutene combustion chemistry is very important in describing the combustion behavior of larger alkanes, as well as being a component of commercial fuels. Despite the fact that the current model accurately captures a wide range of reactivity and speciation results, further fundamental research can aid the important process in improving the accuracy and mechanistic realism of future models. The present study highlights many issues concerning the detailed chemical mechanism development of isobutene combustion, and we summarize these important aspects and present a foundation for future unsaturated alkene combustion mechanism generation.

- The ab initio calculation methods applied in this paper provide very good results for the $\mathrm{H}$ atom abstraction reactions of $\mathrm{iC}_{4} \mathrm{H}_{8}+\dot{\mathrm{O}} \mathrm{H}$, and $\mathrm{iC}_{4} \mathrm{H}_{8}+\mathrm{HO}_{2}$ which are very important in the entire temperature range. The same methods have also been applied to the uni-molecular decomposition reaction of $\mathrm{iC}_{4} \mathrm{H}_{7}$ radical, which is important at higher temperatures.

- Application of the analogous rate constants for isobutene based on propene for similar reaction classes appears to provide reasonable results for the reaction of $\mathrm{i}_{4} \dot{\mathrm{H}}_{7}+\mathrm{HO}_{2}$ and $\mathrm{iC}_{4} \mathrm{H}_{7}+$ $\mathrm{i}_{4} \mathrm{H}_{7}$ which are very important at intermediate temperatures. Further $a b$ initio calculations and experiments are needed to test the accuracy of the rate constants estimated by analogy.

- The H-atom abstraction rate constant from $\mathrm{iC}_{4} \mathrm{H}_{8}$ by molecular oxygen is different from the analogous reaction in propene. As this reaction in the current form results in good predictions of ignition delay times in fuel-rich mixtures, we use the current value. Ab initio calculations for this reaction class in both the propene and isobutene systems are needed in order to improve the fidelity of the model.

- After the fuel radical $\dot{\mathrm{R}}$ reacts with molecular oxygen to form $\mathrm{RO}_{2}$, this radical then decomposes back to $\dot{\mathrm{R}}+\mathrm{O}_{2}$ in unsaturated alkenes, while $\mathrm{RO}_{2}$ is more stable for normal alkanes. Based on this work, and related studies of allylic systems, it is becoming apparent that the reactivity for alkene components at very low temperatures $(<800 \mathrm{~K})$ is from the hydroxyl radical addition reaction followed by addition of the resulting radical to molecular oxygen. At intermediate temperatures $(800-1300 \mathrm{~K})$, the reactivity is controlled by the competition between hydrogen abstraction by molecular oxygen and $\mathrm{O} H$ radicals from alkenes and the reaction between resonantly stabilized $\mathrm{iC}_{4} \mathrm{H}_{7}$ radical reacting with hydroperoxyl radicals resulting in chain branching reactions. At higher temperatures $(>1300 \mathrm{~K})$, the reactivity is mainly from the hydrogen abstraction reactions from the fuel by molecular oxygen.

- Our current treatment captures the low temperature reactivity of isobutene oxidation well; 


\section{Acknowledgments:}

Chong-Wen Zhou thanks the entire group members at Combustion Chemistry Centre for helpful discussions. The work at NUI Galway was supported by Saudi Aramco under the FUELCOM program. The TAMU effort was supported by the Texas A\&M Engineering Experiment Station and by the TEES Turbomachinery Laboratory. The Rensselaer group was supported by the U.S. Air Force Office of Scientific Research (Grant No. FA9550-11-1-0261). The work at UConn was supported by the National Science Foundation under Grant No. CBET-1402231. The work of KAUST authors was supported by Saudi Aramco under the FUELCOM program and by King Abdullah University of Science and Technology (KAUST). The work at LRGP was supported by the European Commission through the "Clean ICE" Advanced Research Grant of the European Research Council. Collaboration between NUI Galway and LRGP enters in the frame the COST Action CM1404. Y J would like to thank the grant support from NETL DE-FE0011822 and NSF CBET-1507358. FLD acknowledges support of this at Princeton by the University Turbine Systems Research (UTSR) program, administered by the National Energy Technology Laboratory of the US Department of Energy (DOE), under award DE-FE0012005. 
[1] C.K. Westbrook, W.J. Pitz, H.J. Curran, Chemical kinetic modeling study of the effects of oxygenated hydrocarbons on soot emissions from diesel engines, J. Phys. Chem. A 110 (2006) 6912-6922.

[2] S.M. Burke, U. Burke, R. Mc Donagh, O. Mathieu, I. Osorio, C. Keesee, A. Morones, E.L. Petersen, W.J. Wang, T.A. DeVerter, M.A. Oehlschlaeger, B. Rhodes, R.K. Hanson, D.F. Davidson, B.W. Weber, C.J. Sung, J. Santner, Y.G. Ju, F.M. Haas, F.L. Dryer, E.N. Volkov, E.J.K. Nilsson, A.A. Konnov, M. Alrefae, F. Khaled, A. Farooq, P. Dirrenberger, P.A. Glaude, F. Battin-Leclerc, H.J. Curran, An experimental and modeling study of propene oxidation. Part 2: Ignition delay time and flame speed measurements, Combust. Flame 162 (2015) 296-314.

[3] S.M. Burke, W. Metcalfe, O. Herbinet, F. Battin-Leclerc, F.M. Haas, J. Santner, F.L. Dryer, H.J. Curran, An experimental and modeling study of propene oxidation. Part 1: Speciation measurements in jet-stirred and flow reactors, Combust. Flame 161 (2014) 2765-2784.

[4] J.C. Bauge, F. Battin-Leclerc, F. Baronnet, Experimental and modeling study of the oxidation of isobutene, International Journal of Chemical Kinetics 30 (1998) 629-640.

[5] J.N. Bradley, K.O. West, SINGLE-PULSE SHOCK-TUBE STUDIES OF HYDROCARBON PYROLYSIS .6. PYROLYSIS OF ISOBUTENE, Journal of the Chemical Society-Faraday Transactions I 72 (1976) 558-567.

[6] H.J. Curran, M.P. Dunphy, J.M. Simmie, C.K. Westbrook, W.J. Pitz, Shock tube ignition of ethanol, isobutene and MTBE: Experiments and modeling, Symposium (International) on Combustion 24 (1992) 769-776.

[7] S. Santhanam, J.H. Kiefer, R.S. Tranter, N.K. Srinivasan, A shock tube, Laser-Schlieren Study of the pyrolysis of isobutene: Relaxation, incubation, and dissociation rates, Int. J. Chem. Kinet. 35 (2003) 381-390.

[8] W. Tsang, J.A. Walker, Mechanism and rate constants for the reactions of hydrogen atoms with isobutene at high temperatures, Symposium (International) on Combustion 22 (1989) 1015-1022.

[9] K. Yasunaga, Y. Kuraguchi, R. Ikeuchi, H. Masaoka, O. Takahashi, T. Koike, Y. Hidaka, Shock tube and modeling study of isobutene pyrolysis and oxidation, Proc. Combust. Inst. 32 (2009) 453-460.

[10] H.J. Curran, The combustion of isobutene and related compounds., PhD Thesis, Department of Chemistry, University College, Galway., (1994).

[11] K. Brezinsky, F.L. Dryer, A FLOW REACTOR STUDY OF THE OXIDATION OF ISO-BUTYLENE AND AN ISOBUTYLENE NORMAL-OCTANE MIXTURE, Combust. Sci. Technol. 45 (1986) 225-232.

[12] P. Dagaut, M. Cathonnet, Isobutene oxidation and ignition: Experimental and detailed kinetic modeling study, Combustion Science and Technology 137 (1998) 237-275.

[13] V. Dias, J. Vandooren, Experimental and modeling study of a lean premixed iso-butene/hydrogen/oxygen/argon flame, Fuel 89 (2010) 2633-2639.

[14] M. Schenk, L. Leon, K. Moshammer, P. Osswald, T. Zeuch, L. Seidel, F. Mauss, K. Kohse-Hoinghaus, Detailed mass spectrometric and modeling study of isomeric butene flames, Combust. Flame 160 (2013) 487-503.

[15] P. Zhao, W.H. Yuan, H.Y. Sun, Y.Y. Li, A.P. Kelley, X.L. Zheng, C.K. Law, Laminar flame speeds, counterflow ignition, and kinetic modeling of the butene isomers, Proc. Combust. Inst. 35 (2015) 309-316.

[16] Y.J. Zhang, J.H. Cai, L. Zhao, J.Z. Yang, H.F. Jin, Z.J. Cheng, Y.Y. Li, L.D. Zhang, F. Qi, An experimental and kinetic modeling study of three butene isomers pyrolysis at low pressure, Combust. Flame 159 (2012) 905-917.

[17] J.H. Cai, L.D. Zhang, F. Zhang, Z.D. Wang, Z.J. Cheng, W.H. Yuan, F. Qi, Experimental and Kinetic Modeling Study of n-Butanol Pyrolysis and Combustion, Energy Fuels 26 (2012) 5550-5568.

[18] C.J. Aul, W.K. Metcalfe, S.M. Burke, H.J. Curran, E.L. Petersen, Ignition and kinetic modeling of methane and ethane fuel blends with oxygen: A design of experiments approach, Combust. Flame 160 (2013) 1153-1167.

[19] H.P.S. Shen, J. Vanderover, M.A. Oehlschlaeger, A shock tube study of iso-octane ignition at elevated pressures: The influence of diluent gases, Combust. Flame 155 (2008) 739-755.

[20] A.K. Das, C.J. Sung, Y. Zhang, G. Mittal, Ignition delay study of moist hydrogen/oxidizer mixtures using a rapid compression machine, Int. J. Hydrog. Energy 37 (2012) 6901-6911.

[21] M.C. Krejci, O. Mathieu, A.J. Vissotski, S. Ravi, T.G. Sikes, E.L. Petersen, A. Kermones, W. Metcalfe, H.J. Curran, Laminar Flame Speed and Ignition Delay Time Data for the Kinetic Modeling of Hydrogen and Syngas Fuel Blends, J. Eng. Gas. Turbines Power-Trans. ASME 135 (2013) 9.

[22] Z. Chen, On the extraction of laminar flame speed and Markstein length from outwardly propagating spherical flames, Combustion and Flame 158 (2011) 291-300.

[23] X. Qin, Y. Ju, Measurements of burning velocities of dimethyl ether and air premixed flames at elevated pressures, Proceedings of the Combustion Institute 30 (2005) 233-240.

[24] M.P. Burke, Z. Chen, Y. Ju, F.L. Dryer, Effect of cylindrical confinement on the determination of laminar flame speeds using outwardly propagating flames, Combustion and Flame 156 (2009) 771-779.

[25] F. Wu, W. Liang, Z. Chen, Y. Ju, C.K. Law, Uncertainty in stretch extrapolation of laminar flame speed from expanding spherical flames, Proceedings of the Combustion Institute 35 (2015) 663-670. 
[26] J. Santner, F.M. Haas, Y. Ju, F.L. Dryer, Uncertainties in interpretation of high pressure spherical flame propagation rates due to thermal radiation, Combustion and Flame 161 (2014) 147-153.

[27] P. Dirrenberger, H. Le Gall, R. Bounaceur, O. Herbinet, P.A. Glaude, A. Konnov, F. Battin-Leclerc, Measurements of Laminar Flame Velocity for Components of Natural Gas, Energy Fuels 25 (2011) 3875-3884.

[28] P. Dirrenberger, P.A. Glaude, R. Bounaceur, H. Le Gall, A.P. da Cruz, A.A. Konnov, F. Battin-Leclerc, Laminar burning velocity of gasolines with addition of ethanol, Fuel 115 (2014) 162-169.

[29] P. Dirrenberger, H. Le Gall, R. Bounaceur, P.A. Glaude, F. Battin-Leclerc, Measurements of Laminar Burning Velocities above Atmospheric Pressure Using the Heat Flux Method-Application to the Case of n-Pentane, Energy Fuels 29 (2015) 398-404.

[30] J.M. Hall, E.L. Petersen, An optimized kinetics model for $\mathrm{OH}$ chemiluminescence at high temperatures and atmospheric pressures, Int. J. Chem. Kinet. 38 (2006) 714-724.

[31] T. Kathrotia, M. Fikri, M. Bozkurt, M. Hartmann, U. Riedel, C. Schulz, Study of the H plus O plus M reaction forming $\mathrm{OH}$ center dot: Kinetics of $\mathrm{OH}$ center dot chemiluminescence in hydrogen combustion systems, Combust. Flame 157 (2010) 1261-1273.

[32] v. CHEMKIN-PRO, Reaction Design: San Diego, 2013.

[33] C.K. Westbrook, W.J. Pitz, J.E. Boercker, H.J. Curran, J.F. Griffiths, C. Mohamed, M. Ribaucour, Detailed chemical kinetic reaction mechanisms for autoignition of isomers of heptane under rapid compression, Proceedings of the Combustion Institute 29 (2002) 1311-1318.

[34] S. Tanaka, F. Ayala, J.C. Keck, A reduced chemical kinetic model for HCCI combustion of primary reference fuels in a rapid compression machine, Combustion and Flame 133 (2003) 467-481.

[35] M. Ribaucour, R. Minetti, L.R. Sochet, H.J. Curran, W.J. Pitz, C.K. Westbrook, Ignition of isomers of pentane: An experimental and kinetic modeling study, Proceedings of the Combustion Institute 28 (2000) 1671-1678.

[36] W.K. Metcalfe, S.M. Burke, S.S. Ahmed, H.J. Curran, A Hierarchical and Comparative Kinetic Modeling Study of C-1 - C-2 Hydrocarbon and Oxygenated Fuels, Int. J. Chem. Kinet. 45 (2013) 638-675.

[37] W.H. Green, J.W. Allen, R.W. Ashcraft, G.J. Beran, C.A. Class, C. Gao, C.F. Goldsmith, M.R. Harper, A. Jalan, G.R. Magoon, D.M. Matheu, S.S. Merchant, J.D. Mo, S. Petway, S. Raman, S. Sharma, J. Song, K.M. Van Geem, J. Wen, R.H. West, A. Wong, H. Wong, P.E. Yelvington, J. Yu, RMG - Reaction Mechanism Generator v3.3 2011, $<\underline{\text { http:}: / / r m g . \text { sourceforge.net/ }>\text {. }}$

[38] Y. Zhao, D.G. Truhlar, The M06 suite of density functionals for main group thermochemistry, thermochemical kinetics, noncovalent interactions, excited states, and transition elements: two new functionals and systematic testing of four M06-class functionals and 12 other functionals, Theor. Chem. Acc. 120 (2008) 215-241.

[39] M.J.e.a. Frisch, Gaussian 09, Gaussian, Inc.,

Wallingford, (2009).

[40] J.M.L. Martin, Ab initio total atomization energies of small molecules - Towards the basis set limit, Chem. Phys. Lett. 259 (1996) 669-678.

[41] D. Feller, D.A. Dixon, Extended benchmark studies of coupled cluster theory through triple excitations, J. Chem. Phys. 115 (2001) 3484-3496.

[42] S. Glasstone, K.J. Laidler, H. Eyring, Theory of Rate Processes; McGraw-Hill: New York,, (1941).

[43] C. Eckart, The Penetration Of A Potential Barrier By Electrons., Phys. Rev. 35 (1930) 1303-1309.

[44] K.S. Pitzer, W.D. Gwinn, Energy Levels and Thermodynamic Functions for Molecules with Internal Rotation I. Rigid Frame with Attached Tops, J. Chem. Phys 10 (1942) 428-440.

[45] A. Keromnes, W.K. Metcalfe, K.A. Heufer, N. Donohoe, A.K. Das, C.J. Sung, J. Herzler, C. Naumann, P. Griebel, O. Mathieu, M.C. Krejci, E.L. Petersen, W.J. Pitz, H.J. Curran, An experimental and detailed chemical kinetic modeling study of hydrogen and syngas mixture oxidation at elevated pressures, Combust. Flame 160 (2013) 995-1011.

[46] S.W. Benson, Thermochemical kinetics, Wiley1976.

[47] S.M. Burke, J.M. Simmie, H.J. Curran, Critical Evaluation of Thermochemical Properties of C-1-C-4 Species: Updated Group-Contributions to Estimate Thermochemical Properties, Journal of Physical and Chemical Reference Data 44 (2015) 29.

[48] E.R. Ritter, J.W. Bozzelli, THERM - THERMODYNAMIC PROPERTY ESTIMATION FOR GAS-PHASE RADICALS AND MOLECULES, Int. J. Chem. Kinet. 23 (1991) 767-778.

[49] T. Held, F.L. Dryer, The oxidation of methanol, isobutene and methyl tertiary-butyl ether, PhD Thesis, Department of Mechanical and Aerospace Engineering, Princeton University., (1993).

[50] W. Tsang, Chemical kinetic data base for combustion chemistry part V. Propene, Journal of Physical and Chemical Reference Data 20 (1991) 221-273.

[51] H.Y. Sun, C.K. Law, Kinetics of Hydrogen Abstraction Reactions of Butene Isomers by OH Radical, J. Phys. Chem. A 114 (2010) 12088-12098. 
[52] R.R. Baker, R.R. Baldwin, R.W. Walker, ADDITION OF I-BUTANE TO SLOWLY REACTING MIXTURES OF HYDROGEN AND OXYGEN AT 480-DEGREES-C, Journal of the Chemical Society-Faraday Transactions I 74 (1978) 2229-2251.

[53] J. Zador, A.W. Jasper, J.A. Miller, The reaction between propene and hydroxyl, Phys. Chem. Chem. Phys. 11 (2009) 11040-11053.

[54] H.Y. Sun, J.W. Bozzelli, C.K. Law, Thermochemical and kinetic analysis on the reactions of O-2 with products from $\mathrm{OH}$ addition to isobutene, 2-hydroxy-1,1-dimethylethyl, and 2-hydroxy-2-methylpropyl radicals: $\mathrm{HO} 2$ formation from oxidation of neopentane, part II, J. Phys. Chem. A 111 (2007) 4974-4986.

[55] S.M. Villano, L.K. Huynh, H.H. Carstensen, A.M. Dean, High-Pressure Rate Rules for Alkyl + O-2 Reactions. 2. The Isomerization, Cyclic Ether Formation, and beta-Scission Reactions of Hydroperoxy Alkyl Radicals, J. Phys. Chem. A 116 (2012) 5068-5089.

[56] A. Miyoshi, Molecular size dependent falloff rate constants for the recombination reactions of alkyl radicals with O2 and implications for simplified kinetics of alkylperoxy radicals, Int. J. Chem. Kinet. 44 (2012) 59-74.

[57] C.F. Goldsmith, W.H. Green, S.J. Klippenstein, Role of O-2 + QOOH in Low-Temperature Ignition of Propane. 1. Temperature and Pressure Dependent Rate Coefficients, J. Phys. Chem. A 116 (2012) 3325-3346.

[58] H.J. Curran, Rate constant estimation for C-1 to C-4 alkyl and alkoxyl radical decomposition, Int. J. Chem. Kinet. 38 (2006) 250-275.

[59] J.A. Miller, S.J. Klippenstein, Dissociation of Propyl Radicals and Other Reactions on a C3H7 Potential, J. Phys. Chem. A 117 (2013) 2718-2727.

[60] J. Zador, S.J. Klippenstein, J.A. Miller, Pressure-Dependent OH Yields in Alkene plus HO2 Reactions: A Theoretical Study, J. Phys. Chem. A 115 (2011) 10218-10225.

[61] S.M. Villano, L.K. Huynh, H.H. Carstensen, A.M. Dean, High-Pressure Rate Rules for Alkyl + O-2 Reactions. 1. The Dissociation, Concerted Elimination, and Isomerization Channels of the Alkyl Peroxy Radical, J. Phys. Chem. A 115 (2011) 13425-13442.

[62] S.M. Villano, H.H. Carstensen, A.M. Dean, Rate Rules, Branching Ratios, and Pressure Dependence of the HO2 + Olefin Addition Channels, J. Phys. Chem. A 117 (2013) 6458-6473.

[63] T. Ingham, R.W. Walker, R.E. Woolford, Kinetic parameters for the initiation reaction $\mathrm{RH}+\mathrm{O} 2 \rightarrow \mathrm{R}+\mathrm{HO} 2$, Symposium (International) on Combustion 25 (1994) 767-774.

[64] C.J. Chen, J.W. Bozzelli, Thermochemical property, pathway and kinetic analysis on the reactions of allylic isobutenyl radical with O-2: an elementary reaction mechanism for isobutene oxidation, J. Phys. Chem. A 104 (2000) 9715-9732.

[65] C.F. Goldsmith, S.J. Klippenstein, W.H. Green, Theoretical rate coefficients for allyl $+\mathrm{HO} 2$ and allyloxy decomposition, Proc. Combust. Inst. 33 (2011) 273-282.

[66] S. Rolland, J.M. Simmie, The comparison of detailed chemical kinetic mechanisms; forward versus reverse rates with CHEMRev, Int. J. Chem. Kinet. 37 (2005) 119-125.

[67] T. W, Chemical Kinetic Data Base for Combustion Chemistry. Part V. Propene, J. Phys. Chem. Ref. Data 20 (1991).

[68] J. Mendes, C.W. Zhou, H.J. Curran, Theoretical Chemical Kinetic Study of the H-Atom Abstraction Reactions from Aldehydes and Acids by $\mathrm{H}$ Atoms and $\mathrm{OH}, \mathrm{HO}_{2}$, and $\mathrm{CH}_{3}$ Radicals, J. Phys. Chem. A 118 (2014) 12089-12104.

[69] A. Fridlyand, P.T. Lynch, R.S. Tranter, K. Brezinsky, Single Pulse Shock Tube Study of Allyl Radical Recombination, J. Phys. Chem. A 117 (2013) 4762-4776.

[70] Y. Li, C.-W. Zhou, K. Somers, K. Zhang, H. Curran, A Comprehensive Experimental and Modelling Study of 1Butene oxidation, In Preparation.

[71] Y. Li, C.-W. Zhou, K. Somers, K. Zhang, H. Curran, The Oxidation of 2-Butene: A High Pressure Ignition Delay, Kinetic Modeling Study and Reactivity Comparison with Isobutene and 1-Butene, Submitted to Proceedings of the Combustion Institute, (2015).

[72] Z. Zhao, M. Chaos, A. Kazakov, F.L. Dryer, Thermal decomposition reaction and a comprehensive kinetic model of dimethyl ether, Int. J. Chem. Kinet. 40 (2008) 1-18.

[73] F.L. Dryer, F.M. Haas, J. Santner, T.I. Farouk, M. Chaos, Interpreting chemical kinetics from complex reactionadvection-diffusion systems: Modeling of flow reactors and related experiments, Progress in Energy and Combustion Science 44 (2014) 19-39. 